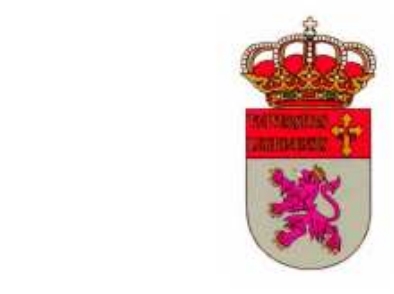

UNIVERSIDAD DE LEÓN

FACULTAD DE VETERINARIA

Departamento de Sanidad Animal

TESIS DOCTORAL

\title{
EPIDEMIOLOGIA Y DIAGNOSTICO DE LA INFECCIÓN POR EL VIRUS MAEDI VISNA EN DIFERENTES SISTEMAS DE EXPLOTACIÓN OVINOS ESPAÑOLES
}

Iratxe Leginagoikoa de la Arena

Septiembre 2010

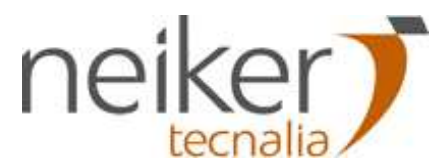



Los abajo firmantes, como directores del trabajo de Tesis Doctoral por artículos con el título: "EPIDEMIOLOGÍA Y DIAGNÓSTICO DE LA INFECCIÓN POR EL VIRUS MAEDI VISNA EN DIFERENTES SISTEMAS DE EXPLOTACIÓN OVINOS ESPAÑOLES" realizado en el Departamento de Sanidad Animal del Instituto Vasco de Investigación y Desarrollo Agrario (Neiker-Tecnalia) y presentado por Dña. IRATXE LEGINAGOIKOA DE LA ARENA para optar al grado de Doctora en Veterinaria, hacen constar que ha sido realizado bajo su dirección y que reune los requisitos necesarios para su defensa y aprobación

En Derio a 15 de Septiembre de 2010

Fdo.Dr. Eduardo Berriatua Fernández de Larrea

Fdo. Dr. Ramón A. Juste Jordán 

La realización de este trabajo de tesis doctoral, ha sido posible gracias a la financiación recibida de los proyectos del Ministerio de Educación y Ciencia: "ESTUDIO DE LA DINAMICA DEL MAEDI-VISNA EN REBAÑOS OVINOS EN PRODUCCIÓN EXTENSIVA E INTENSIVA", (AGL2003-08977-C03-03) y "ESTUDIO DE LA INFLUENCIA DE LOS FACTORES AMBIENTALES, GENÉTICOS Y DE OTRAS INFECCIONES RETROVIRALES EN EXPLOTACIONES OVINAS AFECTADAS POR EL VIRUS MAEDI-VISNA", (AGL2007-66874-C04-03/GAN) y los proyectos "MAEDI CONTROL EN LA CAPV" del Departamento de Medio Ambiente, Planificación Territorial, Agricultura y Pesca del Gobierno Vasco así como una beca de la fundación Candido Iturriaga y Maria Dañobeitia. 

A mi familia en especial a mi amatxu. A las personas que dedican su vida al duro trabajo del mundo ganadero. 

Agradecimientos 



\section{AGRADECIMIENTOS}

Da gusto llegar a este apartado, por que significa que el objetivo se ha cumplido, pese a que en ocasiones haya pensado que no podría acabar hay mucha gente que me ha ayudado a conseguirlo y por eso les dedico estas líneas.

En primer lugar agradecer a mi director de tesis el Dr. Eduardo Berriatua que pensara en mí para el desarrollo del proyecto, con el que he tenido la oportunidad de aprender muchas cosas, introduciéndome en el mundo de la investigación y de la estadística y ha tenido mucha paciencia en transmitirme sus conocimientos en epidemiología.

Gracias también al co-director de esta tesis el Dr. Ramón Juste por su apoyo en este y otros proyectos que han ido apareciendo, por sacar tiempo de su apretada agenda para corregir y orientar el desarrollo de esta tesis. Gracias a los dos por la ayuda y el trabajo dedicado.

Gracias a la Dra. Esmeralda Minguijon por su ayuda en los últimos años, siendo un ejemplo de trabajo y dedicación para mí, ha sido una suerte haber podido trabajar con ella.

A mi tutor en la Universidad de León el Dr. Valentin Pérez y al Dr. Julio Benavides por su apoyo y ayuda en las gestiones administrativas.

Gracias a NEIKER por la aportación de los medios técnicos y de personal que ha permitido el desarrollo de los trabajos que se presentan en esta tesis. Tengo un recuerdo especial para el departamento de Parasitología dirigido por la Dra. Ana L. García Pérez, donde comencé ya hace casi 8 años con una beca de introducción a la investigación y pude hacer mis primeras salidas al campo con Jesse e hice mis pinitos en biología molecular gracias a Bea e Inés.

En la unidad de diagnóstico gracias a los Dres. Gorka Aduriz y Raquel Atxaerandio y a su personal en especial a Itziar por los consejos y la ayuda aportada en la realización de las técnicas serológicas.

A Roberto Ruiz, Josune, Ina y los pastores del departamento de Producción Animal de Arkaute por su colaboración en los diferentes trabajos realizados en el rebaño experimental.

En general muchas gracias a todos los compañeros que hacen de NEIKER un centro de trabajo tan agradable principalmente con los que por diferentes razones he tenido más relación Amaia Ros, Ana H, Belén, Bea, Elena, Fran, lanire, Idoia, Iker, Itziar, Jon Imanol, Laura, Mónica, Natalia, Olaia, Patricia y Rodrigo en especial a Xeider con la que he compartido el duro camino de realizar una tesis doctoral, ha sido un gran apoyo moral, con su trabajo me ha transmitido fuerzas para seguir adelante y ha estado siempre dispuesta a ayudarme en todo.

Agradecer la colaboración de los veterinarios clínicos en Benavente Javier Otaola y Jose Angel Fuertes y Pedro Jose Mora en Agudo (Ciudad Real), al permitirnos contactar y trabajar con sus rebaños y por 
supuesto a todos los ganaderos que nos han abierto las puertas de su casa y han compartido con nosotros sus experiencias y trabajos diarios.

A los Dres. Esther Biescas, Julio Benavides, Mara Daltabuilt, Ramses Reina y Vega Alvarez cuyas tesis doctorales dedicadas al Maedi Visna me han ayudado a mejorar mis conocimientos sobre el tema.

No me quiero olvidar de mis compañeras de estudios en León durante los cinco años de carrera, Bego, Carmen, Noemi, Nuria, Karmele, Patri y Sara que han hecho que esos años sean inolvidables para mí y pese a la distancia que ahora nos separa, se que siempre estarán ahí para lo que necesite.

Agradecer a toda mi familia, en especial a amama Emi y aitite Txus por acompañarme, cuidarme y mimarme tanto siempre, también a mi familia "política" que me ha ayudado sobre todo estos dos últimos años a compaginar la vida familiar con el trabajo.

A mis padres, Soraya y Camilo, por decidir traerme al mundo, por todos los sacrificios realizados para conseguir que su hija estudiara fuera de casa, me alegro de poder tener la oportunidad de tener estas líneas para dedicárselas por que probablemente nunca hubiera encontrado el momento para agradecérselo.

Por ultimo a las dos personas con las que ahora comparto mi vida, a Lezo, gracias por ser como eres, por enseñarme a ver la cara divertida de todos los problemas y por haber estado siempre a mi lado. Y a Aritz por darme la fuerza para seguir adelante, aunque no con palabras, con sus sonrisas y besos a la vuelta del trabajo, perdona por el tiempo que no te he podido dedicar, espero recompensártelo con creces a partir de ahora.

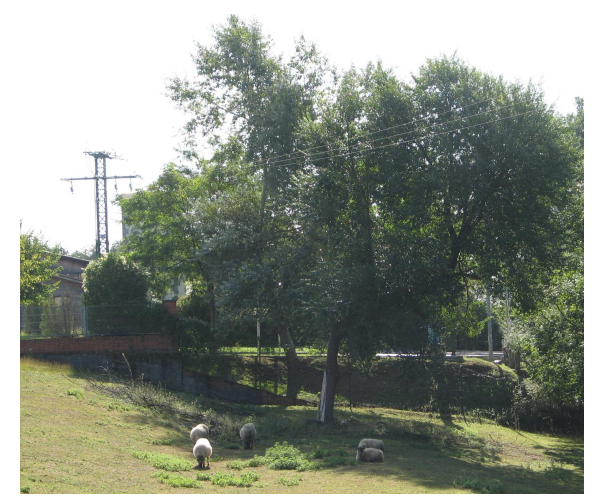


Indice 



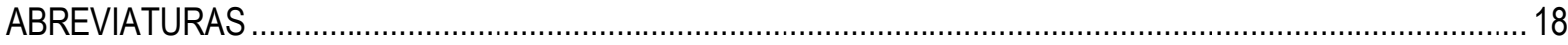

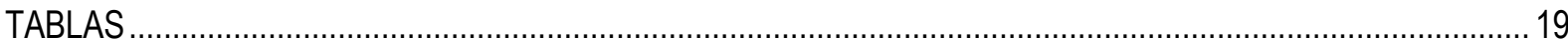

FIGURAS

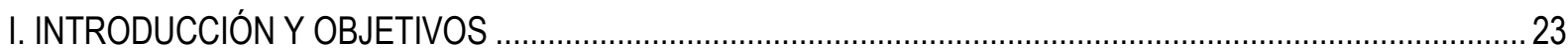

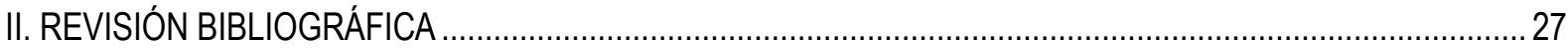

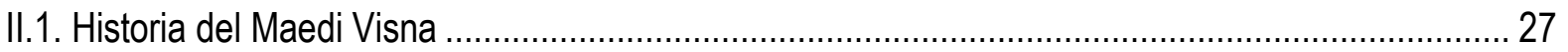

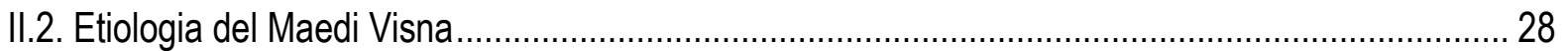

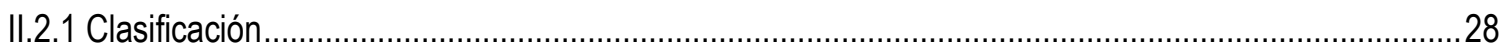

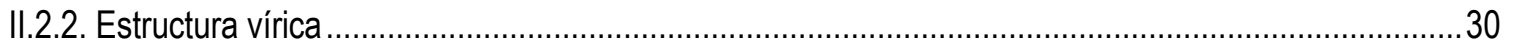

II.2.2.1. Morfología y características fisicoquímicas............................................................ 30

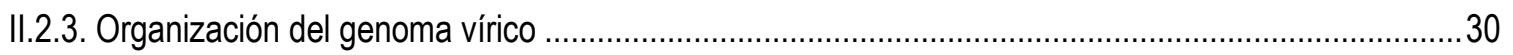

II.2.3.1. Características de los genes y proteínas estructurales............................................ 31

II.2.3.2. Características de los genes auxiliares o patrones de traducción (ORFs) y sus

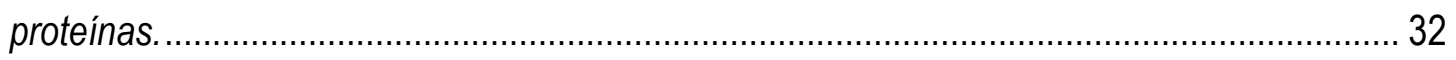

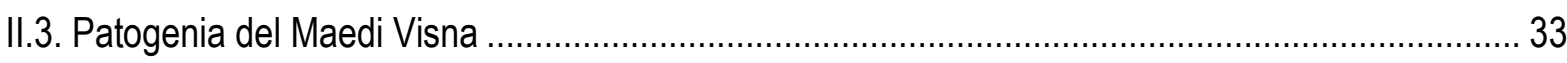

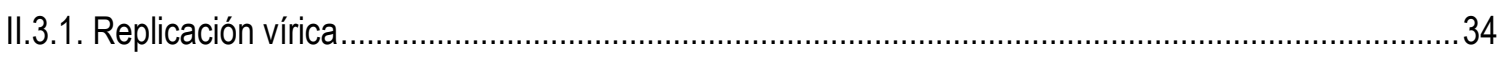

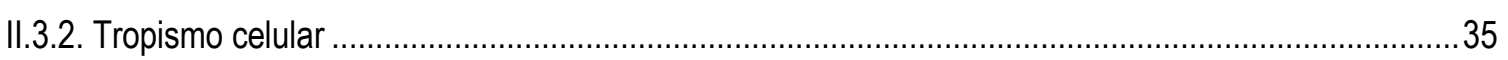

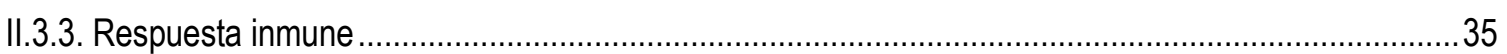

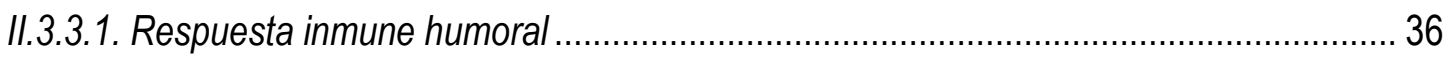

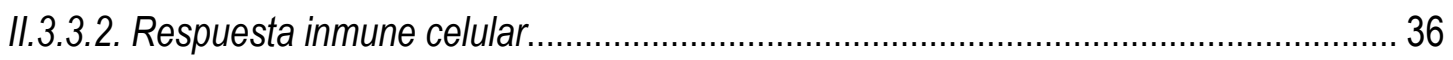

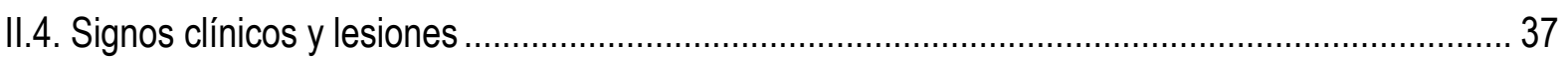

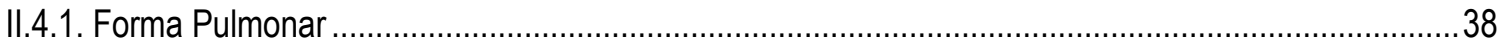

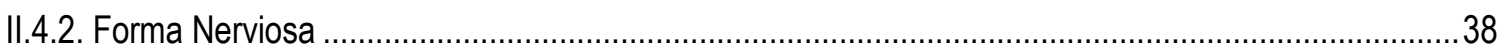

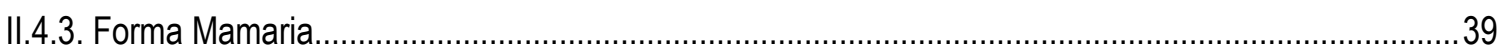

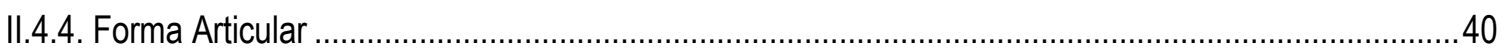

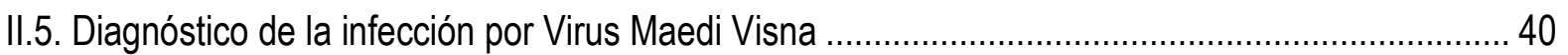

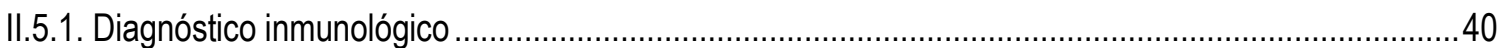

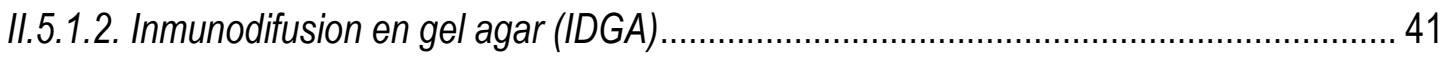

II.5.1.3. Ensayo de inmunoabsorbancia enzimatica o ELISA ............................................... 41

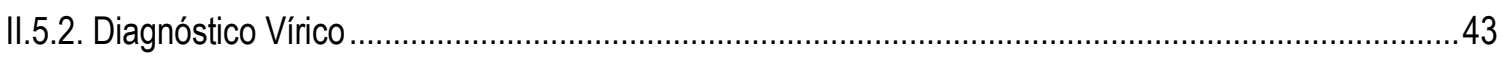

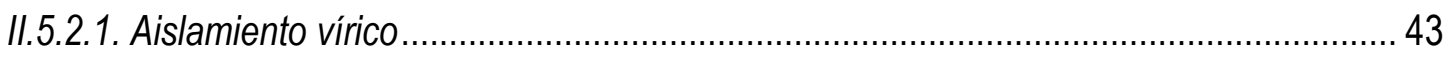

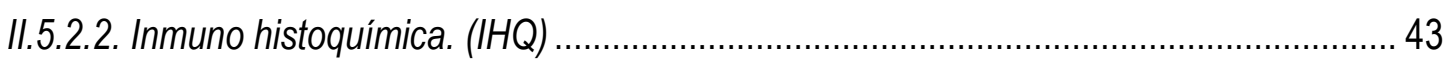

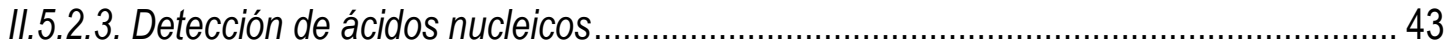

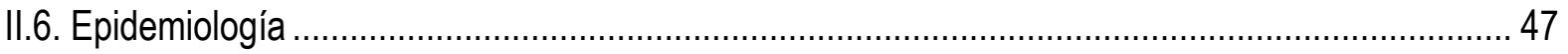

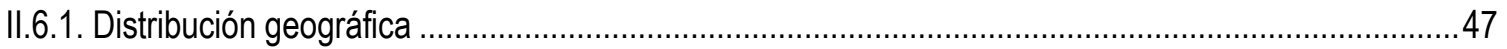


II.6.1.1. Distribución en España ........................................................................................ 47

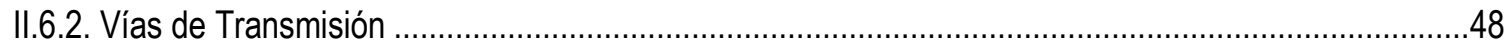

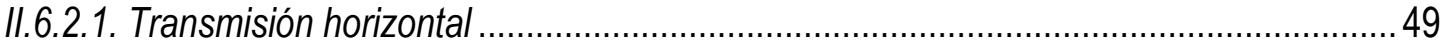

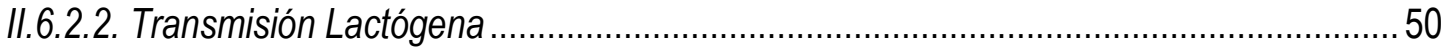

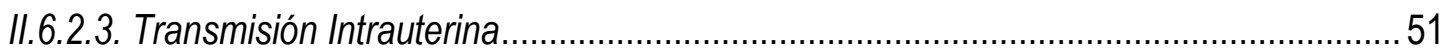

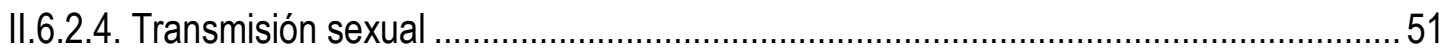

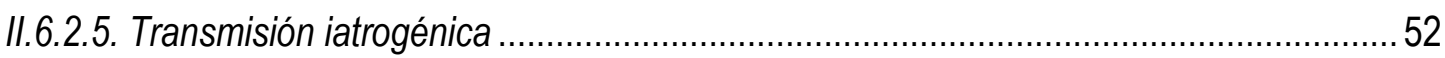

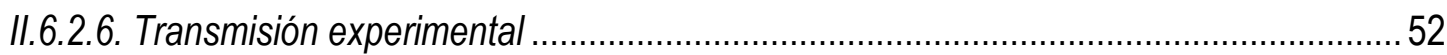

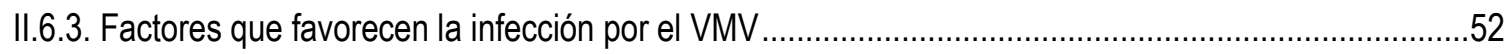

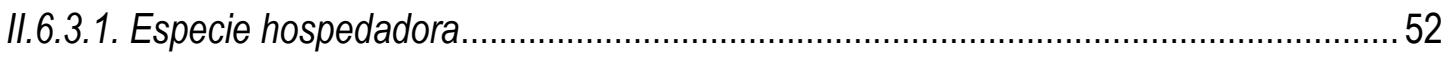

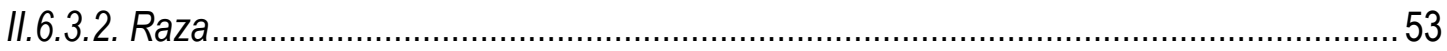

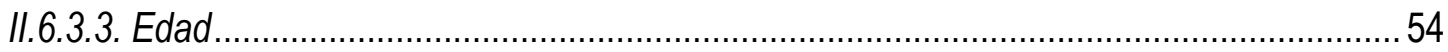

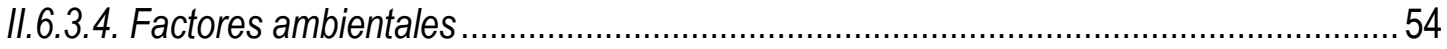

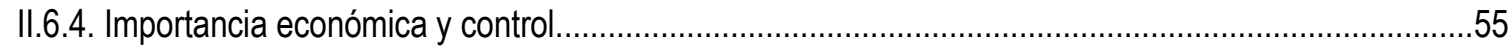

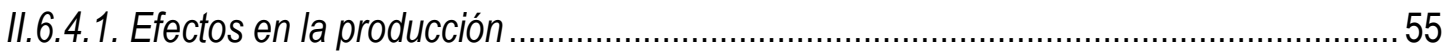

II.6.4.2.. Tratamiento y control de la enfermedad .................................................................56

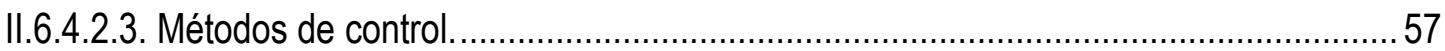

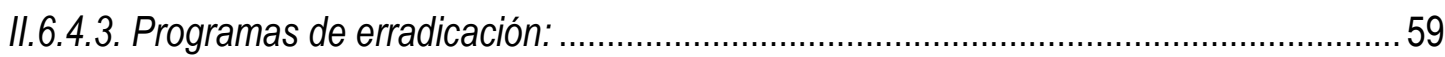

II.6.4.4. Legislación internacional relativa al comercio de animales y la infección por el VMV. 60

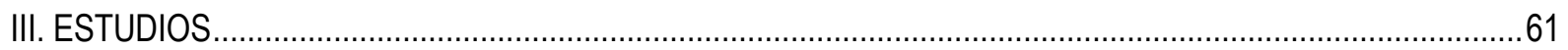

III.1.Horizontal Maedi-Visna virus (MVV) infection in adult dairy-sheep raised under varying MVV-

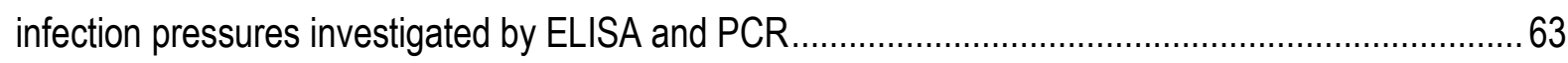

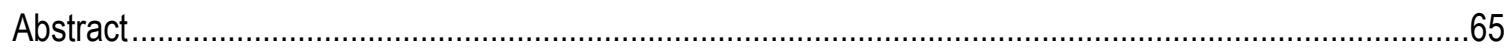

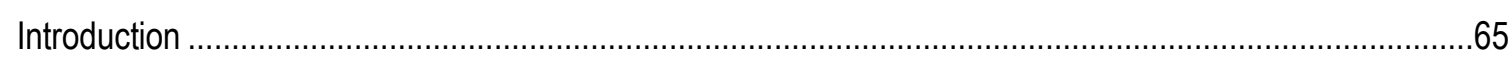

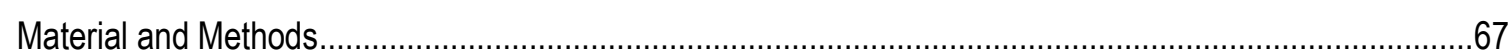

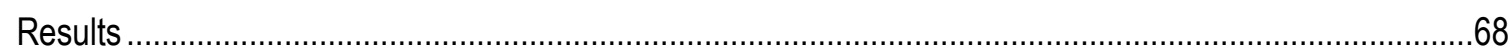

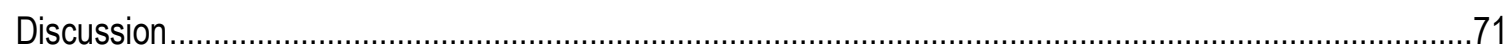

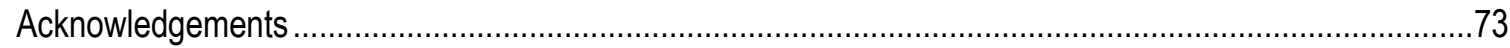

III.2. Extensive rearing hinders Maedi - Visna Virus (MVV) infection in sheep .................................. 75

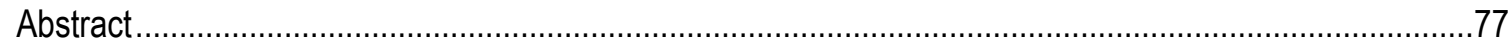

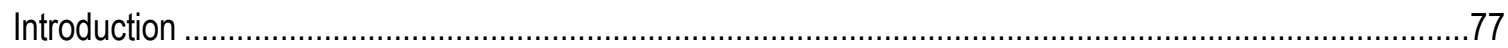

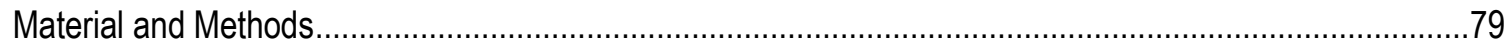

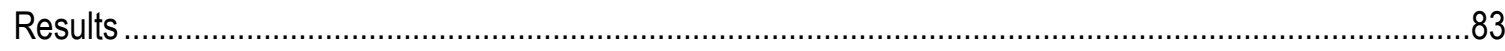

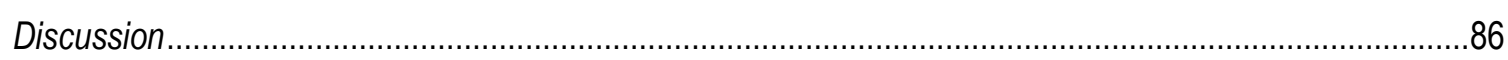

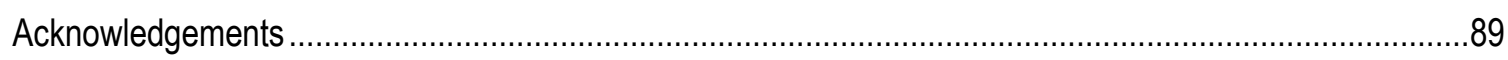


III.3. Effects of housing on the incidence of visna/maedi virus infection in sheep flocks ...................... 91

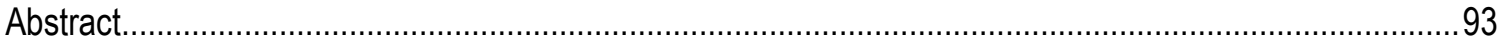

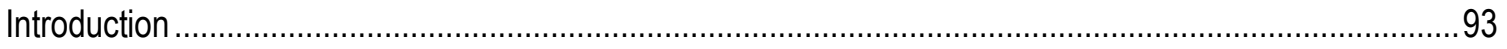

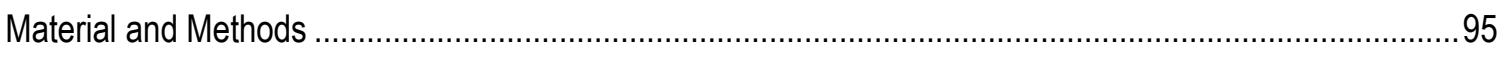

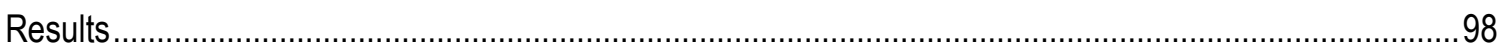

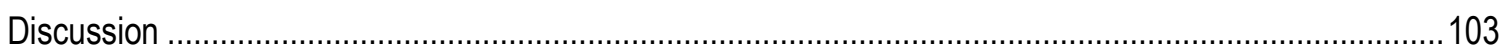

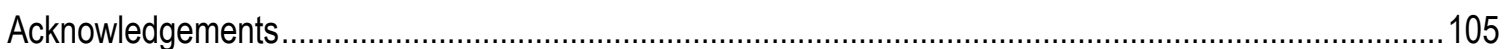

III.4. Improvements in the detection of small ruminant lentivirus infection in the blood of sheep by PCR

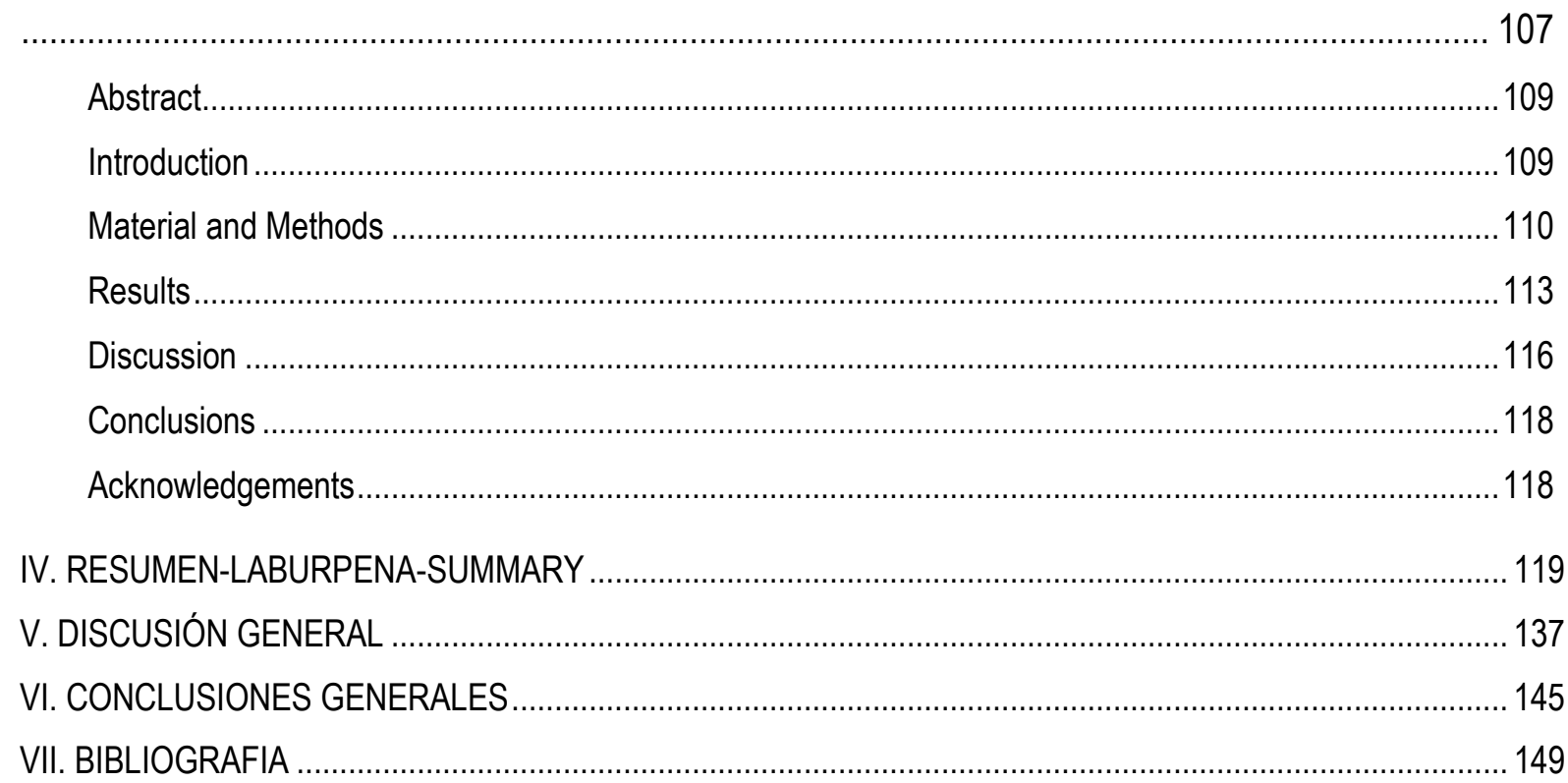




\section{ABREVIATURAS}

ADN: Acido dexosirribonucleico.

ADNc: Acido dexosirribonucleico

complementario.

AGID: Agar-gel immunodiffusion.

AGIDT: Agar-gel immunodiffusion test.

AC: Anticuerpos.

ACc: Anticuerpos fijadores de complemento.

ACn: Anticuerpos neutralizantes.

APO: Adenomatosis pulmonar ovina.

ARN: Acido ribonucleico.

CA: Cápside.

CAEV: Caprine Arthritis encephalitis.

cDNA: Complementary deoxyribonucleic acid.

CMH-II: Complejo mayor de histocompatibilidad de tipo II.

CNS: Central nervous system.

CS: Complementary sensitivity.

DEPC: Diethyl pyrocarbonate.

EDTA: Ethylene-di-amine-tetra-acetic acid.

EEUU: Estados Unidos de America.

ELISA: Ensayo de inmunoabsorbancia enzimática.

ELISA-i: Ensayo de inmunoabsorbancia enzimática indirecto.

FIV: Feline immunodeficiency virus.

gag-PCR: PCR de la región gag.

HIS: Hibridación in situ.

HIV: Human immunodeficiency virus.

IDGA: Inmunodifusión en gel agar.

IFN-y: Interferón-gamma.

Ig G: Inmunoglobulina G.

IHQ: Inmuno Histoquímica.
IL-2: Interleucina tipo 2.

IL-8: Interleucina tipo 8.

IL-14: Interleucina tipo 14.

IN: Integrasa.

LTR-PCR: PCR de la región LTR.

LVPR: Lentivirus de los pequeños rumiantes.

MA: Matriz.

MV: Maedi Visna.

MVV: Maedi Visna virus.

NC: Nucleo capside.

OD: ELISA optical densities.

PBLs: Peripheral blood leukocytes.

PCR: Reacción en cadena de la polimerasa.

PCR-n: PCR anidada.

PCR-ns: PCR semianidada.

PR: Proteasa.

Re: Effective reproduction ratio.

ROD: Relative optical densities.

RT-PCR: PCR transcriptasa inversa.

RT-gag-PCR: PCR transcriptasa inversa de la región gag.

SU: Envoltura externa.

TCID 50 : Median tissue culture infective dose.

TM: Glicoproteina transmenbranal.

TBE: Tris borate-EDTA buffer.

VAEC: Virus de la Artritis Encefalitis Caprina.

VAIE: Virus de la anemia infecciosa equina.

VIH:Virus de la inmunodeficiencia humana.

VMV:Virus Maedi Visna.

WB: Western Blot. 


\section{TABLAS}

Tabla II.1. Clasificación del Virus Maedi Visna

Tabla II.2. Muestra origen, región, técnica de referencia y conclusión de las PCR convencionales publicadas hasta el momento.

Tabla II.3. Muestra origen, región, tecnica de referencia y conclusión de las PCR a tiempo real publicadas hasta el momento

Tabla II.4. Resultados de los diferentes estudios de prevalencia de Maedi Visna realizados en España

Table III.1.1. Estimates from the random effects logistic regression model of MVV seroconversion in groupsof sheep exposed to high and low infection pressure ( $n=327$ from 149 experimental latxa dairy sheep from Spain)...

Table III.2.1. Flock origin, number, size, breed, production system, median weaning age of replacement lambs and housing time and space in an MVV seroprevalence study in sheep in Spain in 2003-04 .... 81

Table III.2.2. Age-specific distribution of antibody-ELISA ROD values in seropositive sheep from 38 extensively raised cross-bred lamb-producing flocks, semi-intensively raised latxa dairy flocks and intensively raised Assaf flocks in Spain

Table III.2.3: Ewe and ewe-flock MVV-seroprevalence in 38 extensively raised cross-bred lambproducing flocks, semi-intensively raised Latxa dairy flocks and intensively raised Assaf flocks in Spain.

Table III.3.1: Annual VMV seroprevalence in Spanish Latxa and Assaf dairy sheep flocks in years 2000 $-2006$.

Table III.3.2. VMV seroconversion incidence rates $(x 100)$ in one year old replacement Latxa and Assaf sheep according to the mode of rearing, housing time, stocking density and shed structural variables. 97

Table III.3.3. VMV seroconversion incidence rates $(x 100)$ in 2 year old and older Latxa and Assaf sheep according to the mode of rearing, housing time, stocking density and shed structural variables.

Table III.3.4: Percentage of VMV seroconversion in Spanish Latxa and Assaf dairy sheep flocks in years 2000 to 2006 .

Table III.3.5. Estimates from the random-effects logistic-regression models of VMV seroconversion in intensive and semi-intensive dairy sheep in Spain (15 flocks; 2000-06). (a) one-year old replacement ewes $(n=2794)$ and $(b)$ two year-old and older ewes $(n=3675)$.

Table III.4.1. Comparison of two methods of extraction of DNA and RNA in serum, PBLs and blood clot from 10 serologically positive sheep. Percent positive samples, in parentheses number of samples examined when different from 10.

Table III.4.2. ELISA and LTR and gag-PCR results comparison in PBLs and blood clot of 25 SRLV ELISA-positive and 25 SRLV ELISA-negative sheep. In parentheses absolute frequency of positives. Kappa: agreement index, CS: complementary sensitivity. 


\section{FIGURAS}

Figura.ll.1. Distribución de estructura, genes y proteínas de los Lentivirus

Figure.III.1.1. Age-specific percentage of MVV ELISA and LTR-PCR-positive sheep in two groups of sheep raised under low and high MV-infection pressure. Data from 191 experimental latxa dairy sheep from Spain.

Figure.III.1.2. Age-specific percentage of coinciding ELISA and LTR-PCR results and degree of agreement and kappa coefficient between both techniques in two groups of lambs exposed to high and low MVV-infection pressure, respectively. Data from 191 experimental latxa dairy sheep from Spain... 71

Figure. III.2.1. Ewe and ewe-flock MVV-seroprevalence in 38 extensively raised cross-bred lambproducing flocks, semi-intensively raised Latxa dairy flocks and intensively raised Assaf flocks in Spain.

Figure III.2.2. Relationship between flock seroprevalence and housing time in Spanish extensively raised cross-bred lamb-producing flocks, semi-intensively raised Latxa dairy flocks and intensively raised Assaf dairy flocks. $(n=38)$.

Figure III. 3.1. Age-specific VMV seroconversion incidence rate (x100) in Spanish Latxa and Assaf dairy sheep flocks in years 2001-2006. 
I. INTRODUCCIÓN Y OBJETIVOS 



\section{INTRODUCCIÓN Y OBJETIVOS}

Esta tesis doctoral pretende reunir información que contribuya al avance en el conocimiento de la epidemiología de la infección por el virus maedi-visna (VMV) y en concreto, de su relación con los sistemas de producción ovina mas importantes en España y otros lugares del mundo. El virus pertenece, junto con el de la artritis encefalitis caprina (CAEV) al grupo de los lentivirus de los pequeños rumiantes (LVPR) que infectan a ovino y caprino indistintamente produciendo una enfermedad crónica, debilitante y de curso fatal. Son agentes cosmopolitas y el maedi-visna (MV) ovino es una enfermedad que se ha descrito en la mayoría de los países donde se ha investigado, exceptuando en tres países de larga tradición ovejera como son Australia, Nueva Zelanda e Islandia.

Los estudios derivados de la epidemia de VMV mas importante descrita, que afectó a Islandia en 1930-1960, sentaron las bases de la epidemiología de esta enfermedad tal y como la conocemos actualmente, y entre los aspectos concluyentes más reseñables incluirían la facilidad del virus de transmitirse por contacto entre animales adultos mantenidos en condiciones de hacinamiento y la existencia de cierta sensibilidad al desarrollo de la enfermedad en determinadas líneas familiares (Palsson 1976). También los autores islandeses y otros posteriormente, descartaron la importancia epidemiológica de la transmisión congénita del VMV (Sigurdsson et al. 1953, Cross et al. 1975, De Boer et al. 1979, Sihvonen 1980, Houwers et al. 1987b, Brodie et al. 1994). Sin embargo, los estudios de Islandia no aportaron datos cuantitativos de la asociación entre la infección y el contacto directo e indirecto con animales infectados y esto ha limitado históricamente el reconocimiento de la importancia de esta forma de infección, en una comunidad científica mayoritariamente no dedicada al estudio de la epidemiología del VMV.

El descubrimiento de VMV en calostro y leche de ovejas infectadas en las décadas de 1960 y 1970 (De Boer 1970, Sihvonen 1980) concentró la atención sobre la transmisión del VMV a la ruta lactógena (Keen et al. 1997b, Pepin et al. 1998). Sin embargo, los estudios epidemiológicos de la infección con CAEV en rebaños caprinos lecheros en estabulación de EEUU y Australia en los años 1980 y 1990 (Ellis et al. 1983, Adams et al. 1983, East et al. 1987, Rowe et al. 1997) reforzaron las conclusiones islandesas sobre la importancia de la transmisión de los LVPR por contacto entre animales adultos mantenidos en hacinamiento aunque por otro lado, estos autores insistieron en la importancia fundamental de la transmisión lactógena del virus de madre a hijo durante la lactancia (Ellis et al. 1983, Ellis et al. 1986). Fueron necesarios los trabajos experimentales de (Daltabuit-Test 2005, Alvarez 2005) para cuantificar por primera vez la transmisión del VMV asociada a la vía lactógena. Dichos estudios demuestran que hasta el $61 \%$ de los corderos que ingieren una elevada cantidad de 
calostro mediante biberón se infectan como consecuencia de ello, que el porcentaje de infección baja al $39 \%$ cuando la cantidad recibida mediante biberón es menor y más aun, que el porcentaje de infección es solo del $16 \%$ cuando los corderos toman el calostro mamando de la madre. En conclusión los trabajos de Álvarez $(2005,2006)$ sugieren que la transmisión lactógena no es esencial en rebaños en condiciones naturales y que la transmisión por contacto a lo largo de la vida es necesaria para que el virus se mantenga en la población.

Esta conclusión es compatible con los resultados de un estudio epidemiológico anterior por Berriatua y colegas (2003) en el que se observó que en condiciones favorables para la transmisión por contacto el riesgo de infección es independiente de la ingestión o no de calostro y leche de madre infectada. Conclusión que puede extraerse también de un trabajo anterior de Houwers et al. (1989), el trabajo de Berriatua et al. (2003), demostró además por primera vez la existencia de un componente familiar de susceptibilidad y resistencia a la seroconversión al VMV, confirmando de este modo las sospechas mencionadas anteriormente de los autores islandeses.

Las hipótesis que se pretenden valorar mediante estudio epidemiológico en la presente tesis doctoral nacieron del estado de conocimiento de la epidemiología del MV a mediados de la década de los 2000 y su esclarecimiento tiene gran importancia práctica en el control de la infección. La principal hipótesis que se plantea es la siguiente: "Si para mantenerse en la población, el VMV precisa de un contacto estrecho entre animales, estamos ante una enfermedad importante en rebaños en producción intensiva y poco importante en rebaños en producción extensiva". Derivada de esta hipótesis se plantea además una investigación de los factores que facilitan y dificultan la transmisión en animales en cría intensiva. Otra cuestión que se consideró importante reevaluar es la existencia del componente genético de resistencia/susceptibilidad a la infección independientemente del sistema productivo o raza ovina.

Por último aprovechando los avances en el diagnóstico de la infección por el VMV y en concreto la posibilidad de realizar la reacción en cadena de la polimerasa (PCR) para detectar pequeñas cantidades de virus mediante la modalidad de retrotranscripción, se ha considerado de importancia aplicar dicha técnica para detectar virus en matrices poco estudiadas hasta la fecha como son el suero y el coagulo sanguíneo que por otro lado son las muestras mas frecuentemente empleadas para el diagnóstico de infecciones de declaración obligatoria en ovino y caprino y de más fácil acceso para la investigación de otras infecciones incluidas las asociadas a los LVPR. 
II. REVISIÓN BIBLIOGRÁFICA 



\section{REVISIÓN BIBLIOGRÁFICA}

\section{II.1. Historia del Maedi Visna}

Maedi Visna (MV) es un nombre que proviene del Islandés (Maedi "fatiga o disnea" y Visna "consunción") para describir una enfermedad crónica y fatal de los pequeños rumiantes que también se conoce con el nombre de "neumonía progresiva ovina".La adopción del nombre islandés se debe a las investigaciones de esta enfermedad llevadas a cabo en este país a raíz de la grave epidemia que padecieron en 1930-50. No se ha descrito otra epidemia similar en ningún lugar y el origen de la misma se asocia a la importación de 20 carneros Karakul desde Alemania en 1933 infectados con el virus causal a un país que era previamente indemne. La gran transmisión del virus maedi-visna (VMV) se vio favorecida por el sistema de manejo Islandés que mantenía los animales estabulados en apriscos de reducidas dimensiones durante el largo invierno y al intercambio de los animales en ferias. Las grandes pérdidas económicas que ocasionó la entrada de la enfermedad llevaron a los islandeses a optar por la erradicación del virus de su cabaña ovina consiguiéndose finalmente tras más de treinta años de esfuerzo y el sacrificio de 150000 ovinos.

Sin embargo, la enfermedad ya se había descrito anteriormente; parece que la primera ocasión fue en Holanda en 1862 donde se observaron síntomas de respiración entrecortada ("broken wind") en ovejas de la isla Holandesa de Texel (Houwers 1990). Este mismo cuadro clínico de afección respiratoria crónica se describe también en Sudáfrica en 1915 (Mitchell 1915) aunque se atribuyó en un principio a la Adenomatosis Pulmonar Ovina (APO). Poco después, en 1929, en el mismo lugar, DeKock diferenció la APO o "Jaagsiekte" de otra neumonía crónica caracterizada por la presencia de folículos linfoides a la que denominó" Graf - Reinet disease" y que hoy reconocemos como MV (Dawson 1980). Así, se puede decir que la infección por LVPR se encuentra extendida por todo el mundo de forma natural y que ha tenido la suficiente importancia y singularidad como para recibir diferentes denominaciones locales. Así, por ejemplo, en Holanda se conoce como "Zwoegerziekte", en Francia como "la bouhite"(Lucam 1942) y en Estados Unidos como "enfermedad de Montana" (Marsh 1923, Bulgin 1990).

Como consecuencia de los primeros estudios de transmisión de la enfermedad, en 1954 Sigurdsson describe por primera vez las características de las enfermedades causadas por virus lentos "slow virus diseases", haciendo referencia al MV y al Scrapie como enfermedades que afectan a los pequeños rumiantes, con largo periodo de incubación de meses a años y de curso fatal, a diferencia de las enfermedades crónicas en las que el curso y el pronóstico puede ser irregular e impredecible. (Sigurdsson 1954b). 
Los cuadros clínicos más característicos del MV son el respiratorio y el nervioso lo que hizo pensar en un principio que eran producidos por dos virus diferentes hasta que en 1965 (Thormar 1965) se demuestra que ambos tienen propiedades casi idénticas y se llega a la conclusión de que son dos síndromes producidos por un mismo virus (Gudnadottir et al. 1967b). Durante el siglo XX se describe la enfermedad en diferentes países y en varias ocasiones se achaca su presencia a la importación de animales infectados como es el caso de Islandia, Hungría, Francia, Noruega y Canadá (Dawson 1980) la diseminación e identificación de la enfermedad coincide con un aumento del comercio e intensificación de los sistemas de producción de los pequeños rumiantes traduciéndose en una mayor estabulación del ganado (Houwers 1990).

El VMV fue erradicado de Islandia en 1965, y es junto con Australia y Nueva Zelanda los únicos países que se reconocen libres de MV, con la diferencia de que en estos dos últimos lugares se deduce que la enfermedad nunca ha estado presente en el ovino (Dawson 1980, Lujan et al. 2001).

\section{II.2. Etiología del Maedi Visna}

\section{II.2.1 Clasificación}

El agente causal del MV es un virus perteneciente a la familia Retroviridae que incluye virus ARN y cuya característica principal es la utilización en la replicación, de la enzima transcriptasa inversa que transforma el ARN genómico en ADN complementario. El ADNc es capaz de mutar rápidamente y tiene baja actividad correctora (Pasick 1998a) lo que facilita la variabilidad genética que caracteriza a estos virus.

Dentro de esta familia se describen siete géneros en los que se encuentran los agentes etiológicos de diversas enfermedades de interés veterinario (Tabla II.1). Concretamente, el VMV pertenece al género Lentivirus de compleja estructura genómica por poseer varios genes que codifican para proteínas reguladoras, a parte de los estructurales comunes para todos los retrovirus incluidos gag, pol y env. Excepto el virus de la anemia infecciosa equina (VAIE), los demás retrovirus originan un proceso clínico lento y de debilitamiento progresivo (Carey et al. 1993).

Es de destacar que el virus de la inmunodeficiencia humana (VIH) también pertenece al genero de los Lentivirus lo que hace que el VMV cobre interés como modelo para el estudio del virus humano (De la Concha-Bermejillo et al. 1995b, Sonigo et al. 1985, Perk 1988, Thormar 2005). EI VMV fue el primero descrito de ese género y junto con el virus de la Artritis Encefalitis Caprina (VAEC) forma el grupo de los lentivirus de los pequeños rumiantes (LVPR: SRLV, Small Ruminant Lentiviruses). Ambos infectan a las dos especies de animales y tienen elevada homología en la secuencia de nucleótidos (Shah et al. 
2004a) y actualmente este subgénero se ha clasificado según sus relaciones filogenéticas en cinco grupos: $A, B, C, D$ y $E$. La mayoría de los aislados pertenecen a los grupos $A$ y $B$, el primero agrupa los aislados tipos VMV e incluye siete subtipos siendo A1 y A2 de origen ovino, A5 y A7 de origen caprino y A3, A4 y A6 de ambas especies. El grupo B es de tipo VAEC e incluye los subtipos B1 y B2 (Pisoni et al. 2005). El grupo C incluye la cepa Noruega (Shah et al. 2004a, Gjerset et al. 2007) y el D las suizas y españolas. (Shah et al. 2004a, Reina et al. 2006). El grupo E es el mas reciente y a el pertenecen aislados de cabras de la región norte de Italia (Grego et al. 2007). En el primer estudio filogenético de cepas ovinas y caprinas en España todas se clasificaron dentro de los grupos A y D (Reina et al. 2006) y en un estudio mas reciente, cepas ovinas de animales con sintomatología artrítica se incluyeron dentro del grupo B2 tipo VAEC (Glaria et al. 2009). Los estudios anteriormente citados claramente demuestran que la proximidad filogenética de los LVPR es independiente del hospedador y concuerdan con la capacidad del virus de transmitirse de cabra a oveja y viceversa (Chebloune et al. 1996, Shah et al. 2004b, Pisoni et al. 2005, Reina et al. 2006).

Tabla II.1. Clasificación del Virus Maedi Visna.

\section{Familia Retroviridae}

\begin{tabular}{|c|c|c|c|}
\hline Subfamilia & Genero & Grupo & Especie (característica de interés veterinario) \\
\hline Spumaretrovirinae & $\begin{array}{l}\text { Alpharetrovirus } \\
\text { Betaretrovirus } \\
\text { Deltaretrovirus } \\
\text { Gammaretrovirus } \\
\text { Epsilonretrovirus } \\
\text { Lentivirus }\end{array}$ & $\begin{array}{l}\text { Lentivirus bovino } \\
\text { Lentivirus equino } \\
\text { Lentivirus felino } \\
\text { Lentivirus } \\
\text { ovino/caprino } \\
\text { Lentivirus de } \\
\text { primates }\end{array}$ & $\begin{array}{l}\text { Virus de la leucosis aviar (ALV, Avian Leukosis } \\
\text { Virus) } \\
\text { Adenomatosis pulmonar ovina(JSRV, Jaagsiekte } \\
\text { sheep retrovirus) } \\
\text { Virus de la leucemia bovina (BLV, Bovine } \\
\text { Leukemia Virus) } \\
\text { Virus de la leucemia felina (FeLV, Feline Leucemia } \\
\text { Virus) } \\
\text { Virus del sarcoma dérmico Walleye } \\
\text { Virus de la inmunodeficiencia Bovina (BIV, Bovine } \\
\text { Immunodeficiency Virus) } \\
\text { Virus de la anemia infecciosa equina (EIAV, } \\
\text { Equine Infectious anemia virus) } \\
\text { Virus de la inmunodeficiencia Felina (FIV, Feline } \\
\text { Immunodeficiency Virus) } \\
\text { Artritris encefalitis Caprina (CAEV, Caprine } \\
\text { Artritis Encephalitis Virus) } \\
\text { Virus Maedi Visna (MVV, Maedi Visna Virus) } \\
\text { Virus de la inmunodeficiencia humana(HIV, Human } \\
\text { Immunodeficiency Virus) } \\
\text { Virus espumoso de los simios(SFV, Simian Foamy } \\
\text { Virus) }\end{array}$ \\
\hline
\end{tabular}

Ref: International Committee on Taxonomy of Viruses. http:// www.ictvonline.org 


\section{II.2.2. Estructura vírica}

\section{II.2.2.1. Morfología y características fisicoquímicas}

Los viriones o virus maduros liberados de las células infectadas tienen forma esférica, miden 80-120 nm de diámetro y se componen de aproximadamente $60 \%$ de proteína, $35 \%$ de lípidos, 3\% de carbohidratos y $1 \%$ de ARN. La presencia de ARN en vez de de ADN les confiere protección frente a la radiación ultravioleta, pero es un virus poco resistente a los agentes químicos y se destruye con el éter, cloroformo, peryodato, etanol, formaldehído, fenol, tripsina y ribonucleasa. Soporta bien la sonicación (Thormar 1965), se inactiva a $56^{\circ} \mathrm{C}$ durante 10 minutos, pero es activo hasta $4-5$ meses a $4^{\circ} \mathrm{C}$ y mantiene su infectividad a $-80^{\circ} \mathrm{C}$ durante años siendo capaz de soportar varios ciclos de congelación y descongelación. Tolera mejor los pH alcalinos que los ácidos manteniendo su infectividad a un pH entre 5,1 y 10 e inactivándose a $\mathrm{pH}<4,2$ (Thormar 1965).

\section{II.2.3. Organización del genoma vírico}

Estructuralmente se compone de las siguientes partes (Fig. II.1) (Pepin et al. 1998):

-Envoltura externa (SU): derivada de la membrana plasmática de la célula hospedadora, está compuesta por una bicapa lipídica de la cual emergen proyecciones glicoproteicas con proteína transmembranal (TM) y de superficie (SU).

-Matriz (MA): de estructura proteica que sirve de unión entre la cápside y la envoltura externa.

-Cápside (CA): proteica e hidrofóbica induce una fuerte respuesta humoral frente a la infección.

-Nucleocápside: envuelve al genoma vírico, deriva del gen gag y contiene varias enzimas indispensables para la replicación vírica como la transcriptasa inversa, la integrasa y la proteasa (DeMartini et al. 2000).

-Genoma: Compuesto por dos cadenas sencillas de ARN que forman un dímero mediante puentes de hidrógeno de 9,4 Kb, con el extremo 5' metilado y el 3' poliadenilado.

Además de los tres genes estructurales (gag, pol y env), el genoma de VMV consta de tres genes reguladores (vif, tat y rev) y destacan en sus extremos dos largas secuencias repetidas LTR (long terminal repeats) que juegan un papel fundamental en la integración del virus en el genoma de la célula hospedadora (De la Concha-Bermejillo 1997, Pepin et al. 1998). 


\section{Genome map of Lentivirus}

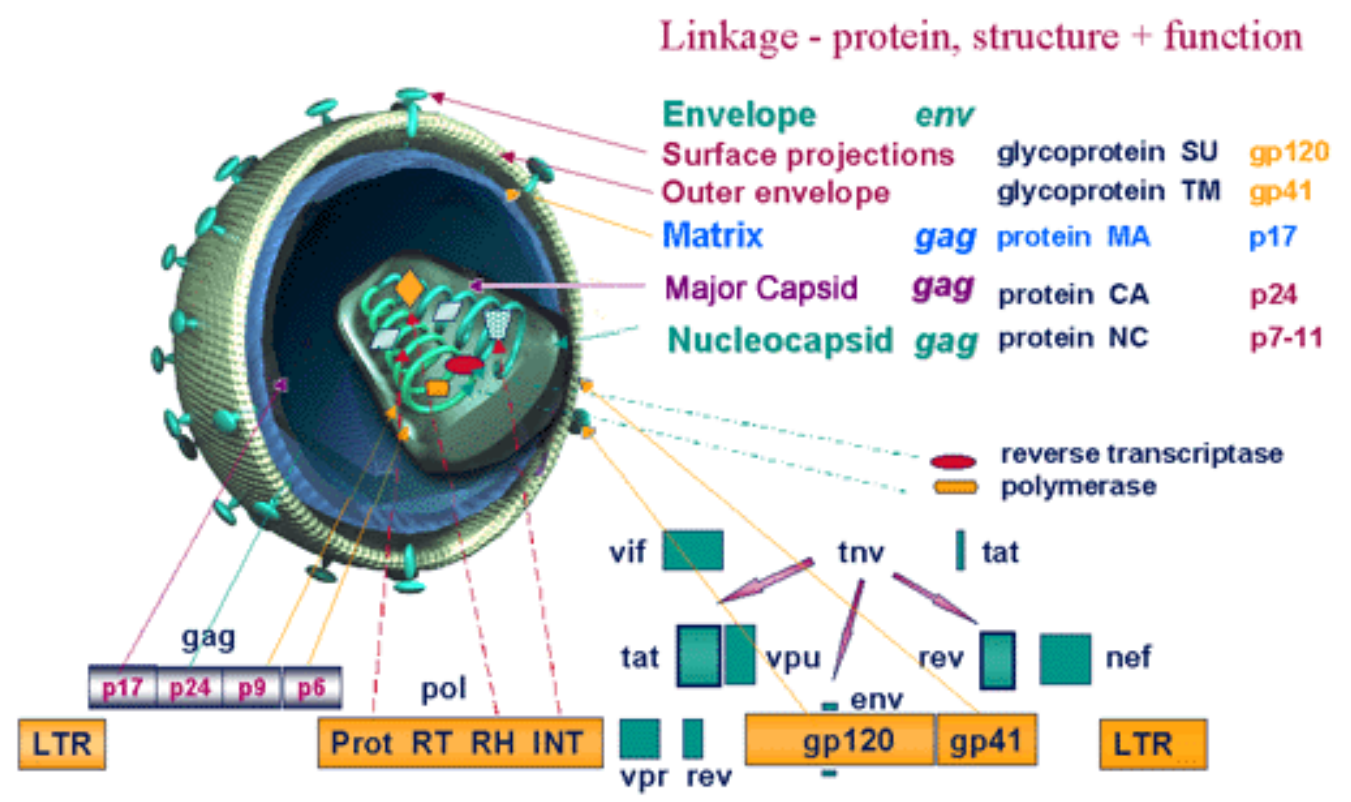

Figura.II.1. Distribución de estructura, genes y proteínas de Lentivirus (C. Büchen-Osmond and J. Whitehead.) http://www.ncbi.nlm.nih.gov

\section{II.2.3.1. Características de los genes y proteínas estructurales}

El gen gag (gen del antígeno de grupo) codifica para el precursor Pr55 de tres proteínas que en sentido 5-3' incluyen las siguientes proteínas:

- p25 (CA): proteína de la cápside, produce gran respuesta inmunógena utilizándose como base para pruebas de diagnóstico serológico.

- p14 (NC): proteína de la nucleocápside suele encontrarse fosforilada, esta configuración es esencial para el ensamblaje del virus.

- p17 (MA): proteína matriz que une la cápside y la envoltura envoltura externa, es responsable de la asociación del precursor del gag con la membrana plasmática celular.

El gen pol (polimerasa): codifica para varias proteínas importantes para la replicación vírica y síntesis proteica:

-Transcriptasa inversa (RT): ADN-polimerasa dependiente de ARN, lo que permitirá al virus integrarse en el ADN de la célula infectada y, más tarde, aprovechar su maquinaria de síntesis de ARN para producir copias víricas.

-Proteasa (PR): fragmenta los precursores proteicos derivados de gag y pol para escindir las proteínas. 
-Integrasa (IN): permite la inserción del ADN vírico en el ADN de la célula hospedadora, las mutaciones que afectan a su estructura bloquean la replicación (Katzman et al. 1994).

-UTPasa: La actividad de esta enzima no se ha detectado en lentivirus de primates pero si en FIV, EIAV, CAEV y MVV (Elder et al. 1992). Favorece la replicación de los virus en células que no se dividen como macrófagos y neuronas, disminuyendo las mutaciones de Guanina (G) y Adenina (A) que pueden alterar el ADN vírico.

El gen env (envuelta): codifica para la glicoproteína precursora gp160 que se fragmenta por una proteasa de la célula hospedadora en dos subunidades:

-gp135 (SU): glicoproteína hidrofílica de superficie responsable de la entrada en la célula hospedadora al interaccionar con el receptor de la misma. La respuesta inmune del hospedador estimula la variación antigénica de la proteína necesaria para la supervivencia del virus y que confiere las propiedades biológicas y serológicas de los distintos aislados.

-gp44 (TM): glicoproteína hidrofóbica transmembranal que se encuentra anclada en la doble capa lipídica de la envuelta soportando a gp135.

\section{II.2.3.2. Características de los genes auxiliares o patrones de traducción (ORFs) y sus proteínas.}

El número y papel de estos genes varía dependiendo del lentivirus y en menor medida de las diferentes cepas de MVV (Pepin et al. 1998). Son encargados de la replicación vírica, se encuentran localizados entre el gen pol y env y destacan los siguientes:

-Gen vif (factor infectante vírico): Codifica a una proteína de 29 kDa que induce una leve respuesta inmunógena. En estudios CAEV y HIV éste gen parece jugar un papel importante en los últimos estadios del ciclo vírico, concretamente en la morfogénesis de la nucleoproteína vírica, es esencial para la infectividad y protege el genoma vírico de actividades mutagénicas (Clements et al. 1996, Keen et al. 1997b, Pepin et al. 1998). En un estudio en el que se eliminó este gen del genoma los virus mutantes fueron incapaces de multiplicarse en cultivo de macrófagos ni de establecerse en ovejas infectadas experimentalmente (Kristbjornsdottir et al. 2004).

-Gen tat (transactivador de la transcripción): codifica para las llamadas proteínas transactivadoras que incrementan los niveles de expresión del virus en la maduración de monocitos a macrófagos (Carruth et al. 1994) además contribuye a la patogénesis induciendo desordenes proliferativos en los órganos diana(Vellutini et al. 1994). 
- Gen rev (regulador de la expresión proteica): produce una proteína de $19 \mathrm{kDa}$ que transporta y protege el ARN mensajero del núcleo al citoplasma y produce "señales de exportación nucleares" que permiten atravesar la membrana del núcleo y regular la expresión vírica. (Tiley et al. 1991) Los virus mutados sin este gen pierden la capacidad infectante (Toohey et al. 1994).

-Gen LTR: en su localización en los extremos del ADN proviral, están compuestas por secuencias repetidas e incluyen en sentido $5^{\prime}-3^{\prime}$, las regiones U3, R y U5. Su función es la activación de la trascripción, integración y poliadenilación proporcionando sitios de unión a los factores de transcripción celulares y regiones que codifican para el comienzo, regulación y promoción de la transcripción (Clements et al. 1996, Pepin et al. 1998). Se ha observado variabilidad en las secuencias en diferentes cepas se SRLV afectando a la actividad transcripcional (Sargan et al. 1995, Barros et al. 2004).Recientemente se ha relacionado una delección de 13-14 pb en la región $\mathrm{R}$ con cepas de baja patogenicidad asociado concretamente a una baja capacidad de la expresión vírica en pulmón (Angelopoulou et al. 2007). Además de su labor en la transcripción vírica, estas secuencias tienen un papel importante en el tropismo celular (Agnarsdottir et al. 2000) y la cinética de replicación in vitro relacionándose con el fenotipo lento/bajo en células pulmonares y de plexo coroideo (Barros et al. 2005)

\section{II.3. Patogenia del Maedi Visna}

Los LVPR tienen predilección por las células de la línea monocito-macrófago. Tras la infección se produce una viremia que se mantiene a lo largo de toda la vida del animal y que es detectable mediante la prueba de la reacción en cadena de la polimerasa (PCR) (Alvarez et al. 2006, Leginagoikoa et al. 2006b). Una vez en los órganos diana, el virus aprovecha la maduración de los monocitos a macrófagos para replicarse (Narayan et al. 1983) y este proceso se acompaña de una respuesta inmune por parte del hospedador (Sihvonen 1981) que es capaz de reducir inicialmente la replicación vírica pero que no elimina el virus completamente. Con las técnicas de detección de anticuerpos modernas altamente sensibles, la seroconversión (generación de anticuerpos específicos) es detectable en la mayoría de casos a las dos semanas post infección (p.i.) y con frecuencia los anticuerpos se mantienen de por vida (Juste et al. 1998). Es importante señalar sin embargo, que en ocasiones y sobre todo si se emplean técnicas serológicas mas antiguas y menos sensibles, la seroconversión puede no ser evidente durante meses e incluso años p.i. (Johnson et al. 1992). La falta de sensibilidad de algunas técnicas se debe en parte a una escasa producción de anticuerpos por parte del hospedador, asociado a la capacidad del virus por minimizar su exposición al sistema inmunitario. 
Se habla de la estrategia del "caballo de Troya" por la que el virus permanece acantonado en las células y órganos diana escapando de la respuesta inmune humoral y celular con diferentes grados de éxito en función de la cepa infectante (Lairmore et al. 1988) y sobre todo del perfil genético individual (De la Concha-Bermejillo et al. 1995a). Sin embargo, durante este periodo, mal llamado "fase de latencia", los macrófagos infectados inducen la producción de citoquinas y la infiltración leucocitaria, generándose la lesión intersticial que caracteriza a esta enfermedad (Narayan et al. 1989). El desarrollo de las lesiones es en la mayoría de los casos lento y transcurren varios años hasta la aparición de los síntomas clínicos y finalmente, la muerte del animal infectado (Cutlip et al. 1988). Como se describirá mas adelante el virus además del pulmón y el sistema nervioso central tiene predilección por la glándula mamaria y el tejido articular.

\section{II.3.1. Replicación vírica}

El ciclo de replicación vírica se completa en 24 horas (Haase 1986) y comienza con la toma de contacto del virus con la célula susceptible anclándose en los receptores celulares gp135 (SU). Tras la fusión de las membranas del virus y de la célula, el virus penetra liberando su envoltura y seguidamente comienza la retrotranscripción modulada por las proteínas tat y rev del ARN vírico, en una doble cadena de ADN que se prolonga ambos extremos con las regiones LTR. Al finalizar la síntesis el ADN vírico es transportado por las proteínas de la nucleocápside al interior del núcleo celular y es la endonucleasa/integrasa la encargada de insertar la copia de ADN lineal en el ADN de la célula hospedadora. Aunque el animal permanecerá infectado para toda su vida, como se ha señalado anteriormente, el virus integrado o "provirus" no se replicará hasta que la célula hospedadora madure (Narayan et al. 1983). La zona donde se localiza el punto de integración es aleatoria, y cada célula sólo integra una única copia del genoma vírico, además existen fenómenos de interferencia que impiden que una célula ya infectada vuelva a infectarse.

Tras la transcripción, el ARN vírico sintetizado permanece en el citoplasma donde se sintetizan las proteínas reguladoras, las de la cápside y las de la envuelta y esto tiene lugar en diferentes organelas así, las proteínas codificadas por gag y pol se sintetizan en los polirribosomas libres del citoplasma celular mientras que las proteínas de la envoltura lo hacen en el retículo endoplasmático rugoso (Coffin 1996). Una vez completada la síntesis de las proteínas víricas se produce el ensamblaje del ARN genómico con precursores gag y otras proteínas (precursoras de la proteína CA y MA) y tras esta unión, el complejo migra hacia la membrana celular a partir de la cual se genera la envoltura y por gemación sale al medio extracelular, donde la unión de las espículas y una proteolísis final constituye la fase de maduración por la que el virión se vuelve infectante(Murphy et al. 1999). 
La eficacia de la replicación del virus in vivo e in vitro varia considerablemente; mientras en cultivo celular éste se reproduce rápidamente y con gran destrucción celular generando gran numero de copias de RNA vírico por célula (Sigurdsson et al. 1960, Thormar 1963), en el animal vivo esta cantidad se reduce a la mitad y es muy focal. En general, a menor productividad in vivo se asocia a una menor síntesis de RNA. (Brahic et al. 1981, Peluso.R. et al. 1985, Stowring et al. 1985).

\section{II.3.2. Tropismo celular}

Además de su preferencia por la línea monocito/macrófago (Narayan et al. 1983, Gendelman et al. 1985, Gendelman et al. 1986) el VMV infecta también células dendríticas, que se encargan de transportar el virus por la linfa hasta los ganglios donde el virus se replica (Ryan et al. 2000). En el ganglio el virus entra en contacto con macrófagos que lo transportan por el torrente sanguíneo a diferentes órganos. Además de estos dos tipos celulares, también se ha demostrado la capacidad infectante in vivo de neumocitos (Carrozza et al. 2003), células epiteliales incluidas las bronquiales (Staskus et al. 1991), de la superficie del intestino, de la glándula tiroides (Zink et al. 1990), del tercer parpado (Capucchio et al. 2003), de la mama (Bolea et al. 2006) y de células del cumulus oophorus del oocito (Ali Al Ahmad et al. 2005). Sin embargo, a diferencia de otros retrovirus como el VIH, el VMV no infecta linfocitos.

In vitro el VMV es capaz de infectar un rango mayor de tipos celulares. Para el cultivo, las células más utilizadas son las de plexo coroideo (Sihvonen et al. 1981, Chebloune et al. 1996) y membrana sinovial de cabra (Juste et al. 1998, Juste et al. 2000). Típicamente VMV produce un efecto citopático que se observa por la formación de sincitios y posterior lisis celular y según el tipo de efecto se distinguen estirpes de virus "lentos/bajos" ("slow/low") por producir la infección lenta y con bajos títulos, característica de las estirpes tipo CAEV, y los "rápidos/altos" (rapid/high) por producir infección rápidamente y con títulos altos y entre ellos se encuentran los virus tipo VMV (Quérat et al. 1984).

\section{II.3.3. Respuesta inmune}

La respuesta inmune humoral y celular que se genera frente al virus no es capaz de eliminarlo, manteniéndose la infección durante toda la vida del animal (Cutlip et al. 1988).No se conoce exactamente la causa de esta falta de efectividad del sistema inmunitario y entre las posibles causas podría estar el mecanismo llamado de "caballo de Troya" citado anteriormente. Además de evadir la respuesta inmunitaria el provirus integrado en el genoma del hospedador tendría la capacidad de dispersarse por el organismo (Peluso.R. et al. 1985). Otros autores postulan que la persistencia del 
virus se debe a su capacidad de variación antigénica por mutaciones en el gen env (Narayan et al. 1987, Clements et al. 1988), aunque por otro lado se ha podido demostrar que estas variaciones son poco frecuentes (Thormar et al. 1983) y que junto a las variantes en animales infectados se encuentra la cepa original (Lutley et al. 1983). En cualquier caso, debido al tropismo del virus por los macrófagos se produce una desregulación de la respuesta inmune que además de no ser efectiva parece desempeñar un papel importante en la persistencia de la enfermedad (Pepin et al. 1998).

\section{II.3.3.1. Respuesta inmune humoral}

El VMV induce la síntesis de anticuerpos fijadores de complemento (ACc) entre 1 semana y 3 meses p.i. y anticuerpos neutralizantes (ACn) tras el primer y quinto mes (Gudnadottir et al. 1967a, De Boer 1970, Brahic et al. 1981, Sihvonen 1981). Estudios más recientes demostraron que la inmunidad humoral es eficaz para limitar la extensión del virus, y detectaron anticuerpos neutralizantes en el fluido cerebroespinal coincidiendo con la desaparición de virus libre de éste a los 3-4 meses p.i. (Andresdottir et al. 2002). En estudios experimentales en corderos se ha demostrado que los anticuerpos reconocen principalmente las proteínas estructurales p25, gp105, p16 y p14 (Kajikawa et al. 1990) y que la producción de anticuerpos frente a p25 es máxima a los 5 semanas, mientras que frente a la proteína transmembranal gp46 aumenta progresivamente (Juste et al. 1998). También se ha descrito que las cepas citolíticas provocan una mayor respuesta de ACc y ACn que precipitantes que las cepas no líticas (Klein et al. 1985). En infecciones naturales los anticuerpos neutralizantes generados son de tipo $\lg G_{1}$, sin producirse respuesta frente a la subclase $\lg _{2}$ lo que favorece la persistencia del virus por la capacidad que tiene esta fracción de opsonización y fagocitosis de las partículas virales (Bird et al. 1995). La incapacidad de los anticuerpos neutralizantes para eliminar completamente el virus parece deberse a su facultad de variar antigénicamente (Petursson et al. 1991), a su capacidad de transmitirse por contacto entre células (Lujan et al. 1994) y a que la afinidad del virus por los macrófagos es mayor que la de los anticuerpos por el virus (Kennedy-Stoskopf et al. 1986).

\section{II.3.3.2. Respuesta inmune celular}

La respuesta celular específica aparece entre una y cuatro semanas p.i. según el inoculo y vía de inoculación y vuelve a niveles basales cuatro a doce semanas mas tarde (Griffin et al. 1978, Sihvonen et al. 1981, Larsen et al. 1982), y parece ser mas importante en la fase aguda de la infección (Petursson et al. 1991). 
En las ovejas infectadas persistentemente la respuesta inmune esta mediada por linfocitos T CD4+ y CD8+ frente a p25 y frente al virus completo (Reyburn et al. 1992). La característica principal es el aumento de la fracción CD8+ en los órganos diana invirtiéndose la razón CD4/CD8. Éstas células se consideran las principales efectoras del sistema inmune celular contribuyendo al control inicial de la carga vírica y produciendo citoquinas inhibitorias (Blacklaws et al. 1994). El aumento de los linfocitos CD8+ se debe a una mayor presentación de antígeno y una mayor expresión de las moléculas del complejo mayor de histocompatibilidad de tipo II (Cordier et al. 1990, Monleón et al. 1997).

También se produce una alteración de la producción de ciertas citoquinas así, la interleucina-2 (IL-2) o factor de crecimiento de células T disminuye en animales clínicamente afectados(Ellis et al. 1985) así como el receptor de la misma en linfocitos CD8+ (Bird et al. 1993). Por otro lado aumenta la fracción de interleucina-8 (IL-8) en animales con lesiones pulmonares lo que favorece la atracción de linfocitos y neutrófilos desarrollándose el cuadro de neumonía intersticial característica de la forma pulmonar (Legastelois et al. 1997).

Se ha descrito la producción de un interferón por parte de las células T específico de lentivirus que aumenta la expresión de moléculas de $\mathrm{CMH}-\mathrm{II}$, retrasando la maduración del monocito y frenando la replicación vírica (Kennedy et al. 1985). El interferón consigue frenar la maduración de la célula diana, incrementa la expresión de los antígenos del $\mathrm{CMH}-\|$ en macrófagos incrementando la liberación de citoquinas y atrayendo linfocitos y macrófagos desencadenando la respuesta linfoproliferativa (Zink et al. 1987).

Se ha estudiado también la capacidad del interferón-tau secretado por el trofoblasto ovino como signo temprano de gestación, de inhibir la replicación vírica y en menor medida la actividad transcriptasa inversa y la lisis celular (Juste et al. 1996)

\section{II.4. Signos clínicos y lesiones}

Las manifestaciones clínicas de la enfermedad son consecuencia del infiltrado inflamatorio de carácter crónico que se produce en los órganos diana. La manifestación de estas formas patológicas viene determinada por el tropismo celular de la cepa vírica (Brodie et al. 1995) y por factores como la raza, la carga genética del animal, la edad, la ruta inicial de exposición, la presencia de infecciones secundarias y las pautas de manejo que favorecen la infección(De la Concha-Bermejillo et al. 1995b, Benavides et al. 2006b, Benavides et al. 2006c). Como rasgo general en todos los cuadros clínicos se produce perdida del estado de carnes y consunción del animal afectado (Sigurdsson 1954a, Watt et al. 1992). 


\section{II.4.1. Forma Pulmonar}

Junto con la mamaria es la forma de presentación de la enfermedad mas frecuente y la mayoritaria en los rebaños latxos de País Vasco (Gonzalez 1989a) La clínica que se observa en los animales se asocia a la neumonía intersticial crónica y los animales afectados presentan disnea. Inicialmente se observa su retraso en la marcha al mover el rebaño, y posteriormente respiración abdominal con extensión de cuello, dilatación de ollares y jadeo (De la Concha-Bermejillo 1997, Lujan et al. 2001). En la fase final el animal termina postrado en el suelo y muere por insuficiencia respiratoria. Puede observarse tos seca y no es frecuente la descarga nasal ni la fiebre salvo que haya complicaciones bacterianas (Sigurdsson et al. 1951). Aunque la infección se produzca a los pocos meses de vida en su forma más frecuente los síntomas clínicos no se manifiestan hasta por lo menos los 2-3 años de vida y una vez que los síntomas son aparentes la esperanza de vida del animal no será superior al año de vida (Watt et al. 1994). Es importante señalar sin embargo, que en corderos y cabritos criados en estabulación intensiva las formas nerviosas antes del año de edad asociadas a MVV y CAEV, respectivamente, no son raras (Houwers et al. 1989, Benavides et al. 2006b).

Macroscópicamente los pulmones presentan aumento de volumen y peso, forma acampanada, bordes redondeados, principalmente el borde dorsal y los lóbulos diafragmáticos y la consistencia es gomosa y poco elástica. Al corte la superficie es seca, no se produce exudado a no ser que haya infección bacteriana. Se observa un fino punteado grisáceo como consecuencia de la hiperplasia de los folículos linfoides (Lujan et al. 1991), los ganglios linfáticos mas afectados son los bronquiales regionales y el mediastinito se pueden presentar muy aumentados de tamaño (Ellis et al. 1985, Watt et al. 1995).

Microscópicamente la inflamación intersticial se acompaña de infiltración de linfocitos, macrófagos monocitos y células plasmáticas afectando a los septos interalveolares. Se producen folículos por agregación de linfocitos (Narayan et al. 1989), hiperplasia del músculo liso interalveolar (Dawson 1980, Lujan et al. 1991), incluso fibrosis en lesiones avanzadas. En los nódulos linfáticos regionales del pulmón existe una linfadenitis reactiva crónica no específica, con hiperplasia de los folículos linfoides corticales e histiocitosis de los senos medulares (Ellis et al. 1985).

\section{II.4.2. Forma Nerviosa}

También denominada "visna", se describió por primera en varios animales en Islandia (Sigurdsson 1957) pero las descripciones posteriores han sido esporádicas (Ressang et al. 1966, Watt et al. 1995, Braun et al. 2001, Payne et al. 2004, Biescas et al. 2005), se presenta con mayor frecuencia en 
cabritos infectados de CAEV y recientemente se ha descrito cómo una presentación clínica frecuente en corderas de raza Assaf de pocos meses de vida en Castilla y León (Benavides et al. 2006a, Benavides et al. 2006b, Benavides et al. 2006c) pese a que generalmente se observe en animales mayores de dos años. (Brahic et al. 1981).

Presenta dos manifestaciones clínicas, la mas característica es la "medular" asociada a lesiones de la medula espinal que provocan parálisis progresiva del tercio posterior los animales arrastran las extremidades posteriores y acaban postrados (Benavides et al. 2006c). La forma "cerebral "se produce por afección del tronco del encéfalo(Christodoulopoulos 2006) y se manifiesta clínicamente como ataxia, movimientos circulares e inclinación de la cabeza, temblor de músculos de la cara e incluso ceguera (Petursson et al. 1990, Watt et al. 1992).

Macroscópicamente se observan áreas grisáceas de malacia en la sustancia blanca periventricular y columnas dorsales de la medula espinal llegando a producir necrosis por licuefacción (Benavides et al. 2006c). Al corte se pueden observar áreas de inflamación en forma de cuña a nivel de la medula espinal (Benavides et al. 2006a).

Microscópicamente se caracteriza por una leucoencefalomielitis no purulenta desmielinizante crónica. Las lesiones se distribuyen principalmente en la pared de ventrículos laterales y columnas dorsales y laterales de la medula espinal (Cutlip et al. 1979) a veces también junto a lesiones en encéfalo y raramente existe destrucción neuronal (Sigurdsson 1957).

\section{II.4.3. Forma Mamaria}

De presentación frecuente (Oliver et al. 1981a, Van der Molen et al. 1985), en España se ha descrito de forma importante en la raza Rasa Aragonesa (Lujan et al. 1991, Bolea 1998) su síntoma característico es la disminución en la producción de la leche que se refleja en corderos de pobre crecimiento y con signos de hambre (Keen et al. 1997a). Los animales infectados presentan mamitis indurativa crónica de carácter difuso, bilateral y no dolorosa y tumefacción de los nódulos linfáticos retromamarios. A diferencia de otros patógenos mamarios, la mamitis por SRLV no se asocia a alteraciones organolépticas de la leche, salvo que existan infecciones de la mama concomitantes de otra etiología.

Macroscópicamente las mamas aparecen afectadas bilateralmente muy endurecidas firmes y tersas. A la sección presentan un aspecto no glandular con superficie lisa, húmeda y uniforme (Dawson 1987, Zink et al. 1994). 
Microscópicamente se aprecia una mamitis intersticial crónica con inflamación linfocitaria e hiperplasia de folículos linfoides (Dawson 1987) que puede producir la perdida de tejido glandular, fibrosis y estenosis de los conductos galactóforos (Anderson et al. 1985).

\section{II.4.4. Forma Articular}

La menos frecuente de todas, en España se ha descrito mayoritariamente en la zona de Aragón (Biescas 2006), la inflamación afecta sobre todo a los carpos pudiendo también afectar a la articulación del tarso observándose tumefacción bilateral provocando cojera y marcha envarada (Watt et al. 1994).

Macroscópicamente se observa engrosamiento de la capsula y la membrana sinovial, cartílago y tendones (Cutlip et al. 1988, Watt et al. 1992). Aparece edema, hiperemia, hiperplasia y necrosis de la membrana sinovial, necrosis y erosión del hueso articular, necrosis y fibrosis del hueso subcondral y fibrosis periarticular que pueden llegar a anquilosar la articulación e incluso producir fracturas (Cutlip et al. 1985b).

Microscópicamente existe proliferación de la membrana sinovial e infiltración de linfocitos, células plasmáticas y macrófagos. Pueden aparecer fibrina y depósitos de inmunoglobulina en la membrana sinovial. Puede evolucionar hacia una degeneración del cartílago articular, mineralización de la cápsula articular y su reemplazo por crecimiento periostial (Narayan et al. 1992).

Con frecuencia se presentan diferentes manifestaciones clínicas en un mismo animal y en un estudio anatomopatológico realizado en 74 ovejas seropositivas el 37,8\% presentaban lesiones tanto en mama como en pulmón (Lujan et al. 1991).

\section{II.5. Diagnóstico de la infección por Virus Maedi Visna}

Si bien la necropsia y el examen histopatológico permiten hacer, en casos avanzados, un diagnóstico certero de la infección, por la naturaleza lenta de la enfermedad el diagnóstico en el animal vivo basado en los signos clínicos es poco útil y se recurre al empleo de pruebas inmunológicas para detectar anticuerpos frente al virus y a la detección directa del mismo o de sus secuencias genéticas.

\section{II.5.1. Diagnóstico inmunológico}

Por la naturaleza de la infección se considera que los animales con anticuerpos específicos contra VMV presentes en el suero están infectados y existen varias técnicas para detectarlos. El Western 
Blotting (WB) se considera la técnica de referencia aunque está por demostrar que sea una técnica $100 \%$ específica y sensible. Las técnicas de mayor utilidad en estudios epidemiológicos son la inmunodifusión en gel de agar (IDGA) y el ELISA (Enzyme-Linked Immunosorbent Assay).

\section{II.5.1.2. Inmunodifusion en gel agar (IDGA)}

Se basa en la detección de anticuerpos frente a antígenos solubles de la proteína de la superficie gp135 y de la cápside p25. Los sueros que contienen dichos anticuerpos específicos generan dos bandas de precipitado correspondientes a cada una de las proteínas (Cutlip et al. 1977). Se considera una técnica altamente especifica ( $>98 \%$ ) pero con una sensibilidad limitada comparada con el ELISA (Simard et al. 1990, Saman et al. 1999, Varea et al. 2001, Toft et al. 2006). La validez de la IDGA está además comprometida a la experiencia del observador ya que su interpretación es subjetiva y puede arrojar diferentes resultados según la persona que haga la lectura. Pese a esto, es la técnica serológica clásica para el diagnóstico de VMV y ha sido la referencia hasta la aparición de los ELISAs de última generación. Ha sido utilizada en numerosos estudios de seroprevalencia de VMV (Knowles et al. 1994, Fournier et al. 2006, Torres-Acosta J.F.J et al. 2008). Estudios recientes indican que la técnica podría ser mas sensible para la detección de CAEV (Brinkhof et al. 2007).

\subsubsection{Ensayo de inmunoabsorbancia enzimatica o ELISA}

Se considera actualmente el test serológico mas sensible y es el más usado en el diagnostico del VMV para el análisis de gran volumen de muestras (De Andres et al. 2005), como es el caso de los programas de erradicación. Se han desarrollado numerosos ensayos tanto para CAEV como para VMV que se diferencian en la naturaleza del antígeno (De Andres et al. 2005). Los mas utilizados son los ELISAs indirectos (ELISA-i) que utilizan anticuerpos marcados con una enzima que reaccionan con los anticuerpos problema y que al añadir el substrato generan una reacción coloreada que se puede medir por espectrofotometría. Según el tipo de antígeno que utilizan se denominan ELISAs de virus completo cuando utilizan antígenos de virus completo y ELISAs recombinantes cuando utilizan como antígeno, proteína recombinante y/o péptidos sintéticos (De Andres et al. 2005). Los cálculos de sensibilidad y especificidad de los ELISAs se han hecho en relación con otras técnicas serológicas ente las que se encuentran otros ELISAs. A modo de síntesis, los que utilizan virus completo obtienen resultados de sensibilidad entre $92 \%$ y $100 \%$ y especificidad entre $93 \%$ y $100 \%$ en comparación las técnicas serológicas de Radioinmunoensayo p28 (RIA), IDGA, WB, Fluorescent cell inmunoperoxidase (FCIP), radioinmunoprecipitación (RIPA), CFT (test de fijación de complenento) y otros ELISAs, la reacción en cadena de la polimerasa (PCR) y la histopatología (Simard et al. 1990, Brodie et al. 1993, Zanoni et al. 1994, Vander et al. 1994). 
Los ELISAs recombinantes que utilizan péptidos sintéticos de la región gag (p55, p25, p16, p14), proteína transmenbranal (TM) (p44, gp 46) y de la región env (gp135) utilizando el WB y la IDGA como técnica de referencia obtienen valores de sensibilidad entre $84 \%$ y $99,4 \%$ y de especificidad entre 98,2\% y 100\%(Kwang et al. 1993, Kwang et al. 1994, Saman et al. 1999, Varea et al. 2001). En un estudio el uso de p25-TM como antígeno obtuvo 100\% de sensibilidad y especificidad con respecto a otro ELISA rp25 (Boshoff et al. 1997) pero al compararlo con otras técnicas de detección de anticuerpos (IDGA, ELISA indirecto y WB) la sensibilidad fue del $64 \%$ y la especificidad del $100 \%$ (DeMartini et al. 1999).

En otros trabajos se utilizó un ELISA de virus completo como referencia y se observaron valores de sensibilidad mucho mas bajos para los ELISAs recombinantes, de entre 50 y $60 \%$ de sensibilidad y 95100\% de especificidad (Celer, Jr. et al. 1993, Zanoni et al. 1994, Rosati et al. 1994). Finalmente cuando se combinan proteínas recombinantes gag y TM mejoran los resultados de sensibilidad igualando los valores a los de la técnica de referencia que utilizan ELISA de virus completo (Keen et al. 1995, Power et al. 1995, Pasick 1998b).

También se han descrito para el diagnóstico serológico del VMV aunque en menor frecuencia, los ELISAs de competición que se basan en el enfrentamiento de anticuerpos monoclonales con el antígeno gp90 de VMV después de la exposición del mismo al suero problema (Fevereiro et al. 1999) y CAEV-63 (Herrmann et al. 2003).

Actualmente existen 4 ELISAs comerciales para detectar anticuerpos frente a VMV: "Checkit CAEV/MVV" (Bomeli AG) (Zanoni et al. 1994), "ELITEST" (Hyphen Biomed) (Saman et al. 1999), "CAEV,Celisa" (VMRD.Inc.) (Herrmann et al. 2003) y "MVVICAEV Elisa" (Intitut Pourquier) del que no hay publicados datos de sensibilidad y especificidad. Al estudiar la eficacia diagnóstica de los diferentes test comerciales se ha demostrado su escasa sensiblidad en las primeras fases de la infección frente a diferentes genotipos del virus (Lacerenza et al. 2006). Se ha sugerido que la heterogeneicidad de los epitopos inmunodominantes del antígeno de la cápside que se utiliza en los test serológicos podría afectar la sensibilidad de los mismos (Grego et al. 2002). Por ello de cara a las campañas de control y erradicación se propone el desarrollo de ELISAs con antígenos específicos de la cepa predominante en la zona estudiada (Grego et al. 2002, Reina et al. 2009, Grego et al. 2009).

Un estudio reciente comparando 5 tests serológicos comerciales (4 ELISAs y una IDGA) (Brinkhof et al. 2007) no observó grandes diferencias en la especificidad pero si en la sensibilidad de las técnicas; el test mas sensible en animales con sintomatología clínica fue el que utilizó como antígenos la proteína de la capside p25 y la de la envuelta gp135. 


\section{II.5.2. Diagnóstico Vírico}

\section{II.5.2.1. Aislamiento vírico}

Es el diagnóstico etiológico tradicional que se basa en el cultivo de células permisivas a la infección con explantes de tejido de los animales posiblemente infectados. Mide el efecto citopático observándose lisis celular y formación de células gigantes multinucleadas o sincitios por adhesión de células infectadas. Se han utilizado numerosas líneas celulares para la replicación vírica siendo las mas frecuentes las del plexo coroideo de corderos o fetos ovinos (Sigurdsson et al. 1960, Sihvonen et al. 1981), explantes de pulmón ovino (Kennedy et al. 1968, Cutlip et al. 1976) y membrana sinovial de cabra (Daltabuit-Test et al. 1999, Lamara et al. 2001).

Algunos lo consideran el método mas fiable pero es lento ya que el efecto citopático necesita al menos seis días de incubación (Lamara et al. 2001) hasta 6 meses (Daltabuit-Test et al. 1999). El cultivo celular es de utilidad para la obtención de antígenos utilizados en otros métodos diagnósticos.

\section{II.5.2.2. Inmuno histoquímica. (IHQ)}

Se basa en la observación del antígeno vírico en diferentes tejidos gracias a la unión de anticuerpos específicos marcados (Georgsson et al. 1989, Lujan et al. 1994, Bolea et al. 2006). Con esta técnica se ha conseguido detectar antígeno vírico en otras células diferentes a las de la línea monocito-macrófago como son las células epiteliales de la glándula mamaria (Lerondelle et al. 1999, Bolea et al. 2006), células de la granulosa del oviducto de cabras (Lamara et al. 2001) y células epiteliales e intersticiales del epidídimo (Preziuso et al. 2003). La IHQ permite localizar con precisión los lugares donde se produce la replicación vírica y ha facilitado el estudio de la patogenia de la enfermedad. El inconveniente es que es una técnica cara y laboriosa, por lo que su utilización se limita a estudios experimentales.

\section{I.5.2.3. Detección de ácidos nucleicos}

\section{II.5.2.3.1. Hibridación in situ. (HIS)}

Permite detectar ácidos nucleicos (ADN y ARN) víricos en preparaciones celulares mediante el uso de sondas oligonucleotídicas marcadas radiactivamente o con fluorocromos como la digoxigenina y la biotina (Amorena et al. 1997).Permite localizar el virus en las células y órganos diana y en combinación con la IHQ ha permitido diferenciar células infectadas en estado latente de las que soportan una infección productiva (Gendelman et al. 1985). Con la utilización de acetona como fijador (Roy et al. 
1992) consiguieron detectar ARN vírico y antígenos de VMV en la misma célula. Junto con la HIS permitió detectar virus en animales de un año de edad que aún no habían seroconvertido. (Johnson et al. 1992). Al igual que con la IHQ la laboriosidad y coste de la técnica explica que solo se haya utilizado en estudios experimentales y no en poblacionales.

\section{II.5.2.3.2. Reacción en cadena de la Polimerasa (PCR)}

La PCR se basa en la amplificación de fragmentos de ADN utilizando oligonucleótidos sintéticos específicos de la secuencia diana (cebadores) con la ayuda de la enzima polimerasa y una serie de ciclos a diferentes temperaturas que permiten generar un número exponencial de copias suficiente para poder ser detectadas con facilidad (Sambrook et al. 1989). Además de la PCR convencional se han utilizado variantes como la PCR-anidada (PCR-n) que consiste en amplificar un subproducto de una amplificación previa, la PCR-semianidada (PCR-sn) que a diferencia de la anterior utiliza en la segunda amplificación un cebador usado también en la primera amplificación, la PCR in situ que combina la PCR con una hibridación in situ y la PCR transcriptasa inversa (RT-PCR) que, utilizando la enzima transcriptasa inversa que transforma el ARN en ADN complementario, es la única que permite detectar virus no integrado en células (virus libre). En los últimos años se han descrito protocolos de PCR cuantitativa a "tiempo real" para la detección de VMV. Según se ha demostrado para otros patógenos entre sus ventajas se encuentran la mayor rapidez, la disminución del riesgo de contaminación con producto amplificado y la capacidad de cuantificar la concentración de los ácidos nucleicos (Niesters 2002). El hecho de poder utilizar secuencias específicas de las estirpes a estudiar podría mejorar la sensibilidad que presentan los protocolos de PCR convencional frente a VMV.

La síntesis de los cebadores se realiza a partir de las zonas específicas más conservadas de las regiones del genoma para aumentar la sensibilidad y las regiones mas utilizadas, de mayor a menor homología entre cepas, son pol, LTR, gag y env.

La mayoría de los estudios de PCR han sido dirigidos a la detección de VMV en células mononucleares de sangre periférica (PBMCs), pero también se han probado en otro tipo de matrices como la leche, el calostro, el semen y el líquido sinovial. Numerosas publicaciones describen la detección de provirus y de virus libre con diferentes resultados de sensibilidad y especificidad y en la tabla II.2.se enumeran los estudios realizados hasta la fecha, incluidos los autores, la muestra substrato, la región del genoma objeto de amplificación, la técnica frente a la que se compara su validez o técnica de referencia y las principales conclusiones extraídas de los mismos. 
Tabla II.2. Muestra origen, región, técnica de referencia y conclusión de las PCR convencionales publicadas hasta el momento

\begin{tabular}{|c|c|c|c|c|}
\hline AUTOR & MUESTRA & REGION & TEC.REF. & CONCLUSIÓN \\
\hline (Zanoni et al. 1990b) & $\begin{array}{r}\text { Células de cultivo celular } \\
\text { plexo coroideo }\end{array}$ & $\begin{array}{r}\text { gag de VMV } \\
\text { y pol de CAEV }\end{array}$ & $\begin{array}{r}\text { Inmunoblot } \\
\text { y cultivo } \\
\text { celular. }\end{array}$ & $\begin{array}{r}\text { Mejores resultados con gag } \\
\text { que con pol. Detección precoz } \\
1 \text { dia p.i. }\end{array}$ \\
\hline (Zanoni et al. 1992) & & $\begin{array}{l}\text { LTR y gag de } 1514 \\
\text { VMV y pol CAEV }\end{array}$ & & $\begin{array}{r}\text { La LTR-PCR más sensible que } \\
\text { el resto. }\end{array}$ \\
\hline (Brodie et al. 1993) & $\begin{array}{r}\text { Leucocitos de lavado } \\
\text { broncoalveolar, sangre, } \\
\text { nódulo linfoide } \\
\text { mediastinico y medula } \\
\text { ósea. }\end{array}$ & LTR y pol VMV & $\begin{array}{r}\text { IDGA, } \\
\text { ELISA, } \\
\text { Inmunoblot. }\end{array}$ & $\begin{array}{l}\text { Buenos resultados pero con } \\
\text { cultivo previo con fibroblastos. }\end{array}$ \\
\hline $\begin{array}{r}\text { (Daltabuit-Test et al. } \\
1999)\end{array}$ & PMBC & gag & IDGA & $\begin{array}{r}\text { Se detectó provirus } 6 \text { meses } \\
\text { después de la infección } \\
\text { experimental. }\end{array}$ \\
\hline (Reddy et al. 1993) & $\begin{array}{l}\text { PMBC, células de fluido } \\
\text { sinovial de cabra, células } \\
\text { de leche sin cocultivación. }\end{array}$ & gag y pol CAEV-co & IDGA & $\begin{array}{r}\text { Detectó el } 90 \% \text { de muestras } \\
\text { seropositivas y } 2 \text { muestras de } \\
\text { PMBC que seroconvirtieron } 2 \\
\text { meses después. }\end{array}$ \\
\hline (Rimstad et al. 1993) & PMBC & DNA-PCR & ELISA & $\begin{array}{r}\text { De los seropositivos } 92.3 \% \\
\text { tambien PCR positivos, detecto } \\
10 \text { infectados antes de } \\
\text { seroconvertir. }\end{array}$ \\
\hline (Wagter et al. 1998) & Leucocitos & gag & IDGA & $\begin{array}{r}\text { Detección de } 1 \text { animal PCR } \\
\text { positivo antes de seroconvertir, } \\
88 \% \text { de seropositivos } \\
\text { detectados por PCR mejoran } \\
\text { los resultados utilizando mas } \\
\text { volumen de sangre }\end{array}$ \\
\hline (Barlough et al. 1994) & $\begin{array}{r}\text { Pulmón, ganglio } \\
\text { mesenterico, medula } \\
\text { osea, menbrana sinovial, } \\
\text { glandula mamaria. }\end{array}$ & $\begin{array}{r}\text { pol y gag PCR -n } \\
\text { CAEV }\end{array}$ & $\begin{array}{r}\text { ELISA. } \\
\text { (Rimstad et } \\
\text { al. 1994) }\end{array}$ & $\begin{array}{r}\text { Buena concordancia entre } \\
\text { ELISA y PCR, } k=0.912 .41 \% \\
\text { PCR pos. en sangre también } \\
\text { en leche. }\end{array}$ \\
\hline (Johnson et al. 1992) & $\begin{array}{r}\text { PBMC cultivados durante } \\
14 \text { días. }\end{array}$ & LTR & ELISA & $\begin{array}{r}\text { Tras el cultivo } 70 \% \text { fueron PCR } \\
\text { e Hibridación in situ positivos } \\
\text { frente al } 10 \% \text { seropositivos. }\end{array}$ \\
\hline (Leroux et al. 1997) & $\begin{array}{r}\text { Celulas de la leche y } \\
\text { secreciones mamarias }\end{array}$ & RT-PCR region pol & $\begin{array}{r}\text { IDGA(Pour } \\
\text { quier) y } \\
\text { ELISA } \\
\text { (Chekit) }\end{array}$ & $\begin{array}{r}\text { Detección de RNA en todas } \\
\text { las muestras de animales } \\
\text { infectados natural y } \\
\text { experimentalmente. }\end{array}$ \\
\hline (Travassos et al. 1998) & $\begin{array}{r}\text { PBMC, semen separado } \\
\text { en fluido seminal sin } \\
\text { células, fracción celular } \\
\text { sin espermatozoides y } \\
\text { espermatozoides }\end{array}$ & $\begin{array}{r}\text { Env y pol PCR } \\
\text { doble anidada CAEV }\end{array}$ & $\begin{array}{r}\text { ELISA } \\
\text { (Chekit) }\end{array}$ & $\begin{array}{l}100 \% \text { positivos a PBMC, no se } \\
\text { detecto virus en la fracción de } \\
\text { espermatozoides, env-PCR fue } \\
\text { más efectiva que la región pol. }\end{array}$ \\
\hline (Celer et al. 2000) & PBMC & gag PCR -sn & $\begin{array}{r}\text { IDGA, } \\
\text { Inmunoblot }\end{array}$ & $\begin{array}{r}\text { PCR positivos } 70 \% \text { de los } \\
\text { seropositivos y } 8.8 \% \text { de } \\
\text { seronegativos. }\end{array}$ \\
\hline $\begin{array}{r}\text { (Extramiana et al. } \\
\text { 2002) }\end{array}$ & $\begin{array}{l}\text { Leucocitos de sangre } \\
\text { periférica, leche y tejidos. }\end{array}$ & LTR-PCR & $\begin{array}{r}\text { IDGA, } \\
\text { ELISA } \\
\text { (Saman et } \\
\text { al. 1999) }\end{array}$ & $\begin{array}{r}100 \% \text { especificidad, } 98 \% \\
\text { sensibilidad en conjunto que } \\
\text { disminuye por tejidos: } 84 \% \text { en } \\
\text { PBL, } 67 \% \text { en leche y } 88 \% \text { en } \\
\text { tejidos. }\end{array}$ \\
\hline
\end{tabular}




\begin{tabular}{|r|r|r|r|r|}
\hline AUTOR & MUESTRA & REGION & TEC.REF. & CONCLUSIÓN \\
\hline (Zhang et al. 2000) & $\begin{array}{r}\text { Macrófagos alveolares y } \\
\text { leucocitos de sangre } \\
\text { periférica. }\end{array}$ & $\begin{array}{r}\text { PCR cuantitativa de } \\
\text { competición de la } \\
\text { región pol de MVV } \\
\end{array}$ & $\begin{array}{r}\text { EV1 } \\
\text { Histopatolo } \\
\text { gía }\end{array}$ & $\begin{array}{r}\text { La cantidad de DNA vírico fue } \\
\text { mayor en macrófagos } \\
\text { alveolares que en PBL y } \\
\text { correlacionada con la } \\
\text { severidad de las lesiones. }\end{array}$ \\
\hline (Gil et al. 2006) & Leucocitos de sangre \\
& periférica. & gag-PCR -n y -sn & $\begin{array}{r}\text { ELISA } \\
\text { (Pourquier) }\end{array}$ & $\begin{array}{r}\text { PCR menos sensible que el } \\
\text { ELISA. La combinación de } \\
\text { ambas técnicas mejora la } \\
\text { detección de la infección }\end{array}$ \\
\hline (Eltahir et al. 2006) & Sangre entera y PBMC. & pol-PCR-sn & $\begin{array}{r}\text { IDGAT } \\
\text { (Cutlip et } \\
\text { al. 1977) }\end{array}$ & $\begin{array}{r}\text { Mas sensible que el IDGA y } \\
\text { capaz de detectar diferentes } \\
\text { variantes de SRLV y } \\
\text { detectable en sangre entera. }\end{array}$ \\
& & & & \\
\end{tabular}

Tabla II.3. Muestra origen, región, técnica de referencia y conclusión de las PCR a tiempo real publicadas hasta el momento

\begin{tabular}{|r|r|r|r|r|}
\hline \multicolumn{1}{|c|}{ AUTOR } & MUESTRA & REGION & TEC.REF. & CONCLUSIÓN \\
\hline $\begin{array}{r}\text { (Gudmundsson et } \\
\text { al. 2003) }\end{array}$ & $\begin{array}{r}\text { Sobrenadante de } \\
\text { cultivo de células } \\
\text { sinoviales fetales } \\
\text { ovinas infectadas. }\end{array}$ & $\begin{array}{r}\text { RealTime-PCR } \\
\text { cuantitativa,gag-pol, } \\
\text { tat, rev, env, vif. }\end{array}$ & $\begin{array}{r}\text { La técnica descrita puede } \\
\text { utilizarse en el estudio del } \\
\text { papel de los elementos } \\
\text { genéticos en la infección y } \\
\text { patogénesis del VMV. }\end{array}$ \\
\hline $\begin{array}{r}\text { (Herrmann-Hoesing } \\
\text { et al. 2007b) }\end{array}$ & Suero y PBMC & $\begin{array}{r}\text { Real Time-PCR } \\
\text { cuantitativa-env. }\end{array}$ & cELISA(Herrmann et \\
al. 2003) & $\begin{array}{r}\text { Buena concordancia entre } \\
\text { PCR y ELISA }(k=0.93), \\
\text { buenos resultados para medir } \\
\text { cantidad de virus en PBMC }\end{array}$ \\
\hline (Brinkhof et al. & Buffy coat & Real Time-PCR-gag & ELISA(Saman et al. & $\begin{array}{r}100 \% \text { de especificidad, buena } \\
\text { herrramienta junto con la } \\
\text { serologia para monitorizar } \\
\text { rebaños en programas de } \\
\text { control }\end{array}$ \\
\hline
\end{tabular}

Las principales ventajas de la PCR en el diagnóstico del MV frente a las técnicas serológicas es que es mas sensible durante el primer año de vida permitiendo detectar la infección en animales con anticuerpos calostrales y en los que se encuentran en estado de latencia serológica o que se han infectado recientemente (Rimstad et al. 1993, Wagter et al. 1998, Celer et al. 2000, Daltabuit-Test 2005, Gil et al. 2006, Alvarez et al. 2006)

Sin embargo, en muestras de sangre la PCR por lo general presenta menor sensibilidad que el ELISA debido a la baja carga vírica (Brodie et al. 1992) y a la variabilidad genética de las distintas cepas del virus. Esto sugiere que la pauta más efectiva para la detección de la infección es la combinación de la serología con la PCR (De Andres et al. 2005, Gil et al. 2006).

En el estudio de la relación de la PCR y las técnicas serológicas (IDGA y ELISA) (Karanikolaou et al. 2005), el ELISA (Saman et al. 1999) presentó la mayor sensibilidad de las tres técnicas pero su especificidad fue baja (59\%). En contraste, con la LTR-PCR (Extramiana et al. 2002) se obtuvo una 
especificidad del 100\%, y una sensibilidad del 56,7\%, mientras que la IDGA (Cutlip et al. 1977) tuvo una sensibilidad del $90 \%$ y una especificidad del $100 \%$. La mejor combinación fue para la IDGA y la PCR en 1436 rebaños con historia de SRLV en el norte de Grecia.

Recientemente, un estudio (Brinkhof et al. 2010) describe la combinación de ELISA (Saman et al. 1999, Brinkhof et al. 2007) y PCR a tiempo real (Brinkhof et al. 2008) aplicado a un rebaño con un $52 \%$ de seropositividad, consiguiendo erradicar la enfermedad en dos años sacrificando a los animales positivos a las dos técnicas y realizando muestreos frecuentes cada 3 meses.

\section{II.6. Epidemiología}

\section{II.6.1. Distribución geográfica}

Es difícil comparar la prevalencia e incidencia de la infección por VMV en los distintos lugares del mundo ya que los estudios realizados se basan en diferentes pruebas serológicas (IDGA, Fijación de complemento y ELISA) y en muestreos con diseños y tamaños muestrales muy diferentes. En el continente americano la infección por el VMV se ha descrito en diferentes estados de EEUU, (Cutlip et al., 1977b, Molitor et al., 1979, Madewell et al., 1990, Campbell et al., 1994, Keen et al., 1997) en Canadá (Lamontagne et al., 1983, Simard y Morley, 1991), México (Molina et al. 1986), en Perú (Snyder et al. 1983, Rosadio et al. 1984) y en Argentina (Robles et al. 2003). En Asia se ha descrito la infección en la India y en China. Sudáfrica es uno de los primeros países en los que se denunció la enfermedad (Houwers 1990). En Europa la infección por el VMV se ha descrito en Suiza (Krieg y Peterhans, 1990), Reino Unido (Dawson y Wilesmith, 1985), Italia (Caporale et al. 1985) Francia, Alemania, Holanda, Bélgica y España(Peterhans et al. 2004).

\section{II.6.1.1. Distribución en España}

El VMV se describió por primera vez en España en 1984, en ovejas adultas del País Vasco que presentaban neumonía crónica con una prevalencia de animales infectados del 31,95\% (Gonzalez et al. 1984). En un estudio más amplio en el País Vasco, tres años después, se describió infección en el $100 \%$ de rebaños muestreados, con un $47 \%$ de prevalencia media por rebaño (Juste et al. 1987). Posteriormente, en un estudio todavía más amplio se obtuvieron cifras del $99,2 \%$ de los rebaños y del $52,4 \%$ (Gonzalez 1989b).

El VMV se ha estudiado en varias comunidades autónomas (tabla II.4.) en las que se han observado diferentes niveles de infección. Así, el porcentaje de rebaños muestreados con al menos un animal 
positivo osciló entre un 12\% en Castilla la Mancha y un 100\% en País Vasco y la prevalencia media de los animales entre 13,9\% en Murcia (León et al. 1996) y 66\% en León (Sotelo et al. 1995).

Tabla II.4. Resultados de los diferentes estudios de seroprevalencia de Maedi Visna realizados en España

\begin{tabular}{|c|c|c|c|c|c|}
\hline $\begin{array}{l}\text { Comunidad } \\
\text { Autónoma }\end{array}$ & Referencia & \% Rebaños positivos & Técnica & $\begin{array}{l}\text { Prevalencia } \\
\text { por animal }\end{array}$ & Localización \\
\hline \multirow[t]{2}{*}{ País Vasco } & (Gonzalez 1989a) & $31,95 \%$ & IDGA & - & - \\
\hline & (Juste et al. 1987) & $100 \%$ & IDGA & $47 \%$ & \\
\hline \multirow[t]{4}{*}{ Aragón } & (Lujan et al. 1993) & $95-97,8 \%$ & - & $38,6-44,7 \%$ & $\begin{array}{r}\text { Aragon, sur de } \\
\text { Navarra y } \\
\text { Rioja } \\
\end{array}$ \\
\hline & (Abril-Galve et al. 1994) & $\begin{array}{r}27 \% \text { rebaños trashumantes, } \\
9 \% \text { sedentarios }\end{array}$ & $\begin{array}{r}\text { ELISAi } \\
\text { POURQUIER } \\
\end{array}$ & & Teruel \\
\hline & (Abril et al. 2004) & - & IDGA / ELISA & $15,31 \% / 53.06 \%$ & Teruel \\
\hline & (Biescas et al. 2004) & $100 \%$ & ELISA(Innotest) & $56 \%$ & $\begin{array}{r}\text { Zaragoza, } \\
\text { Huesca y } \\
\text { Teruel }\end{array}$ \\
\hline Madrid & (García et al. 1994) & $43,4 \%$ & - & $24,5 \%$ & - \\
\hline $\begin{array}{r}\text { Castilla la } \\
\text { Mancha }\end{array}$ & (de la Cruz et al. 1994) & $12 \%$ & $\begin{array}{r}\text { IDGA(Windward } \\
1979) \\
\end{array}$ & - & - \\
\hline \multirow{2}{*}{$\begin{array}{r}\text { Castilla y } \\
\text { León }\end{array}$} & (Sotelo et al. 1995) & $96 \%$ & IDGA & $66 \%$ & León \\
\hline & (Reviriego F.J. 1998) & $30 \%$ & IDGA & $14,95 \%$ & Avila \\
\hline Murcia & (León et al. 1996) & $21,7 \%$ & IDGA & $13,9 \%$ & - \\
\hline Navarra & (Ameztoy et al. 1998) & $89 \%$ & $\begin{array}{r}\text { ELISAi } \\
\text { POURQUIER } \\
\end{array}$ & $26 \%$ & - \\
\hline Andalucía & (Artigas et al. 1999) & $31 \%$ & $\begin{array}{r}\text { ELISAi } \\
\text { POURQUIER } \\
\end{array}$ & - & Sevilla \\
\hline Asturias & (Espí et al. 2001) & - & $\begin{array}{r}\text { ELISAi } \\
\text { POURQUIER }\end{array}$ & $\begin{array}{r}24 \% \text {, de } 900 \\
\text { animales } \\
\text { muestreados }\end{array}$ & \\
\hline Cataluña & (Alba et al. 2008) & $90 \%$ (Cl:85-94\% ) & $\begin{array}{r}\text { ELISAi } \\
\text { ELITEST } \\
\end{array}$ & $58,3 \%$ & \\
\hline Galicia & (Lago et al. 2009) & $74 \%$ & $\begin{array}{r}\text { ELISAi } \\
\text { POURQUIER } \\
\end{array}$ & $24,99 \%$ & \\
\hline
\end{tabular}

\section{II.6.2. Vías de Transmisión}

Cualquier secreción de los órganos diana que contenga macrófagos infectados con el VMV es una fuente potencial de infección para otros animales y las principales son el calostro y la leche (vía lactógena) y las secreciones pulmonares (vía horizontal) (Lujan et al. 1994, McNeilly et al. 2008). 


\section{II.6.2.1. Transmisión horizontal}

El contacto con secreciones pulmonares puede producirse de manera directa por contacto con animales infectados o indirectamente por contacto con material infectado. Como ya se ha explicado, la importancia del contagio horizontal quedó patente en la epidemia de Islandia originada por la introducción de animales adultos infectados en rebaños libres de la infección. (Palsson 1976). Esta forma de transmisión se ha descrito en otros países como Dinamarca (Hoff-Jorgensen 1978) Noruega,(Krogsrud et al. 1978) Canadá(Dukes et al. 1979), Hungría(Suveges et al. 1973), Francia(Cottereau et al. 1977), Finlandia(Sihvonen et al. 1999, Blacklaws et al. 2004) y España. Los trabajos en España de Berriatua et al. (2003), Álvarez et al. (2005a y 2006), Perez et al. (2009) y los de Leginagoikoa $(2006 \mathrm{a}, \mathrm{b})$ incluidos en esta tesis, claramente demuestran la estrecha relación entre la estabulación y la prevalencia de VMV.

La eficacia de la transmisión por contacto está influenciada por diferentes factores como el manejo, el clima y el tipo de producción (Houwers 1990). La importancia del tipo de manejo en la transmisión se hizo patente en la epidemia Islandesa donde los animales permanecían estabulados durante el invierno en pequeñas bordas sin apenas ventilación (Palsson 1976) favoreciendo la rápida expansión de la infección.Este efecto también se demostró experimentalmente en un estudio realizado por Houwers and Van der Molen (1987) en el que la introducción de dos animales infectados en un rebaño libre de la enfermedad ocasionó en cinco años el contagio del $83 \%$ de los individuos de los cuales el $70 \%$ presentó lesiones macroscópicas en mama y/o pulmón.

De Boer et al. (1979) realizaron un estudio en grupos de animales expuestos a diferentes tiempos con un rebaño infectado y relacionaron una mayor severidad de presentación de lesiones con un mayor tiempo de contacto con los animales infectados. (De Boer et al. 1979). El contagio se ve facilitado en mayor o menor medida según el grado de contacto entre animales; así, se ha descrito que una separación de 2 metros entre animales es suficiente para evitar el contagio de LVPR (Adams et al. 1983, Straub 1985, Walker et al. 1991) se ha demostrado también una correlación positiva entre la distancia entre animales y el riesgo de seroconversión (Peretz et al. 1994). La transmisión a través de material contaminado fue demostrada por Sigurdsson et al. 1953, consiguiendo infectar animales a través de agua contaminada con heces aunque los autores no aislaron el virus de estas muestras (Gudnadottir et al. 1965). La detección del virus en orina es inconsistente (Houwers 1990) aunque se ha detectado en tejido renal (Angelopoulou et al. 2006b) y también pero en baja proporción en saliva e hisopos nasales de animales infectados (Gudnadottir et al. 1965).

Es importante tener en cuenta que las condiciones higiénico-sanitarias en el rebaño y en concreto la presencia de otras afecciones respiratorias que favorezcan la tos y la descarga nasal, como por 
ejemplo la adenomatosis pulmonar ovina pueden facilitar la transmisión aerógena del VMV (Straub 1985, Dawson et al. 1990, Gonzalez et al. 1993, Lujan et al. 1994).

\section{II.6.2.2. Transmisión Lactógena}

La mama es uno de los órganos diana del VMV, el cual se detecta en lesiones del tejido mamario (Cutlip et al. 1981, Kennedy-Stoskopf et al. 1985) así como en calostro y en leche (Sihvonen 1980, Cutlip et al. 1985a, Ouzrout et al. 1990, Lerondelle et al. 1990). Las células infectadas incluyen tanto los monocitos (Carrozza et al. 2003) como las células epiteliales:(Bolea et al. 2006) actuando estas como reservorio del virus. La replicación del mismo se produce tras la activación de estas células que se favorece por factores del hospedador de tipo hormonal como ocurre en la lactación tras el parto (Lerondelle et al. 1999).La elevada permeabilidad del intestino de los corderos recién nacidos facilita la entrada del virus a través de la ingestión de calostro infectado (Pepin et al. 1998) siendo esta una fuente de infección importante para ellos. También está bien descrita la importancia de esta vía de transmisión para el CAEV (Ellis et al. 1983, Adams et al. 1983), habiéndose demostrado la presencia de virus tanto en células como en sobrenadante lácteo y la posibilidad de inactivar el virus por calentamiento del calostro a $56^{\circ} \mathrm{C}$ durante 60 minutos. (Adams et al. 1983, Ravazzolo et al. 2006). Preziuso et al. (2004) detectaron la presencia de antígenos del VMV en el citoplasma de monocitos/macrófagos de calostro de ovejas infectadas, en células epiteliales de la lámina propia del intestino delgado y en las placas de Peyer de donde podrían alcanzar vía linfática los linfonodos mesentéricos.

Un estudio filogenético de secuencias nucleotídicas de la región env de virus presente en calostro y sangre demuestra la compartimentalización de los SRLV; las células epiteliales se infectan con variantes específicas indicando que la transmisión lactógena podría asociarse a determinadas cepas de virus que podrían ser distintas a las detectadas en la sangre (Pisoni et al. 2007b).

Estudios experimentales en corderos lactantes han demostrado que la ingestión de calostro y de leche es una fuente de infección para los corderos (De Boer et al. 1979, Alvarez et al. 2005, Alvarez et al. 2006, Herrmann-Hoesing et al. 2007a). Como se expuso anteriormente, en el estudio realizado por Álvarez et al en ovino lechero del País Vasco en régimen semi-intensivo con una presión de infección media se demostró que un $16 \%$ de corderos de madres seropositivas se infectan tras ingerir calostro de forma natural de la madre(Alvarez et al. 2005). Un estudio reciente realizado en rebaños de Aragón y los resultados de esta tesis, evidencian una relación negativa entre el tiempo que pasan las crías con la madre y la seroprevalencia en el rebaño. Se piensa que este resultado es consecuencia de una menor intensificación de los rebaños en los que la reposición se desteta de forma tardía y por lo tanto de un menor riesgo de contagio horizontal siendo compatible con los estudios que demuestran que la 
transmisión lactógena no es esencial en el mantenimiento de la enfermedad en el rebaño (Perez et al. 2009).

\section{II.6.2.3. Transmisión Intrauterina}

Experimentalmente se ha conseguido infectar fetos por inoculación intracerebral (Narayan et al. 1974, Georgsson et al. 1978) y por inyección dentro del saco amniótico (Cutlip et al. 1982) produciéndose reabsorción fetal si la infección se hace antes de los 60 días de gestación.

Se ha aislado el virus en fetos de progenie de ovejas seropositivas e incluso en un feto de una madre seronegativa que había estado en contacto con animales infectados (Cutlip et al. 1981) y se han observado lesiones típicas de VMV en corderos de 2-4 meses nacidos por histerectomía de ovejas seropositivas (Cross et al. 1975). Además se ha descrito la detección de ADN proviral en PBMC de 6$11 \%$ corderos recién nacidos tomadas antes de que estos ingirieran calostro (Brodie et al. 1994, Alvarez et al. 2005).

Sin embargo, en otros estudios no se ha conseguido demostrar la presencia del virus en fetos 0 neonatos de madres infectadas (Gudnadottir 1974, De Boer et al. 1979, Sihvonen 1980, Houwers et al. 1987b) y aunque existe controversia al respecto la opinión generalizada entre los investigadores de esta enfermedad es que la transmisión intrauterina no es una ruta de transmisión esencial (Blacklaws et al. 2004).

\section{II.6.2.4. Transmisión sexual}

No se ha demostrado la transmisión coital aunque se han descrito lesiones asociadas al VMV en testículos de carneros infectados con VMV con lesiones típicas en pulmón (Palfi et al. 1989). Además se ha demostrado relación entre el VMV y Brucella ovis; en animales infectados con ambos agentes se detectó VMV en células intersticiales y epiteliales del epidídimo. Se considera que la epididimitis que produce la bacteria podría facilitar la eliminación del virus a través del semen (De la Concha-Bermejillo et al. 1996, Preziuso et al. 2003). Otros autores denuncian la presencia intermitente de DNA proviral en semen y tejidos del tracto genital masculino de carneros y machos cabrios infectados de forma natural (Peterson et al. 2007, Ali Al Ahmad et al. 2007b, Ramirez et al. 2009). La importancia de los machos en la transmisión no parece por tanto relacionada tanto con la vía seminal como por el contacto horizontal general asociado a la tradición de intercambiar machos entre rebaños.

Otro aspecto importante de cara al empleo de tecnología de reproducción artificial es la posibilidad de infección vía óvulos de ovejas infectadas. En este sentido, estudios realizados tanto en cabras 
infectadas con CAEV (Ali Al Ahmad et al. 2005) como en ovejas infectadas por el VMV (Cortez et al. 2006) demuestran la presencia de DNA proviral en células del cumulus oophorus pero no en oocitos libres. Además se ha conseguido obtener embriones libres de CAEV y oocitos libres de VMV a partir de hembras infectadas (Cortez et al. 2006, Ali Al Ahmad et al. 2007a).

\section{II.6.2.5. Transmisión iatrogénica}

Dawson et al. (Dawson 1987) utilizaron agujas contaminadas con sangre con VMV para la inoculación subcutánea de varios animales no infectados pero la tentativa no tuvo éxito. La transmisión durante el ordeño mecánico a través de pezoneras contaminadas podría ser una forma de contagio importante; se ha demostrado la posibilidad de infección de VAEC por instilación de células infectadas en el conducto galactóforo (Lerondelle et al. 1995) y otro estudio demostró que la desinfección de las máquinas tras el ordeño de animales infectados evita la transmisión a animales libres de la enfermedad (Adams et al. 1983). Aunque está por demostrar, el hombre podría contribuir a diseminar la infección a través de ropa y equipamiento contaminado con el virus (Greenwood et al. 1995).

\section{II.6.2.6. Transmisión experimental}

Se han realizado con éxito infecciones experimentales utilizando diferentes dosis y cepas de LVPR a través de diferentes vías, incluidas la intracerebral (Nathanson et al. 1976, Palsson et al. 1977, Sihvonen et al. 1980), la intraarticular(Oliver et al. 1981b), la intranasal, la intrapulmonar, la digestiva, la intravenosa y la intraconjuntival (Niesalla et al. 2008b). En el tracto respiratorio la infección es mas efectiva cuanto mas profunda se haga la inoculación, así la infección intratraqueal es mas efectiva que la intranasal, (Torsteinsdottir et al. 2003) y en el pulmón, es mas efectiva en los tejidos distales que en la traquea (McNeilly et al. 2007).Recientemente se ha determinado la dosis mínima infectante vía intravenosa en corderos de seis meses en $10^{0.6} \mathrm{TCID}_{50}$ apareciendo el primer seropositivo entre 3-19 semanas sin observarse relación con la dosis infectante (Herrmann-Hoesing et al. 2009).

\section{II.6.3. Factores que favorecen la infección por el VMV}

\section{II.6.3.1. Especie hospedadora}

Aunque algunos autores han defendido que la transmisión natural del VMV a cabras es poco eficiente (Smith et al. 1985) existen estudios en los que se denuncia el contagio de cabras con cepas de tipo VMV por contacto con ovinos en ferias ganaderas (Vogt et al. 1999). En el subtipo A4 de la 
clasificación de los LVPR realizada por Shah (2004) se engloban secuencias tanto de cabras como de ovejas que apoyan la transmisión natural entre ambas especies (Shah et al. 2004b).

Se ha descrito que en rebaños mixtos de cabras y ovejas los aislados de ambas especies pertenezcan a subtipos tipo CAEV como el B1 (Grego et al. 2007, Pisoni et al. 2007a) y el C (Gjerset et al. 2008). En España el primer aislamiento de VMV que se ha secuenciado completamente procede de un brote en ovejas con síntomas clínicos de artritis y presenta mas correlación con aislados tipo CAEV que con los de tipo VMV descritos anteriormente en España (Reina et al. 2006)así, se ha clasificado dentro del grupo B2 tipo CAEV (Glaria et al. 2009). En un estudio de seroprevalencia realizado en Cataluña la mayor proporción de rebaños positivos se observa en rebaños mixtos de ovejas y cabras (tasa: 2,95 ) frente a los rebaños únicamente de ovinos (Alba et al. 2008).

La posibilidad de transmisión entre especies debe tenerse en cuenta a la hora de realizar programas de control y erradicación de los LVPR; buena prueba de ello es lo ocurrido en el programa de erradicación de CAEV en ganado caprino en Suiza, en el que se demostraron nuevas infecciones en caprino de rebaños calificados como libres en contacto con ovejas infectadas que no habían sido analizadas por no formar parte del programa de control (Brulisauer et al. 2005).

\section{II.6.3.2. Raza}

Diferentes trabajos han estudiado el efecto raza en la susceptibilidad de infección (Gates et al. 1978, Light et al. 1979) éste último autor demuestra una mayor frecuencia y severidad de síntomas en ovejas Border Leicester que en las de raza Columbia, tanto en infecciones naturales como experimentales. En Islandia los cruces de Border Leicester con ovinos Islandeses presentaron mayor resistencia a la infección que las razas autóctonas (Palsson 1976)). Sin embargo, en un estudio de infección natural en un rebaño en cuatro razas ovinas incluidas la Rambouillet, la Targhee, la Columbia y la Polypay se observó una prevalencia similar en todas las razas a lo largo de los 10 años del estudio (Snowder et al. 1991). En Holanda, se observaron prevalencias del $37.9 \%$ y $5.6 \%$ en ovejas Finnish Landrace e lle de France, respectivamente, mantenidas en el mismo rebaño y los autores argumentaron la posibilidad de que las diferencias de prevalencia podrian estar relacionadas en mayor medida con factores de resistencia genética asociados a determinadas líneas familiares que a raza concretas (Houwers et al. 1989). En el País Vasco se observó mayor seroprevalencia de VMV en ovejas Latxa cara negra que en las Latxa cara rubia y los cruces con Rasa Aragonesa, Castellana y Manchega de aptitud cárnica (Gonzalez 1989a).

En un estudio reciente (Herrmann-Hoesing et al. 2008) en el que se midieron los niveles de provirus en ovejas de tres grupos de razas que se manejaron en las mismas condiciones se observaron menor 
concentración de provirus en la raza Rambouillet que en la Columbia y Polypay siendo esta diferencia mas acusada en edades avanzadas entre los 5 y 6 años.

\section{II.6.3.3. Edad}

Muchos estudios demuestran el incremento de la seropositividad a VMV con la edad, asociado a un mayor tiempo de exposición (Gates et al. 1978, Light et al. 1979, Snowder et al. 1991, Khaled Al-Qudah et al. 2006). Sin embargo, como se describe en esta tesis no existe necesariamente una relación positiva entre la incidencia de infección y la edad dependiendo del sistema de producción que modula la transmisión horizontal del virus, y de otros factores, sobre todo el estado de infección de la madre. La exposición prolongada a una elevada carga de virus en el medioambiente acelera la seroconversión y la aparición de lesiones incluso en corderos de un año de edad (Sihvonen 1980, Houwers et al. 1989, Benavides et al. 2006b)

Aunque el patrón de seroconversión asociado a la edad varía según los estudios varios autores describen un aumento progresivo de la seroprevalencia al VMV hasta los 3-4 años (Van der Molen et al. 1987, Keen et al. 1997b, Berriatua et al. 2003). Además, los animales mas viejos demuestran un mayor potencial transmisor y son la fuente principal de VMV para los jóvenes (De Boer et al. 1979, Stevenson et al. 1984). En este sentido,(Sihvonen 1980, Berriatua et al. 2003, Khaled Al-Qudah et al. 2006) observaron que la descendencia de seropositivos adultos seroconvierte en mayor grado que la de seropositivas jóvenes.

\section{II.6.3.4. Factores ambientales}

No hay muchos estudios que relacionen directamente las condiciones de manejo con la seroprevalencia en el rebaño. Algunos trabajos demuestran una correlación positiva entre el tamaño del rebaño y la seroprevalencia (Simmard et al. 1991) y se piensa que esto podría ser debido a que los rebaños mas grandes son más intensivos y tienen mayor intercambio de animales que podría favorecer la presencia de infección en el rebaño. Como ya se ha comentado anteriormente, otro factor de riesgo es la existencia en el rebaño de enfermedades concomitantes que favorecen la infección con VMV y la enfermedad que mas frecuentemente se describe como facilitadora de la infección por el VMV es la Adenomatosis Pulmonar Ovina (APO) que se caracteriza por un aumento de la producción y eliminación de secreciones pulmonares con un elevado número de macrófagos potencialmente infectados con el VMV (Snyder et al. 1983, Dawson et al. 1985, Rosadio et al. 1988, Dawson et al. 1990, Pritchard et al. 1990, Gonzalez et al. 1993, Woldemeskel et al. 2010).También se ha observado correlación positiva en la presencia de parásitos pulmonares y la seropositividad al Maedi (Giangaspero et al. 1993). En un trabajo reciente realizado en España en el que se estudiaron ovejas coinfectadas de 
Scrapie y Maedi-Visna se ha observado que las lesiones inducidas por VMV en mama, pulmón y folículos linfoides favorecen el depósito de PrPSc en estos órganos no considerados como diana en el Scrapie (Salazar et al. 2010).

\section{II.6.4. Importancia económica y control}

\section{II.6.4.1. Efectos en la producción}

Aparte de las perdidas producidas por las muertes, el sacrificio temprano de los animales y el aumento de la tasa de reposición, se han estudiado los efectos de la infección sobre otros parámetros de la producción con resultados discordantes como reflejan los estudios de variables reproductivas en ganado seronegativo y seropositivo realizados por distintos autores. De este modo (Gates et al. 1978, Huffman et al. 1981, Juste et al. 1987, Snowder et al. 1990) no hallaron diferencias en ninguno de los parámetros reproductivos estudiados mientras que (Dohoo et al. 1987, Keen et al. 1997a) demostraron que las ovejas seronegativas presentaron una tasa de fertilidad, número de corderos por parto y peso al nacimiento mayor que las ovejas seropositivas subclínicas. Por su parte, (Pekelder et al. 1991) observó una relación estadísticamente significativa entre las lesiones de madres seropositivas y la reducción del peso de sus crías a los 80 días de vida. Otro estudio realizado en Quebec concluyó que los corderos criados por ovejas seropositivas de cuatro o más años de edad tenían menor peso al destete que los de madres seronegativas y que la mortalidad perinatal era menor en este último grupo (Arsenault et al. 2003).

Legrottaglie et al. (1999) no pudieron demostrar diferencias en la composición y la producción lechera, el peso al nacimiento y el crecimiento de los corderos en ovejas lecheras de raza Sarda infectadas y no infectadas de un rebaño con $21 \%$ de seropositividad. Sin embargo, en un estudio de rebaños comerciales lecheros en Grecia se observó una disminución de la producción anual lechera del 3,2\% y de grasa del $2 \%$ asociada a las lesiones mamarias y a la pérdida de condición corporal en las ovejas infectadas por el VMV (Christodoulopoulos 2005). Por el contrario, otro estudio observó una mayor producción en las primeras lactaciones en las ovejas seropositivas que en las seronegativas sugiriendo una mayor sensibilidad a la infección por parte de las ovejas con mas potencial productivo (Ploumi et al. 2001). Recientemente en un estudio realizado en Israel en rebaños ovinos Assaf con prevalencias entre $25-75 \%$ no se observaron diferencias en la producción lechera entre animales seropositivos y seronegativos (Kenigswald et al. 2009). 


\section{II.6.4.2.. Tratamiento y control de la enfermedad}

Por el momento no existe ningún tratamiento terapéutico eficaz y se está trabajando en el desarrollo de vacunas pero aún no se ha obtenido ninguna que consiga prevenir la enfermedad. Por ello, el control se basa necesariamente en la aplicación de medidas de control zoosanitario que permitan erradicar o al menos reducir la infección en el rebaño.

\section{II.6.4.2.1. Tratamientos}

Entre los tratamientos probados que demuestran mayor eficacia anti-VMV destaca la utilización del Interferón-tau; esta sustancia, producida por las células del trofoblasto de la oveja, tiene actividad antiviral in-vitro y se ha observado que su empleo temprano en corderos infectados experimentalmente se asocia a una reducción de la viremia y previene el desarrollo de la enfermedad. (Juste et al. 1997, Juste et al. 2000)

\section{II.6.4.2.2.Vacunación}

Como ya se ha mencionado anteriormente no existen vacunas eficaces para el control de los LVPR si bien es un área en la que se ha trabajo extensamente. La dificultad de desarrollar una vacuna eficaz se debe en parte a la elevada variabilidad genética y antigénica de los LVPR y a que no se conocen bien los antígenos protectores, los mecanismos de inmunidad y las rutas de administración, vehículos de vacunación y adyuvantes ideales. Los primeros estudios vacunales se basaron en la utilización de vacunas inactivadas que demostraron una incapacidad para evitar el desarrollo de la enfermedad (Nathanson et al. 1981, Cutlip et al. 1985a, McGuire et al. 1986).

La mayoría de ensayos posteriores se han basado en el empleo de virus atenuados (Petursson et al. 2005), plásmidos recombinantes (Gonzalez et al. 2005) y proteínas/péptidos (Torsteinsdottir et al. 2007). Las vías de administración utilizadas incluyen la mucosa empleando una pistola de genes vía vaginal (Gonzalez et al. 2005) y la intramuscular e intradérmica (Torsteinsdottir et al. 2007). En modelos en ratón de laboratorio la vacuna genética con secuencias gag induce títulos elevados de anticuerpos específicos (Henriques et al. 2007).El estímulo de la producción de citoquinas del tipo IFN-y (Th1) e IL14 (Th2) podría ser determinante en la progresión de la enfermedad pero su utilización en las vacunas no parece conferir protección frente a LVPR (Cheevers et al. 2001, Cheevers et al. 2003). La ruta de inmunización y el gen vírico usado parece afectar a los resultados de la vacunación. En las vacunas de plásmidos la vía de administración es importante y se ha observado que las vacunas con el gen env inoculadas a través de las mucosas disminuyen la cantidad de DNA proviral en sangre (Gonzalez et al. 2005, Reina et al. 2008a) y que las basadas en el gen gag disminuyen la aparición de lesiones 
tempranas (Reina et al. 2008a). Sin embargo, por vía intradérmica solo el gen gag confiere protección parcial a la infección (Niesalla et al. 2008a).

En los últimos estudios realizados con vacunas de DNA se ha conseguido protección frente al desarrollo de lesiones tempranas y disminución de la cantidad de virus (De Andres et al. 2009). Se ha estudiado el efecto de las moléculas B7 (CD 80 y CD86) en la inmunización con genes gag y env observándose un incremento de la respuesta celular temprana (linfocitos $T$ citotóxicos) y una reducción en el porcentaje de provirus en sangre y otros tejidos, aunque los autores reconocen la necesidad de seguir investigando en esta línea para conseguir inmunidad a más largo plazo (Reina et al. 2008a, De Andres et al. 2009).

\section{II.6.4.2.3. Métodos de control.}

Ante la carencia de tratamientos y de vacunas eficaces frente a la infección, las estrategias de control que se han aplicado para controlar la infección por VMV son de naturaleza zoosanitaria, esto es orientadas a evitar el contagio de los animales no infectados mediante la eliminación de los infectados y la reposición exclusiva con animales sanos. Históricamente se han puesto en práctica estas pautas de control de forma simultánea o independientemente y con éxito variable. A continuación se describen las estrategias de control de las infecciones por LVPR descritas en la literatura y las ventajas y problemas asociados las mismas.

1) Reemplazo total del rebaño infectado por ganado libre de la infección

El método más drástico y efectivo de control de VMV y que se utilizó en la epidemia Islandesa consiste en sacrificar todos los animales de los rebaños infectados y reponerlos con animales libres de la enfermedad.Esta estrategia solo es posible a efectos prácticos cuando la prevalencia de rebaños infectados es relativamente baja y es posible obtener animales libres de infección de los rebaños no infectados. El uso de esta estrategia se ha descrito en países como Polonia, Suiza, Bélgica y Malta (Reina et al. 2008b).

2) Análisis serológicos periódicos y sacrificio de animales seropositivos

En Estados Unidos, Cutlip y sus colaboradores realizaron análisis serológicos semestrales mediante IDGA y, eliminando los animales seropositivos, consiguieron erradicar la enfermedad en 6-7 años (Cutlip et al. 1986a). Si además se elimina toda la progenie de los animales seropositivos, se consigue acelerar el proceso, pudiendo eliminar la enfermedad hasta en dos años (Houwers et al. 1984). Este abordaje es fácilmente aplicable en rebaños con seroprevalencia baja o media. 
3) Creación de un rebaño paralelo con animales no infectados

Cuando la prevalencia es alta y es difícil encontrar animales de reposición no infectados, otra alternativa es dividir el rebaño en dos grupos segregando los animales infectados de los que no lo están (Peretz et al. 1994, Peterhans et al. 2004) y abasteciendo de animales el rebaño libre de infección con corderas no infectadas separadas de la madre en el momento del nacimiento. La ventaja de esta estrategia en relación con las anteriores es que se reduce el riesgo de perder las líneas genéticas interesantes desde el punto de vista productivo; el inconveniente principal es que requiere mucho trabajo por parte del ganadero que debe gestionar dos rebaños separados durante tres o cuatro años hasta la desaparición del rebaño infectado.

4) Cría de los corderos con calostro artificial para reducir el contagio de la reposición

Para evitar que las corderas de reposición se infecten a través del calostro y la leche, se recomienda separarlos de sus madres nada mas nacer y administrarles calostro libre de virus que bien puede ser de vaca, de ovejas seronegativas 0 de ovejas seropositivas pero tratado a $56^{\circ} \mathrm{C}$ durante 1 hora para inactivar el VMV, seguido de leche libre de virus o reconstituida a partir de extracto seco ("leche en polvo"). Se ha descrito la efectividad de este método en la prevención de la infección en corderas y cabritas (Houwers et al. 1983, Rowe et al. 1991) pero también se ha demostrado que la tasa de infección de los corderos que toman calostro natural de la madre seropositiva es relativamente baja cercana al $16 \%$ comparada con hasta el $61 \%$ de seroconversión que presentaron los corderos que tomaron calostro hembras seropositivas a través de biberón. Sin embargo el encalostramiento artificial supone un gran esfuerzo para el ganadero y es importante insistir que puede servir de poco si no se complementa con la prevención de la transmisión horizontal. (Berriatua et al. 2003, Alvarez et al. 2005).

\section{5) Compra anual de animales libres}

Cuando las tasas de seroprevalencia son muy altas y no se puede reponer con animales seronegativos del propio rebaño se puede optar por la compra de animales libres de la enfermedad. El problema es que en determinadas regiones y sistemas productivos en España es difícil encontrar rebaños libres de la enfermedad pero esta opción puede servir para incentivar a los ganaderos a conseguir eliminar la enfermedad de su rebaño para luego poder vender animales a otros rebaños. Otro problema añadido es la facilidad con la que se podrán infectan los animales al entrar en un rebaño con alta prevalencia con lo que esta estrategia debe compaginarse con la cría separada de animales infectados y libres de infección. 
6) Reemplazo a partir de hijas de seronegativas o seropositivas jóvenes

En rebaños donde la incidencia de infección es inferior o similar a la tasa de desvieje y reposición, es posible reducir la prevalencia progresivamente centrando el desvieje en animales seropositivos. La eficacia de esta estrategia mejora realizando la reposición a partir de corderas hijas de madres seronegativas preferentemente mayores de 3 años de edad (Berriatua et al. 2003). En el caso que las prevalencias sean superiores se puede optar a reponer a partir de hijas de seropositivas jóvenes ya que se ha demostrado experimentalmente que la transmisión de las ovejas es menos efectiva y que la descendencia tiene menor probabilidad de infectarse en los estadios tempranos de la enfermedad que en estadios posteriores(Sihvonen 1980).

\section{7) Selección genética de animales resistentes}

Se ha propuesto la selección de razas o líneas familiares resistentes a la enfermedad (DeMartini et al. 1991) aunque se está trabajando en el teman aun no se conocen los marcadores genéticos de la resistencia al MV(Herrmann-Hoesing et al. 2008, Larruskain et al. 2010) pero el hecho de que, en los rebaños infectados, la descendencia de ovejas seronegativas adultas de más de cuatro años presente menor riesgo de seroconversión sugiere la existencia de un componente heredable de resistencia y susceptibilidad a la infección que podría ser útil de cara al control de la infección (Berriatua et al. 2003, Alvarez 2005).

\section{II.6.4.3. Programas de erradicación:}

Los programas de erradicación llevados a cabo en distintos países se han basado en la eliminación simultánea de todos los animales seropositivos del rebaño y de su progenie en algunos casos, y su reemplazo con animales seronegativos, procedentes de rebaños libres de la enfermedad por lo menos en los dos últimos años. Esta fue la estrategia empleada en Islandia para erradicar la enfermedad del país (Palsson 1976). Otros países llevaron a cabo programas de erradicación a nivel regional incluidos EEUU y Canadá (Schipper et al. 1985, Williams-Fulton et al. 1989, Menzies 2006), Irlanda (Guven 1985), Holanda (Houwers et al. 1987a), Finlandia (Sihvonen et al. 2000), Bélgica (Biront et al. 1985), Dinamarca (Hoff-Jorgensen 1985), Francia (Remond et al. 1985), Noruega(Krogsrud 1985), Suiza (Scheer-Czechowski et al. 2000) y Suecia(Valsson et al. 2001). Dada la sensibilidad limitada de las técnicas serológicas y en concreto la de IDGA, para ser efectivo, este abordaje requiere analizar el rebaño e identificar nuevos seropositivos cada 6-12 meses.

En España no existen programas nacionales de control aunque si existen ejemplos a nivel regional y de asociaciones ganaderas. Así, en Aragón desde el año 2002 se está llevando a cabo un programa de 
erradicación del VMV que se basa en el desvieje de animales seropositivos y su reposición a partir de hijas de madres seronegativas sin necesariamente aumentar la tasa de desvieje y reposición del rebaño (Biescas 2006). Cuando los rebaños alcanzan prevalencia inferior a 5\% alcanzan el estatus de "rebaños controlados" y se procede a sacrificar todos los animales seropositivos restantes en el rebaño de una sola vez. Cuando la prevalencia está por debajo del $1 \%$ se les otorga el estatus de "rebaños libres" y cuando mantienen la seroprevalencia en el $0 \%$ durante tres años consecutivos se les denomina "rebaños indemnes". El programa ha comenzado en los rebaños con prevalencia inferior al $50 \%$ con el objetivo de que una vez se conviertan en rebaños libres, sirvan de fuente de animales seronegativos para los rebaños con altas prevalencias (Biescas 2006).

\section{II.6.4.4. Legislación internacional relativa al comercio de animales y la infección por el VMV}

Para finalizar el apartado de control de las LVPR es importante señalar que el Código Sanitario para los animales terrestres de la OIE http://www.oie.int/esp/normes/mcode/es_chapitre_1.14.6.htm plantea una serie de exigencias respecto a la infección por LVPR aplicables al comercio internacional de ovinos y caprinos destinados a la reproducción y a los machos que ingresen en un centro de inseminación artificial. De este modo, el Código exige que dichos animales no presenten signos clínicos en el momento del embarque, que los animales mayores de un año sean negativos a la prueba diagnóstica de MV en los 30 días anteriores al embarque y que procedan de rebaños libres de la enfermedad durante los 3 últimos años. 
III. ESTUDIOS 



\section{ESTUDIO 1}

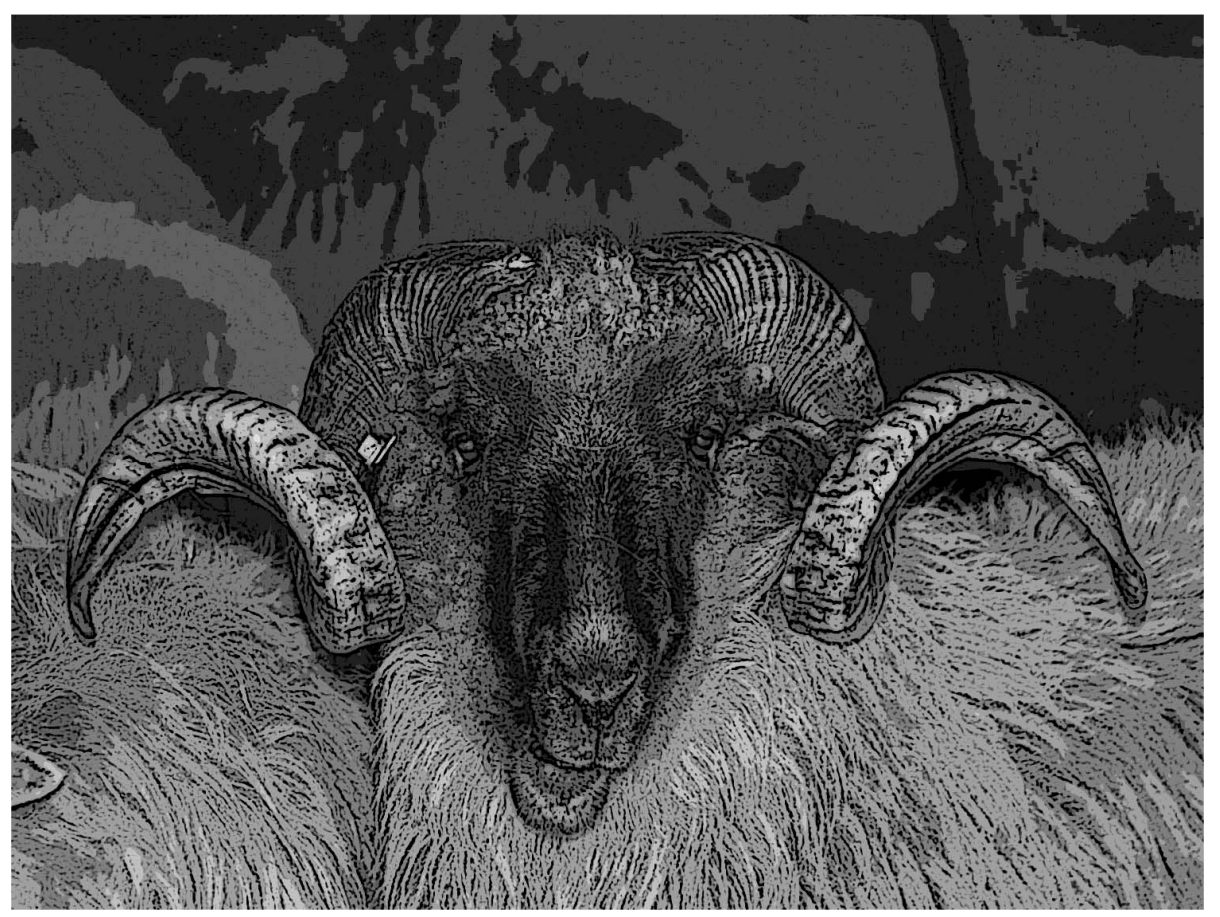

Horizontal Maedi-Visna virus (MVV) infection in adult dairy-sheep raised under varying MVV-infection pressures investigated by ELISA and PCR

I. Leginagoikoa 1; M. Daltabuit-Test 1, V.Alvarez 1, J. Arranz', R.A. Juste 1; B. Amorena 2; D. de Andrés 2; L.L. Luján 3; J.J. Badiola 3; E. Berriatua1.

${ }^{1}$ Instituto Vasco de Investigación y Desarrollo Agrario-NEIKER, Derio, Bizkaia, Spain.

${ }^{2}$ Instituto de Agrobiotecnología y Recursos Naturales, CESIC-UPNA, Pamplona, Spain

${ }^{3}$ Departamento de Patología Animal. Universidad de Zaragoza, Zaragoza, Spain.

Research in Veterinary Science 80 (2006) 235-24 



\section{Abstract}

A three year long experimental study was carried out to investigate horizontal MVV-infection by PCR and ELISA, in 191 one year-old latxa dairy-sheep raised in two separate groups under low and high MVVinfection pressure, respectively. Sheep originated from a previous MVV-transmission study in lambs and seroprevalence among one year-old sheep in both groups was 15\% approximately. The high infectionpressure group (H-group) consisted of 147 replacement ewes that joined a milk-producing, housed dairy flock with 42-66\% MVV-seroprevalence and the low infection-pressure group (L-group) were castrated males raised in a separate shed. In contrast to results obtained when infection was investigated in lambs, the overall degree of agreement between ELISA and PCR results was very good and there was some indication that it increased further as sheep became older. MVV-prevalence did not change in the L-group and increased to $57 \%$ in three year-old sheep in the H-group $(p<0.001)$. Random effects logistic regression confirmed seroconversion was significantly higher in the H-group compared to the L-group and was highest during the year after the sheep were introduced in the dairy flock and did not increase with age as in previous studies using less sensitive antibody assays. The evidence that horizontal transmission can be very low in spite of prolonged close contact between infected and non-infected sheep is valuable for MVV-control purposes. Furthermore it highlights the need to investigate virus excretion dynamics in infected animals and animal to animal transmission to improve our overall understanding of horizontal MVV transmission in MVV endemic populations.

\section{Introduction}

Maedi-Visna (MV) in sheep and Caprine Arthritis encephalitis (CAE) are conditions caused by small ruminant lentiviruses (SRLV) belonging to the retroviridae family. The virus infects monocytes and induces pneumonia, mastitis, arthritis and central nervous system (CNS) disease that most commonly are not clinically evident for several years after infection. Sheep may become infected at an early age from consuming colostrum and milk containing the virus and throughout their lives from horizontal contact with infected sheep that excrete virus in lung and other secretions (Radostits et al. 2000). A recent study showed that colostrum from seropositive ewes constitutes a major risk factor for MVV-infection when bottlefed, but the risk of infection is greatly reduced if lambs are allowed to naturally suckle the ewe and the reasons for this are not known (Alvarez et al. 2006).Horizontal infection can be very efficient if subclinically infected animals enter a susceptible population of sheep raised in close confinement as evidenced in the Icelandic MVV epidemic (Blacklaws et al. 2004). However, transmission and horizontal infection in particular may differ in flocks where MVV is endemic and according to sheep management practices, which can vary greatly between countries and regions. Understanding transmission however, is critical for disease control and adequate knowledge may allow developing specific control strategies for particular sheep 
production systems. A recent study of dairy sheep in Basque region in Spain, where sheep are raised semi-intensively and housed in the winter for two to six months a year, showed that the extent of horizontal infection was such that artificial rearing of lambs to prevent lactogenic infection did not reduce the lifetime risk of seroconversion (Berriatua et al. 2003). However, incidence of seroconversion under this rearing system was not high and the proportion of new infections over a period of time was lower than the proportion of sheep culled so it was possible to reduce flock seroprevalence without increasing average flock culling rates. The risk of seroconversion augmented with increasing degree of contact with seropositive sheep and for a given degree of contact, the risk of seroconversion increased with age until four years-old. The reason for the positive interaction between age and contact with seropositive ewes is not known. It could reflect a reduced ability of older sheep compared to younger sheep to control infection because cumulative and increasing production stress and exposure to the virus increased the host's susceptibility to infection. Alternatively, older sheep repeatedly exposed to MVV were more able to produce detectable antibodies by the agar-gel immunodiffusion test (AGIDT) used than younger sheep with shorter and less intense exposure to MVV. This technique is highly specific but lacks sensitivity compared to more recent recombinant ELISA antibody tests (Saman et al. 1999, Varea et al. 2001).

The lack of a relationship between seroconversion and exposure to lactogenic infection in the previous study prompted an experiment to investigate the relative importance of colostrum in MVV transmission using PCR tests and a highly sensitive antibody-ELISA, mentioned above (Alvarez et al. 2006). A further finding of this study was that among PCR-positive lambs, those that fed ovine colostrum were more frequently PCR positive than bovine colostrum fed lambs and at least 19\% of lambs had been PCR-positive at least once and not seroconverted when the experiment ended at 10 months-old. Moreover, the degree of agreement between PCR and ELISA results was poor during the first 6 months of life and substantial by 10 months. Differences between ELISA and PCR were argued to be related to the pathogenesis of MVV infection and the possibility that some sheep might have overcome low challenge infections demonstrable by PCR and not by ELISA.

When tested thereafter by ELISA at mostly 6 months intervals and by PCR every 12 months until up to four years-old. The H-group included 147 female sheep born in January 2000, 2001 and 2002, incorporated as replacement ewe-lambs to the parent infected experimental dairy sheep flock raised 


\section{Material and Methods}

\section{Study design and population}

The study, lasting for three years started in December 2000 and ended in November 2003 and included 191 sheep of which 176 had previously participated in an investigation of MV-infection associated to colostrum from seropositive ewes (Alvarez et al. 2006). When entering the study at one year-old, 162 sheep were ELISA-seronegative and 29 were seropositive. Among seronegatives, 124 sheep had tested PCR-negative when analysed six times between birth and 10 months-old and the remaining 38 seronegative sheep had tested PCR-positive at least and mostly (82\%) once when similarly tested. Sheep were allocated to two separate groups raised under low (group-L) and high (group-H) MVV-infection pressure (see below for group definition). Seroprevalence was around 15\% (see Section 3) in both groups at the start of the trial and sheep were tested thereafter by ELISA at mostly 6 months intervals and by PCR every 12 months until up to four years-old.

The H-group included 147 female sheep born in January 2000, 2001 and 2002, incorporated as replacement ewe-lambs to the parent infected experimental dairy sheep flock raised commercially for milk production, housed in a $35 \times 13 \times 4-\mathrm{m}^{3}$ building for approximately 6 months a year and raised at pasture the rest of the time. MVV-ELISA seroprevalence in the flock measured every December was $66 \%$ (157/237) in 2000, 42\% (123/291) in 2001 and 47\% (128/271) in 2002.

In contrast, the L-group was made of 44 castrated males born in January 2001 and was raised for the purpose of the experiment only, in a separate $20 \times 9 \times 4-m^{3}$ well-ventilated building from December 2001 until the end of the experiment. During this time no other sheep were raised in this shed except 62 newborn lambs that were introduced in January 2002 and remained until they were 10 months-old in separate pens (see Alvarez et al. 2005a for details of these lambs). At this time, seroprevalence in this later group of lambs was $8 \%(5 / 60)$ and two lambs were MVV-PCR-positive.

\section{Blood sampling and ELISA and PCR tests}

Sheep were blood-sampled with EDTA-containing vacuum tubes every six months except the first year when sheep were only sampled at the beginning and end of the year. Plasma recovered by centrifugation of the blood sample was used to test for anti-MVV antibodies using a recombinant commercially available ELISA (Innogenetics). Peripheral blood leukocytes (PBLs) were purified from the remaining blood in the samples by the ammonium-chloride method as described by Extramiana et al (2002). DNA from PBLs was then purified by the phenol-chloroform-isoamyl alcohol method and a PCR procedure for the long-terminal repeat sequences (LTR) of integrated MVV provirus, was carried out in samples taken at yearly intervals 
from the beginning of the study. The ELISA used in this study claims a sensitivity and specificity relative to combined western-blotting and the AGIDT of $99.4 \%(98.4,99.8)$ and $99.3 \%(98.7,99.6)$, respectively (Saman et al. 1999) and the LTR-PCR has an estimated sensitivity of $78 \%$ and a specificity of $100 \%$ in subclinically infected cases (Extramiana et al. 2002).

\section{Statistical analysis}

Percentage of ELISA and PCR-positive sheep were estimated and compared using Yates-corrected chi squared test in Epi-Info 6.04 (CDC, Atlanta). The relationship between ELISA and PCR results was investigated and the degree of agreement was estimated using the kappa statistic (Dohoo et al. 2003a). Seroconversion in sheep of two years-old and older was investigated and a random effects logistic regression using the GLIMMIX macro in SAS (SAS Institute) was employed to study the relationship between seroconversion and age, dams serological status at birth, mode of rearing during the first $24 \mathrm{~h}$ of life and having had a PCR-positive result during the first 10 months of life, adjusting for year and taking into account the lack of independence between sheep fathered by the same ram. In the models, seroconversion was the dependent binary variable (positive or negative). Independent fixed variables considered included year (three categories: 1, 2 and 3) and three lamb-level variables. Lambs-level variables were: (i) a variable combining age (years) and exposure group $(\mathrm{H}$ or $\mathrm{L})$, with four categories (2.0$\mathrm{H}, 2.5-\mathrm{H},>2.5-\mathrm{H}$ and $>1-\mathrm{L}$ ), (ii) a binary variable indicating if the lamb had or had not been PCR-positive when tested six times from birth to 300 days-old (see Alvarez et al., 2005b) and (iii) a variable with five different combinations of maternal ELISA-MVV status at birth (seropositive or seronegative) and mode of rearing during the first $24 \mathrm{~h}$ of life(see Alvarez et al., 2005a ). In addition to fixed variables, models also incorporated sire as a random variable. A backward-elimination strategy was used to eliminate fixed variables not significantly associated with the outcome or whose removal did not change the regression coefficients of "age-experimental group" by $>5 \%$ (Kleinbaum et al. 1998). The restricted maximumlikelihood estimation method was used and p-values estimated from likelihood-ratio chi-squared test, were considered significant at $5 \%(p<0.05)$ for a twotailed test. Odds ratios of variables associated with seroconversion were calculated by exponentiating estimated regression coefficients.

\section{Results}

Percentage of ELISA-and PCR-positive sheep

The percentage of ELISA-and PCR-positive sheep in H-and L-groups are shown in Figure III.1.1. ELISA prevalence in the H-group increased significantly from $16 \%$ in one year-old sheep to $57 \%$ in three year-old sheep $(p<0.05)$ and did not change significantly after that $(p>0.05)$. Instead, ELISA-prevalence in the L- 
group ranged between 14\% among one year-old sheep and 18\% among 1.5- 2 years-old sheep and was significantly lower than in the H-group for all age groups except for one year-old sheep $(p<0.05)$. The percentage of PCR-positives was similar to the percentage of ELISA-positives within groups. Percentage PCR-positives in the H-group increased from $11 \%$ in one year-old sheep to $49 \%$ in two years-old sheep and was similar after whilst in the L-group it did not change significantly with age and ranged between $18 \%$ in one year-old sheep and $14 \%$ in two years-old sheep (Fig.III.1.1).

Similarly, the proportion of PCR-positives was significantly lower in the L-group compared to the H-group except in one year-old sheep $(p<0.05)$.

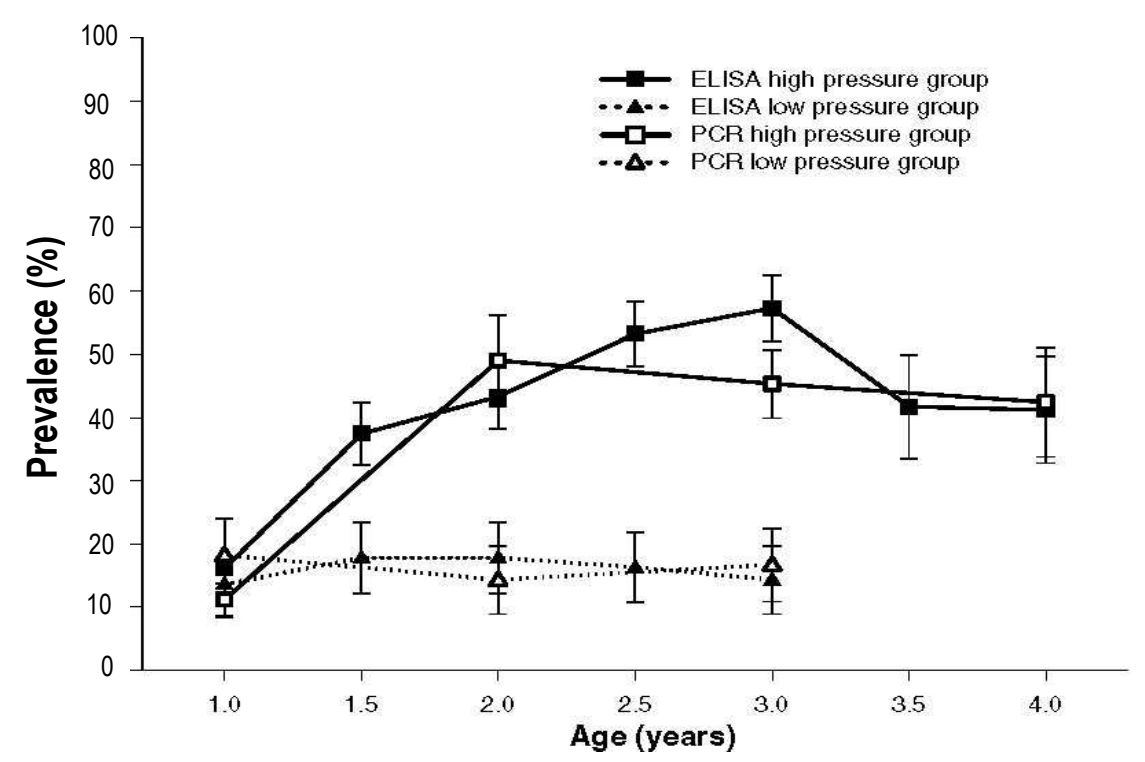

Figure III.1.1. Age-specific percentage of MVV ELISA and LTR-PCR-positive sheep in two groups of sheep raised under low and high MV-infection pressure. Data from 191 experimental latxa dairy sheep from Spain.

Age-specific percentage seroconversion and relationship between seroconversion and exposure group, maternal ELISA MVV-status at birth, mode of rearing during the first $24 \mathrm{~h}$ of life and being PCR-positive in the first 10 months of life in H-group sheep

Age-specific cumulative incidence of ELISA-positive sheep (percentage of seroconverted among susceptible sheep) in the $\mathrm{H}$-group rose to $27 \%$ six months after the lambs entered the experiment and gradually decreased thereafter to $0 \%$ at four years of age. In contrast only one sheep in the L-group seroconverted between 1 and 1.5 years-old. Bivariate analysis indicated that seroconversion was not related to experimental year, maternal ELISA-status at birth, mode of rearing during the first $24 \mathrm{~h}$ of life and having had at least one PCR-positive test during the first 10 months of life ( $p>0.05)$. The random effect logistic regression model contained all fixed explanatory variables and the random variable for sire and seroconversion was significantly associated with experimental group and age in the H-group, marginally 
associated to year and there was some evidence of variation between sires (Table III.1.1). Seroconversion was not associated to maternal MVV-serological status at birth, mode of rearing during the first $24 \mathrm{~h}$ of life and having been PCR-positive at least and mostly once during the first 10 months of life. Age-specific odds ratios for sheep in the H-group using sheep in the L-group as the baseline for comparison, were highest for two years-old sheep and decreased with increasing age in this group $(p<0.05)$ (Table III.1.1).

Table III.1.1. Estimates from the random effects logistic regression model of MVV seroconversion in groups of sheep exposed to high and low infection pressure ( $n=327$ from 149 experimental latxa dairy sheep from Spain)

\begin{tabular}{|c|c|c|c|}
\hline Variable & $\mathrm{OR}$ & $95 \% \mathrm{Cl}$ & $p$-value \\
\hline Fxed effects & 1 & & \\
\hline \multicolumn{4}{|c|}{ Exposure group: age (years) } \\
\hline La: $1.5-3$ & 1 & - & - \\
\hline$H^{a}: 2$ & 84.56 & $12.73 ; 571.7$ & $<0.0001$ \\
\hline$H: 2.5$ & 41.34 & $5.77 ; 296.46$ & 0.0003 \\
\hline$H: 3-4$ & 14.28 & $1.79 ; 113.97$ & 0.0126 \\
\hline \multicolumn{4}{|c|}{ Experimental year } \\
\hline 1 & 1 & & \\
\hline 2 & 2.89 & $0.93 ; 8.97$ & 0.067 \\
\hline 3 & 1.90 & $0.51 ; 7.05$ & 0.34 \\
\hline \multicolumn{4}{|c|}{ Random effects: variance estimate and standard error } \\
\hline Between-sires & 0.58 & 0.44 & 0.0961 \\
\hline Residual & 0.81 & 0.07 & $<0.0001$ \\
\hline
\end{tabular}

a Low and high MVV-exposure groups

\section{Relationship between ELISA and PCR results}

By the end of their experimental lives, 109 sheep had never been ELISA- or PCR-positive, 78 were ELISApositive and PCR-positive at least once, 3 were ELISA-negative and PCR-positive once and 1 was ELISApositive and never PCR-positive. Hence, the percentage of agreement of cumulative ELISA and PCR results was $98 \%$ and the overall degree of agreement $k=95.7( \pm 0.07)$, considered almost perfect (Dohoo et al. 2003a). However, the percentage and degree of agreement between the ELISA and the PCR varied according to the age of the lambs (Fig.II.1.2). Percentage agreement was $>88 \%$ throughout and the degree of agreement increased with age from $k=0.63$ (substantial) in one year-old to $k=0.94$ (almost perfect) among four years-old. 


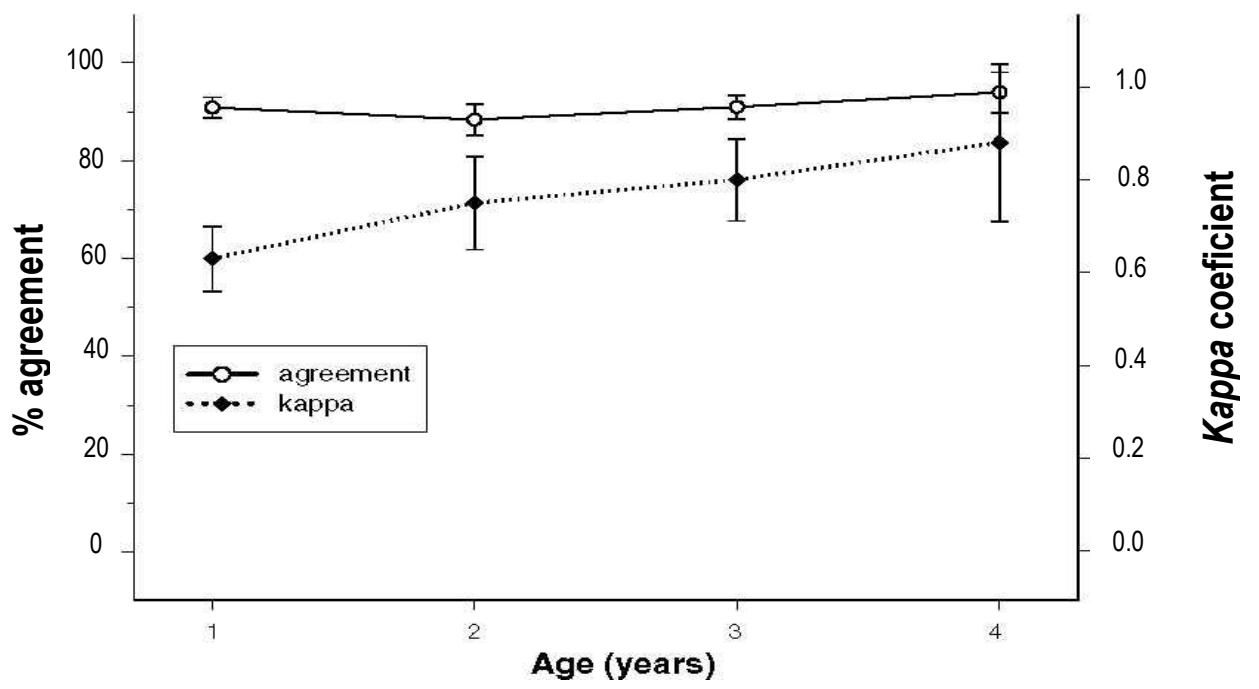

Figure III.1.2. Age-specific percentage of coinciding ELISA and LTR-PCR results and degree of agreement and kappa coefficient between both techniques in two groups of lambs exposed to high and low MVV-infection pressure, respectively. Data from 191 experimental latxa dairy sheep from Spain

\section{Discussion}

It is considered that horizontal MVV transmission is important in most sheep production systems (Radostits et al. 2000), particularly in those in which sheep are housed for long periods (Houwers 1990). In spite of a 14-18\% MVV-prevalence at the start of the trial, horizontal infection in the group of 44 castrated male sheep housed together for up to two years, was almost non-existing. In contrast, horizontal transmission was relatively efficient in the H-group following introduction to the dairy housed flock and similar to that observed in dairy goat herds (Adams et al. 1983, Robinson et al. 1986) and in a previous epidemiological study in latxa flocks (Berriatua et al. 2003). However, in contrast to the previous study, the risk of MVVinfection was highest in the months immediately after sheep were exposed to MVV and did not increase with age until four years. This finding is biologically and epidemiologically plausible and the most likely explanation for the difference between studies is that the ELISA and PCR techniques used in the present experiment allowed detecting infection earlier than the AGIDT used previously. The comparatively small amount of data in this study did not allow a precise investigation of the independent contribution to infection of age and degree of horizontal contact with infected sheep. However, the risk of seroconversion in the $\mathrm{H}$ group was marginally higher in year 1 than in year 2 when seroprevalence in the dairy flock at the start of the year was $65 \%$ and $41 \%$, respectively, but similar to year 3 when seroprevalence was $47 \%$. Seroprevalence at the start of an MVV-exposure period is not as good predictor of seroconversion as the average seroprevalence during the exposure period which takes into account sheep entering and leaving 
the experiment between testing times (Berriatua et al. 2003). Still, the number of sheep in the L-group did not change and in spite of an initial seroprevalence of $14 \%$ only one sheep seroconverted after two years. Clearly, variables other than flock seroprevalence influence seroconversion. Groups $\mathrm{H}$ and $\mathrm{L}$ differed with respect to the age of infected sheep, they were exposed to production stress and other managementrelated factors. In contrast to sheep in the L-group, those in the H-group were exposed to older infected ewes and lambs born to sheep that have been infected for a long time have greater risk of infection than lambs born to sheep infected for less time (Sihvonen 1980, Radostits et al. 2000). Sheep that have been infected for longer may have a larger viral load and excrete more virus than similarly but more recently infected sheep. It is possible that the amount of virus excreted by infected males was below the threshold for MVV-infection. The relationship between production stress and susceptibility to most infections is not well documented but, for example, high-yielding cows can be more prone to clinical mastitis than lowerproducing dairy cows (Slettbakk et al. 1995). Similarly, lactating dairy ewes could be more immunologically compromised and sensitive to MVV-infection than idle castrated males. Furthermore, sheep in the H-group were housed at a higher stocking density in an older and less ventilated shed compared to L-group sheep and their food was placed on a conveyer belt allowing sheep to have nose-to-nose contact instead of in the one-sided food troughs used to feed the males. It is very likely that differences in husbandry conditions favoured infection of sheep in the H-group. Finally, several studies have reported gender differences in MVV-seroprevalence yet, there are no apparent biological reasons to justify them and they most likely reflect differences in management of females and males in most flocks (Simard et al. 1991, Arsenault et al. 2003). The correlation between ELISA and LTR-PCR results in this study was overall very good and significantly better than during the first six months of life (Alvarez et al. 2006). Both techniques are highly specific (Saman et al. 1999, Varea et al. 2001, Extramiana et al. 2002) and differences in sensitivity could result from the techniques measuring different biological processes. LTR-PCR targets monocyte integrated provirus and ELISA detects circulating antibodies and these processes may not necessarily occur simultaneously. The increased degree of agreement between the assays as animals get older suggests cell-associated viremia increased with time. Viremic animals are likely to be more contagious than nonviremic animals, but as previously discussed, the clinical and epidemiological significance of viremia in lentivirus infections can be difficult to interpret (Alvarez et al. 2006). The risk of seroconversion after one year of age was independent of having had a PCR-positive result during the first 300 days of life. This could indicate that certain individuals under particular circumstances are able to eliminate infection. However, there is no evidence of self-cure following MVV and generally, retroviral infections. Alternatively, they could indicate these animals were infected but did not generate MVV-specific antibodies (Sihvonen 1980, Houwers et al. 1987b, Rimstad et al. 1993). Moreover, some results could have been wrongly interpreted as positive although the test is considered $100 \%$ specific. The accuracy of the results of the 
previous studies (Alvarez et al. 2005, Alvarez et al. 2006) is further reinforced in the present study by absence of a relationship between seroconversion and mode of rearing during the first $24 \mathrm{~h}$ of life.

The finding that several sheep raised with colostrum from seropositive ewes remained seronegative until introduced in the main dairy flock supports previous findings that in semi-intensively raised dairy sheep, horizontal MVV-transmission between adult sheep is relatively more important than transmission from seropositive dams to offspring (Berriatua et al. 2003). This could be because the amount of time sheep are exposed to horizontal infection is much longer than the time sheep are exposed to colostral infection and because colostrum may not necessarily contain sufficient virus to produce infection.

The results from this study have important applications in MVV-diagnostics and control. Recombinant ELISA tests like the one used in this study may suffice for routine diagnosis of MVV-infected adult sheep, given that its sensitivity is similar to that of the LTR-PCR test and that the PCR test is much more expensive than the ELISA (about 10 times more expensive in our laboratory). There are hardly any published comparative studies between MVV-PCR tests however, Alvarez et al. (2005b) showed the LTRPCR was significantly more sensitive than the PCR targeting pol sequences described by (Tolari et al. 2010).

In terms of MVV-control, little benefit in terms of preventing MVV-infection may be achieved by raising replacement lambs by artificially preweaning and segregating from the main flock during the first year of life if they are to be later introduced to a flock with medium or high prevalence of infection. It may however, be beneficial in terms of delaying onset of clinical disease to an age at which sheep have already passed peak productivity. Furthermore, the study shows that horizontal infection can remain very low if sheep are raised in a low MVV-prevalence flock. By extension, it is likely that horizontal transmission is also inefficient when contact between sheep is scarce. The latter coupled with possible low lactogenic transmission could partly explain why MVV-prevalence is low or null in extensively reared sheep flocks in Spain (personal investigations) and other countries such as Australia and New Zealand where infection has never been reported (Radostits et al. 2000).

\section{Acknowledgements}

This work was financially supported by grants RTA01-107-C3-3 from the Instituto Nacional de Investigaciones Agrarias (INIA), AGL2003-08977-c03-03 of the Ministerio de Ciencia y Tecnologia (MCYT), SED2003011 of the Departamento de Agricultura del Gobierno Vasco and QLK2-CT-2001-70356 from the EU5thFrameworkProgram. 



\section{ESTUDIO 2}

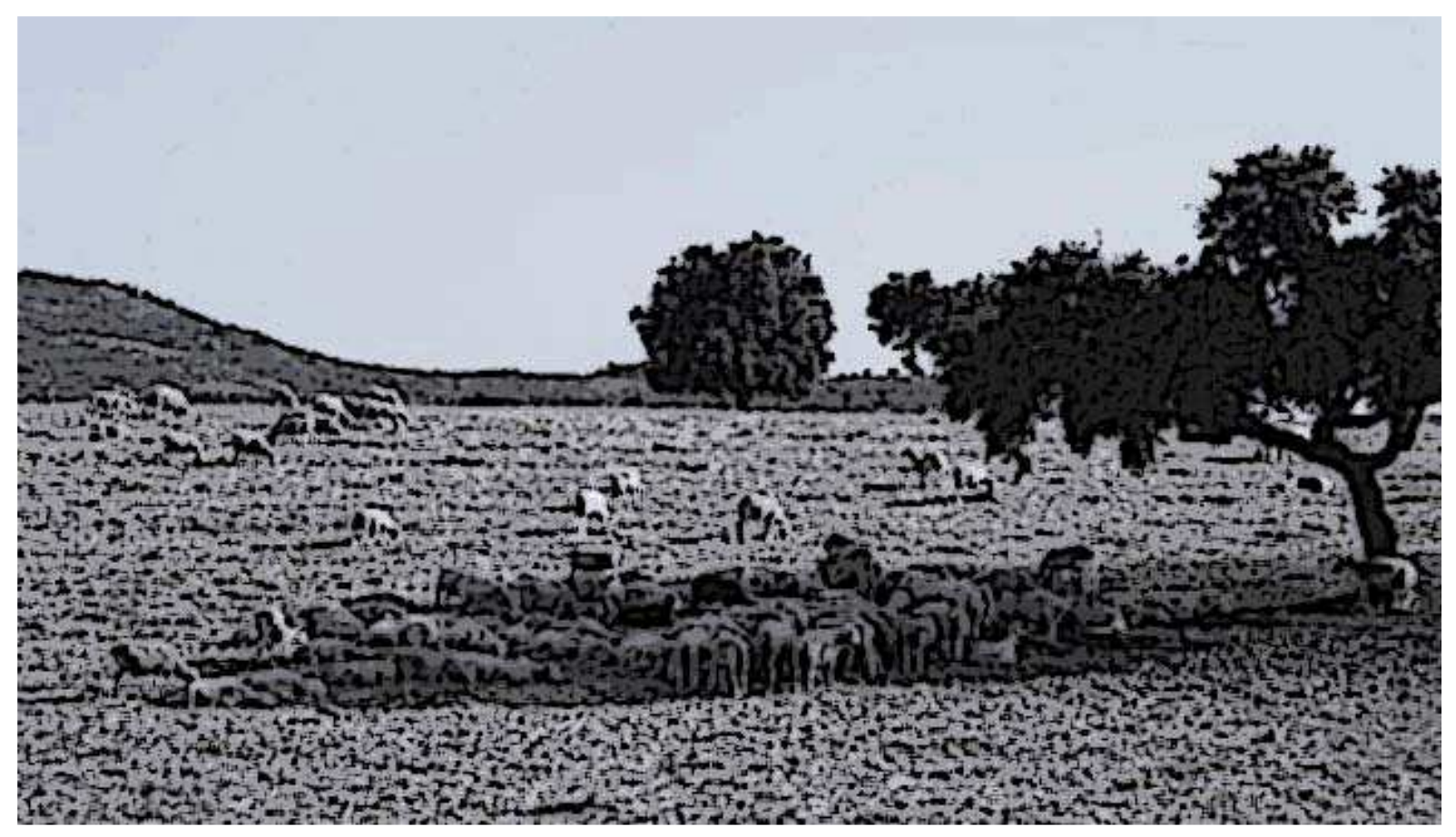

\section{Extensive rearing hinders Maedi - Visna Virus (MVV) infection in sheep}

I. Leginagoikoa1, R.A. Juste' ${ }^{1}$, J.Barandika1

B. Amorena², D. de Andrés², L.L. Luján³, J.J. Badiola³, E. Berriatua4.

\footnotetext{
${ }^{1}$ Instituto Vasco de Investigación y Desarrollo Agrario-NEIKER, Derio, Bizkaia, Spain.

2 Instituto de Agrobiotecnología y Recursos Naturales , CESIC-UPNA, Pamplona, Spain

${ }^{3}$ Departamento de Patología Animal. Universidad de Zaragoza, Zaragoza, Spain.

${ }^{4}$ Enfermedades Parasitarias, Facultad de Veterinaria. Universidad de Murcia, Murcia, Spain.
} 



\section{Abstract}

MVV seroprevalence and its relationship with housing and mode of rearing of replacement ewe-lambs was investigated in 38 non-randomly selected sheep-flocks in Spain. They included extensive lambproducing Manchega cross-bred flocks raised almost permanently at pasture, semi-intensive Latxa dairy flocks house 2-8 months/year and intensively raised Assaf dairy flocks housed most time and at higher stocking density in less ventilated buildings than other flocks. Most flocks raised replacement lambs naturally with their dams until weaning and as a separate flock thereafter until lambing at one year of age. Seroprevalence (95\% confidence intervals) was 77\%, 25\% and 5\% (4-6) in intensive, semiintensive and extensive flocks, respectively and the median (interquartile range) flock-seroprevalence was $82 \%(66-94)$ in intensive flocks, $31 \%(14-31)$ in semi-intensive flocks and $4 \%(0-7)$ in extensive flocks. Seroprevalence was the lowest in one year-old sheep and increased to flock levels during the year after introduction into the adult flock in most intensive flocks and more gradually in other flocks. Adult flock seroprevalence was associated with housing time but this relationship was not evident within a particular rearing system, indicating that other unknown factors are critical in horizontal MVV transmission. Low seroprevalence in extensive flocks further supports previous indications that lactogenic MVV infection is relatively inefficient and horizontal transmission is necessary to ensure longterm maintenance of MVV and this could explain that MVV has not been reported from countries with mainly extensively reared sheep such as Australia and New Zealand. Moreover, it indicates that MVV control in extensive and semi-intensive flocks can be simple and inexpensive.

\section{Introduction}

Maedi-Visna virus (MVV) and the closely related Caprine Arthritis Encephalitis virus (CAEV) are grouped as Small Ruminant Lentiviruses (SRLV) generative and fatal diseases of the lungs, central nervous system, mammary gland and joints that can result in very significant production losses and have major welfare implications. Viral tissue tropism depends on the infecting strain and on the host's genetics. Disease is often not apparent until two years or more after initial infection, which occurs from ingesting colostrum and milk from infected dams and from horizontal contact with lung secretions and excretions from infected sheep. There is evidence that transplacental infection may occur, however this route of infection is considered of limited epidemiological importance and there is now ample epidemiological and experimental evidence indicating that horizontal infection is the main form of SRLV infection in animals raised with some degree of confinement (Blacklaws et al. 2004). For example, in semi-intensively reared Latxa dairy sheep flocks housed for 2-6 months/year the efficiency of horizontal infection is such that lactogenic transmission does not significantly increase the risk of MVV 
seroconversion (Berriatua et al. 2003). Moreover, there is some recent evidence that SRLV infection is low or even absent in extensively reared sheep flocks and goat herds in Patagonia (Robles et al. 1999, 2003). The risk of lactogenic SRLV infection has only been partially quantified and the percentage of naturally raised lambs that become infected from suckling colostrum from seropositive dams has been estimated at approximately only $20 \%$ (Alvarez et al. 2005). If the risk of lactogenic infection during the preweaning period is below $1(100 \%)$ then it is evident that some other form of infection is necessary to achieve an $R_{e}$ (effective reproduction ratio: average number of secondary infections produced by one infected individual) value above one, necessary for infection to last in the population (Anderson et al. 1992). It is possible that in some extensive sheep production systems, sheep do not have sufficiently close contact for horizontal infection to occur, but this has not been investigated. Moreover, little is known of the type and extent of contact between infected and uninfected animals necessary for MVV infection to occur. Uninfected sheep introduced in an infected flock may quickly become infected, but in some cases uninfected sheep can be housed with other infected sheep for several years without becoming infected and the reasons for this are unknown (Leginagoikoa et al. 2006a).

The limited knowledge on the mechanisms of MVV transmission between sheep contrasts with the numerous seroprevalence studies of Maedi-Visna worldwide (Houwers 1990), indicating that MVV has been reported from most major sheep producing countries except Australia and New Zealand (Greenwood et al. 1995). Several studies have shown some evidence of breed associated susceptibility or resistance to MVV infection and disease (Cutlip et al. 1986b, Dawson 1987, Houwers et al. 1989, Snowder et al. 1990, Perk et al. 1996). However, very few have attempted to investigate the relationship between infection and sheep management and transmission and control implications. In a previous study by Berriatua et al. 2003, incidence of infection in semi-intensive Latxa dairy flocks was relatively low and in most flocks the number of sheep that seroconverted was lower than the number of sheep culled with flock culling percentages being 14-25\%. This offers the possibility of gradually reducing flock seroprevalence by selective culling without increasing the flock's culling percentage and this represents an alternative to the more drastic traditional MVV control methods based on flock testing and culling of all seropositive animals and their young progeny (or on developing a separate MVV-free flock) (Houwers 1990) and highlights the need for similar investigations in other sheep production systems. In order to investigate this, long-term longitudinal studies have been initiated in extensive and intensive sheep production systems in several regions in Spain. This article reports MVV-seroprevalence, its relationship with housing and mode of rearing preweaned replacement lambs and investigates MVV in control lamb-producing extensive flocks and intensive and semi-intensive dairy flocks from southern, central and northern Spain, respectively. 


\section{Material and Methods}

\section{Study design and population}

Thirty-eight flocks were investigated including 10 intensive Assaf dairy flocks in Castile-León, 5 semiintensive Latxa dairy flocks in the Basque Country and 23 extensive lamb-producing Manchega cross Merino or Talaverana flocks in Castile-La Mancha. Resources were not available to investigate more flocks. Moreover, it was initially predicted that approximately 30 flocks of 300 sheep with a similar number of flocks from each production system could be investigated. However, different numbers of flocks from each system were selected because average flock sizes varied between systems, there was no data on seroprevalence of MVV infection in the extensive Manchega cross-bred flocks and it was necessary to accommodate the study design to detect MVV in this system. Furthermore, given the good knowledge of the epidemiology of MVV infection in semi-intensive Latxa flocks available (Berriatua et al. 2003, Alvarez et al. 2005, Leginagoikoa et al. 2006a), it was decided to allocate more resources to investigating MVV in other sheep production systems.

The Basque Country is situated in the Atlantic northern region of Spain where the climate is mild and rain ensures green pastures throughout the year. In contrast, Castile represents the Spanish Central Plain situated at around $700 \mathrm{~m}$ above sea level, being dominated by a dry continental climate. CastileLeón is the northern part of the Plain and Castile-La Mancha is the southern part of the Plain. In 2004, there were 22.7 million sheep in Spain including 15\% dairy sheep. Castile-León had 4.3 million sheep and produced $60 \%$ of the sheep milk commercialised in Spain and Assaf dairy sheep were present in $86 \%$ of the dairy flocks in the region. Latxa sheep represent $90 \%$ of the 0.4 million ovines in the Basque Country. Manchega cross Talaverana and Merino sheep reared extensively for lamb production like in this study, represent a minority of the 3.2 million sheep in Castile-La Mancha. However, most of the 7.8 million sheep in the neighbouring regions of Extremadura and Andalucia, represented by the Merino breed reared for fine wool production in the past and for lamb production nowadays, are raised similarly and more extensively (Esteban-Muñoz et al. 1986, MAPA 2004).

Typical intensive Assaf dairy flocks in Castile-León are made of 200-1000 sheep, the animals are reared almost permanently indoors, their oestrous is not markedly seasonal and they are bred for three lambings in two years. They have a milking period of 7-9 months/year and the average milk production is $400 \mathrm{~kg}$ of milk per ewe (kme). In contrast, Latxa dairy sheep flocks are mostly < 500 sheep, they lamb once a year in the winter, have a five month milking period with an average milk production of $135 \mathrm{kme}$, and are mostly raised on pasture and housed mostly during lactation at night and in rainy weather. Manchega cross-bred sheep are managed in large size flocks sometimes including several thousand sheep, they are raised extensively in low yielding "dehesa" pastures, and they are not seasonally 
polyoestrus and cycle all year round. In all three systems, most lambs are weaned at 4-6 weeks of age and sold for slaughter or in Castile, also for fattening in feedlots. The exceptions are replacement lambs that remain with the dam for 2-3 months and that are thereafter kept as a separate flock until after their first lambing at 12-14 month-old, when they join the adult flock.

\section{Selection of flocks and animals}

The ten intensive Assaf dairy flocks were selected from a list of 30 flocks under the care of a veterinary practitioner concerned with the high incidence of clinical Maedi-Visna (MV) including animals with typical yet comparatively uncommon, Visna nervous forms (Benavides et al. 2006c). They were the only ones in the list registered with the local Milk-Board. Sheep were born and bred at home, uniquely identified and had dates of birth accurate to the month and year for three years prior to the start of this study. The five selected semi-intensive Latxa dairy flocks had participated in previous MVV serological and control studies continuously since the early 1990s, they had no reported MV clinical cases for almost a decade and the farmers were keen to continue testing for MVV infection. They were considered among the most professionalised and intensively raised flocks in the region and except one flock, none had incorporated outside sheep for several years preceding the study. Sheep were uniquely identified and had precise dates of birth. The 23 Manchega cross-bred flocks selected for the study were from clients of a veterinarian that had expressed interest in investigating MVV although he had never diagnosed a case of MVV infection. To maximise resources, selected flocks included all the flocks under his care with < 500 sheep. Sheep were born and bred at home, uniquely identified and dates of birth were accurate to the season and year. Not all sheep in these flocks were sampled and tested for MVV antibodies and the number of sheep selected in each flock was calculated to allow detecting at least one seropositive sheep with a 95\% probability, assuming a flock seroprevalence of at least 5\%(Thrusfield 1995).

\section{Flock husbandry and housing}

Every farm was visited to complete a flock management questionnaire by personally interviewing the farmer and to measure sheep housing facilities. Table III.2.I describes flocks origin, number, size, breed and production system, weaning age of replacement lambs and sheep's housing time and space.

Housing and management of replacement lambs was characteristic of the sheep production systems described above. They were naturally raised, except in the three Latxa flocks where lambs stayed with their dams until 24-h old and were then artificially raised with milk replacer until 6 weeks of age and one Assaf flock where lambs were raised artificially from birth with bottle-feeding of the dam's colostrum during the first day of life and milk replacer until 6 week-old. After being separated from their mothers, 
the replacement lambs in all flocks were raised as a separate flock until a few weeks before lambing at approximately 1 year of age. During this time, the lambs and adults used separate fields or field partitions and different buildings except one of the Latxa flocks that raised lambs artificially preweaning and two Assaf flocks that raised lambs with their dams preweaning, which used separate pens within the adult flock building when housing sheep.

The time sheep were indoors and the characteristics of the sheep buildings varied between and within systems and for adult and replacement sheep (Tab. III.2.1). Assaf adults were housed for longer periods, at somewhat greater stocking density and in more poorly ventilated buildings than adults in other systems. This was also the case for replacement lambs except that Latxa and Manchega cross-bred flocks housed lambs for longer than the adults, flooring space for lambs was slightly smaller in Latxa flocks compared to Assaf flocks and lamb sheds in Manchega cross-bred flocks were smaller than those for adults.

Table III.2.1 Flock origin, number, size, breed, production system, median weaning age of replacement lambs and housing time and space in an MVV seroprevalence study in sheep in Spain in 2003-04.

\begin{tabular}{|c|c|c|c|c|c|c|c|}
\hline \multirow{2}{*}{$\begin{array}{l}\text { Region, } \\
\text { Number of } \\
\text { flocks and } \\
\text { flock size }\end{array}$} & \multirow[t]{2}{*}{$\begin{array}{l}\text { Breed and } \\
\text { production } \\
\text { system }\end{array}$} & \multirow{2}{*}{$\begin{array}{c}\text { Median } \\
\text { (range) } \\
\text { weaning age } \\
\text { (days) }\end{array}$} & \multicolumn{5}{|c|}{$\begin{array}{c}\text { Flock median (range) housing time (days) and area }\left(\mathrm{m}^{2}\right) \text { and volume }\left(\mathrm{m}^{3}\right) \text { of } \\
\text { housing available for ewes and replacement lambs }\end{array}$} \\
\hline & & & $\begin{array}{l}\text { Adults } \\
\text { Lambs }\end{array}$ & $\begin{array}{l}\text { Housing } \\
\text { timec }\end{array}$ & $\begin{array}{c}\text { Floor } \\
\text { area/sheepc }\end{array}$ & $\begin{array}{c}\text { Shed } \\
\text { volume/sheep }\end{array}$ & $\begin{array}{l}\text { Shed open } \\
\text { area/sheep }\end{array}$ \\
\hline $\begin{array}{c}\text { Castile-León } \\
10\end{array}$ & $\begin{array}{c}\text { Assaf } \\
\text { Intensive dairy }\end{array}$ & $\begin{array}{c}42^{a} \\
(20-60)\end{array}$ & $\mathrm{A}$ & $\begin{array}{c}338 \\
(326-365)\end{array}$ & $\begin{array}{c}1.0 \\
(0.6-1.4)\end{array}$ & $\begin{array}{c}7.1 \\
(3.0-17)\end{array}$ & $\begin{array}{c}0.08 \\
(0.03-0.14)\end{array}$ \\
\hline $211-700$ & & & $L$ & $\begin{array}{c}365 \\
(290-365)\end{array}$ & $\begin{array}{c}1.1 \\
(0.6-2.2)\end{array}$ & $\begin{array}{c}5.8 \\
(2.6-50)\end{array}$ & $\begin{array}{c}0.26 \\
(0.02-0.75)\end{array}$ \\
\hline $\begin{array}{l}\text { Basque } \\
\text { Country }\end{array}$ & $\begin{array}{c}\text { Latxa } \\
\text { Semi-intensive }\end{array}$ & $\begin{array}{c}37^{\mathrm{a}} \\
(30-43)\end{array}$ & $A$ & $\begin{array}{c}171 \\
(83-242)\end{array}$ & $\begin{array}{c}1.1 \\
(0.6-2.0)\end{array}$ & $\begin{array}{c}10.3 \\
(3.3-17)\end{array}$ & $\begin{array}{c}0.14 \\
(0.05-0.32)\end{array}$ \\
\hline $\begin{array}{c}5 \\
272-283\end{array}$ & dairy & & $L$ & $\begin{array}{c}242 \\
(123-365)\end{array}$ & $\begin{array}{c}1.0 \\
(0.7-1.6)\end{array}$ & $\begin{array}{c}5.9 \\
(1.7-44)\end{array}$ & $\begin{array}{c}0.26 \\
(0.02-0.86)\end{array}$ \\
\hline $\begin{array}{l}\text { Castile-La } \\
\text { Mancha }\end{array}$ & $\begin{array}{c}\text { Cross-bred b } \\
\text { lamb }\end{array}$ & $\begin{array}{c}62 \\
(45-90)\end{array}$ & A & $\begin{array}{c}10 \\
(1-53)\end{array}$ & $\begin{array}{c}1.9 \\
(0.4-5.4)\end{array}$ & $\begin{array}{c}7.9 \\
(0.8-29)\end{array}$ & $\begin{array}{c}0.20 \\
(0.07-0.87)\end{array}$ \\
\hline $\begin{array}{c}23 \\
150-392\end{array}$ & production & & $L$ & $\begin{array}{c}49 \\
(2-153)\end{array}$ & $\begin{array}{c}1.5 \\
(0.3-4.7)\end{array}$ & $\begin{array}{c}5.1 \\
(0.6-22)\end{array}$ & $\begin{array}{c}0.23 \\
(0.04-1.98)\end{array}$ \\
\hline
\end{tabular}

a Excluding flocks that raised lambs artificially preweaning.

b Cross-bred Manchega- Merino and Manchega-Talaverana.

c Calculations exclude seven extensive flocks where sheep were not housed. 


\section{Sampling and MVV-antibody testing}

All sheep $\geq 1$ year-old in intensive and semi-intensive flocks and 50-65, $\geq 1$ year old sheep/flock in extensive flocks were blood sampled from the jugular vein with vacuum tubes with no anticoagulant. Sampling took place between November 2003 and April 2004 when replacement lambs were 12-14 months old and had not yet joined the adult flock. In the laboratory, serum was recovered and kept frozen at $-20^{\circ} \mathrm{C}$ until tested for MVV antibodies using an indirect commercial ELISA test (Elitest, Hyphen BIOMED, Neuville sur Oise, France). The assay has a sensitivity (se) and specificity (sp) and 95\% confidence intervals compared to the Agar Gel Imunodifussion Test (AGID) and western blotting of 99.4\% (98.4-99.8) and 99.3\% (98.7-99.6), respectively (Saman et al. 1999).

Single tests were carried out in serum samples from Castile-León and Basque Country and samples were deemed positive for ELISA optical densities (OD) above or equal to the cut-off point and negative otherwise. The cut-off point was calculated according to the manufacturer's instructions using the following formula:

Cut-off $=\left(\mathrm{ODP}_{450-595}-\mathrm{ODN}_{450-595}\right) / 4+\mathrm{ODN}_{450-595}$.

Where, OD 450-595: optical density at $450 \mathrm{~nm}$ using $595 \mathrm{~nm}$ as reference wave length, of the positive control $(\mathrm{P})$ and negative control $(\mathrm{N})$.

Moreover, to increase the precision of the estimated low seroprevalence in extensive Castile-La Mancha flocks, a major finding of this investigation, samples with $\mathrm{OD}$ values of 0.1 units below or above the cutoff value, more common in extensive than in intensive flocks (Tab. III.2.2), were tested once or twice again. The samples were tested once again only if the result of the second test was similarly above or below the cut-off point and accordingly, were classified as positive or negative. Instead, if the second test result was different from the first result a third assay was performed and the samples were considered positive if two of the three test results were above the cut-off OD values and inconclusive otherwise. Inconclusive results were not included in seroprevalence calculations. To standardise the results, relative $O D(R O D)$ were calculated by dividing the sample $O D$ by the $O D$ of the plate's positive control.

\section{Statistical analysis}

Epilnfo 2002 (CDC, Atlanta, USA) was used for all the statistical analysis, including sample size calculations, frequency distributions, chi-square tests with the Yate correction to compare proportions, non-parametric Kruskal-Wallis analysis to compare means and linear regression to investigate the relationship between ewe-flock seroprevalence and independent flock-average variables, including the 
number of days spent indoors per year and area of floor and open space and volume of housing per adult sheep available.

Table III.2.2. Age-specific distribution of antibody-ELISA ROD values in seropositive sheep from 38 extensively raised cross-bred lamb-producing flocks, semi-intensively raised latxa dairy flocks and intensively raised Assaf flocks in Spain.

\begin{tabular}{|c|c|c|c|c|c|c|c|c|c|c|c|c|c|}
\hline \multirow{3}{*}{ Breed and production system } & \multicolumn{13}{|c|}{ Age (years) } \\
\hline & \multirow{2}{*}{$\frac{\text { All }}{\text { Mean }}$} & \multicolumn{6}{|c|}{1} & \multicolumn{6}{|c|}{$>1$} \\
\hline & & Mean & Min. & $25 \%$ & $50 \%$ & $75 \%$ & Max. & Mean & Min. & $25 \%$ & $50 \%$ & $75 \%$ & Max \\
\hline Intensive Assaf dairy & 2.32 & 2.12 & 0.17 & 1.36 & 2.13 & 2.87 & 5.75 & 2.35 & 0.25 & 1.55 & 2.37 & 3.06 & 6.29 \\
\hline Semi-intensive Latxa dairy & 1.52 & 1.00 & 0.35 & 0.51 & 0.99 & 1.47 & 1.98 & 1.56 & 0.30 & 1.16 & 1.65 & 1.99 & 2.80 \\
\hline Extensive a lamb product. & 0.92 & $1.21 \mathrm{~b}$ & 1.21 & 1.21 & 1.21 & 1.21 & 1.21 & 0.92 & 0.23 & 0.35 & 0.60 & 1.46 & 2.23 \\
\hline Total & 2.21 & 2.06 & 0.17 & 1.25 & 1.98 & 2.82 & 5.75 & 2.22 & 0.23 & 1.45 & 2.18 & 2.96 & 6.29 \\
\hline
\end{tabular}

a Manchega-Merino and Manchega-Talaverana cross-bred ewes.

b One sheep only

All variables were incorporated in the models as continuous variables. The models were fitted using the least-square method. Partial F-tests were used to assess the significance of independent variables taken at the $5 \%(p<0.05)$ level for a double-sided test.

\section{Results}

\section{MVV-seroprevalence}

Seroprevalence was 77\% (3046/3974) in intensive Assaf dairy sheep, 25\% (391/1570) in semi-intensive Latxa dairy sheep and $5 \%(72 / 1360)$ in extensive Manchega cross-bred sheep $(p<0.001)$. Seroprevalence $(95 \% \mathrm{Cl})$ in males and females was, respectively, $75 \%$ and $77 \%$ in intensive flocks $(p>$ $0.05), 19 \%$ and $25 \%$ in semi-intensive flocks $(p>0.05)$ and $8 \%(3-14)$ and $5 \%(4-6)$ in extensive flocks $(p>0.05)$. However, seroprevalence varied between flocks within sheep production systems. Table III.2.3 presents the estimated seroprevalence in ewes and the distribution of ewe-flock seroprevalence in the three systems. Ewe seroprevalence was significantly higher in Assaf ewes than in the other ewes and in Latxa ewes compared to Manchega cross-bred ewes ( $p>0.05)$. Among the latter, 6 flocks had $0 \%$ seroprevalence and the highest flock seroprevalence was $21 \%$, found in one flock (Tab III.2.3). In contrast, seroprevalence in Assaf flocks was $44-96 \%$ and $>80 \%$ in half the flocks. Seroprevalence in Latxa flocks was intermediate between the other two breed groups and ranged between $5 \%$ and $47 \%$ (Tab III.2.3). 
Table III.2.3. Ewe and ewe-flock MVV-seroprevalence in 38 extensively raised cross-bred lamb-producing flocks, semi-intensively raised Latxa dairy flocks and intensively raised Assaf flocks in Spain.

\begin{tabular}{|c|c|c|c|c|c|c|c|c|}
\hline \multirow{4}{*}{$\begin{array}{l}\text { Sheep breed } \\
\text { and production system }\end{array}$} & \multicolumn{2}{|c|}{ Ewes } & \multicolumn{6}{|c|}{ Flocks } \\
\hline & \multirow{3}{*}{$\begin{array}{l}\text { No. } \\
\text { tested }\end{array}$} & \multirow{3}{*}{$\begin{array}{l}\% \text { sero- } \\
\text { positive }\end{array}$} & \multirow{3}{*}{$\begin{array}{l}\text { No. } \\
\text { tested }\end{array}$} & \multicolumn{5}{|c|}{$\%$ seropositives } \\
\hline & & & & \multirow[t]{2}{*}{ Min. } & \multicolumn{3}{|c|}{ Quartiles } & \multirow[t]{2}{*}{ Max. } \\
\hline & & & & & $25 \%$ & $50 \%$ & $75 \%$ & \\
\hline Intensive Assaf dairy & 3913 & 77 & 10 & 44 & 66 & 82 & 94 & 96 \\
\hline Semi-intensive Latxa dairy & 1479 & 25 & 5 & 5 & 14 & 31 & 31 & 47 \\
\hline Extensivea lamb production & 1262 & 5 & 23 & 0 & 0 & 4 & 7 & 21 \\
\hline
\end{tabular}

a Manchega cross Talaverana or Merino breeds.

Age-specific MVV-seroprevalence and relationship with mode of rearing of replacement sheep and adult flock seroprevalence.

Age-specific seroprevalence patterns in infected flocks differed between and within sheep production systems depending on the mode of rearing of replacement sheep during their first year of life and adult flock seroprevalence. This is graphically shown in Figure III.2.1 where AF, AS, NF and NS refer to the mode of rearing of replacement lambs during the first year of life (A: artificially with milk replacer, $\mathrm{N}$ : naturally with the preweaning dam and F: in the adult flock building and $\mathrm{S}$ : in a separate shed until 1 year-old). The rate of increase in seroprevalence with age was very slow in extensive flocks and one semi-intensive flock, moderate in the remaining semi-intensive flocks and one intensive flock and high in the other intensive flocks. In intensive Assaf flocks, seroprevalence among one-year-old sheep was the lowest $(20 \%)$ in the flock where lambs were raised artificially preweaning with ovine colostrum and milk replacer (AS) and 25-80\% elsewhere according to adult seroprevalence and apparently independent of post-weaning place of rearing (Fig. III.2.1). However, at 2 years of age, seroprevalence was $>60 \%$ in all flocks except one where seroprevalence was lower and only reached $60 \%$ among $\geq 4$ year-old sheep (Fig. III.2.1). The age-specific pattern in most semi-intensive Latxa flocks was close to that in the latter intensive Assaf flock except that in the Assaf flock seroprevalence was greater among one year-old sheep and increased more slowly thereafter compared to two Latxa flocks that raised lambs artificially preweaning (AS and AF) (Fig. III.2.1). Like in Assaf flocks, there was little evidence in Latxa flocks of an association between place of rearing post-weaning and seroprevalence at one year of age. 
Relationship between adult flock-seroprevalence and housing variables

The regression models confirmed the significant positive association between seroprevalence in the adult flock and the number of days sheep are housed per year $(p>0.001)$. However, these two variables were not associated within a particular sheep rearing system (results not shown).

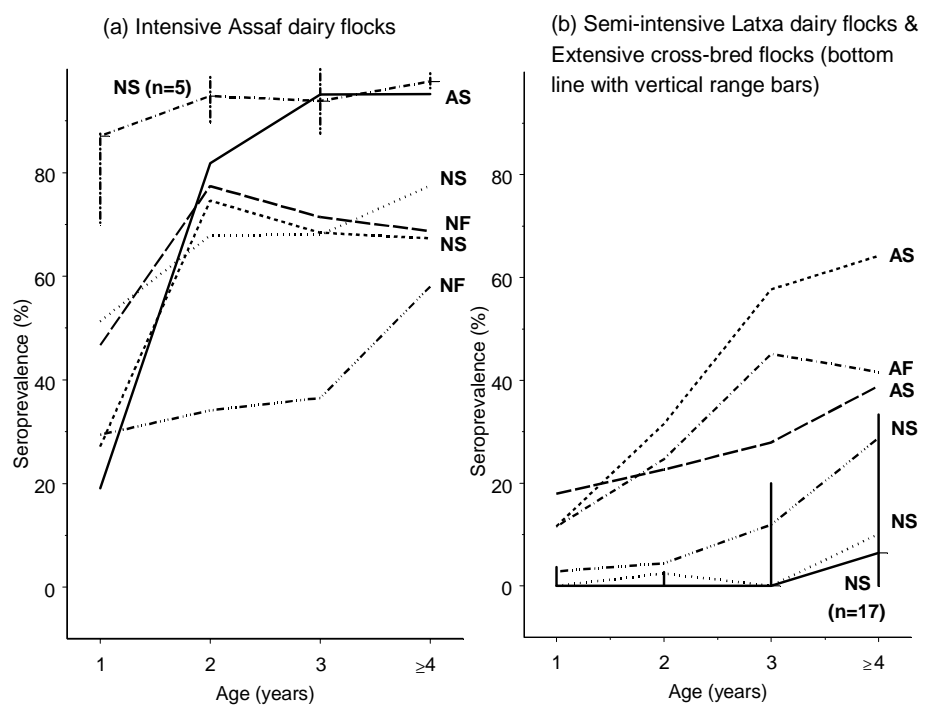

Figure III.2.1: Ewe and ewe-flock MVV-seroprevalence in 38 extensively raised cross-bred lamb-producing flocks, semi-intensively raised Latxa dairy flocks and intensively raised Assaf flocks in Spain.

1: Age-specific MVV-seroprevalence in (a) intensive and (b) semi-intensive and extensive sheep flocks in Spain, including median and range for intensive $(n=5)$ and infected extensive $(n=17)$ flocks with very similar ageseroprevalence patterns. Symbols refer to replacement sheep's mode of rearing pre-weaning; N: naturally with the dam; A: artificially with bovine colostrum and milk replacer separate from the dam and place of rearing postweaning until 1 year-old; $F$ : in the adult flock building; $S$ : in a separate shed with no other sheep.

Moreover, adult flock seroprevalence was not associated with open area, flooring area or volume of shed available per sheep in models containing or excluding housing time. Figure III.2.2.shows the observed unadjusted relationship between adult flock seroprevalence and housing time per year. The percentage of variation explained by the bivariate model was $86 \%\left(r^{2}=0.86\right)(p>0.001)$ and did not change after including any of the other independent variables relating to stocking density and open area per sheep available.

\section{ELISA-antibody optical densities}

Mean ELISA-antibody OD values for seropositive and seronegative ewes were 1.66 and 0.025 in intensive Assaf flocks, 1.36 and 0.024 in semi-intensive Latxa flocks and 0.54 and 0.024 in extensive Manchega cross-bred flocks ( $p>0.05)$, respectively. Moreover, one-year-old ewe lambs had lower OD 
values than adult ewes $(p>0.05)$. Table III.2.2 presents the age-specific distribution of ROD values in seropositive ewes in the different systems.

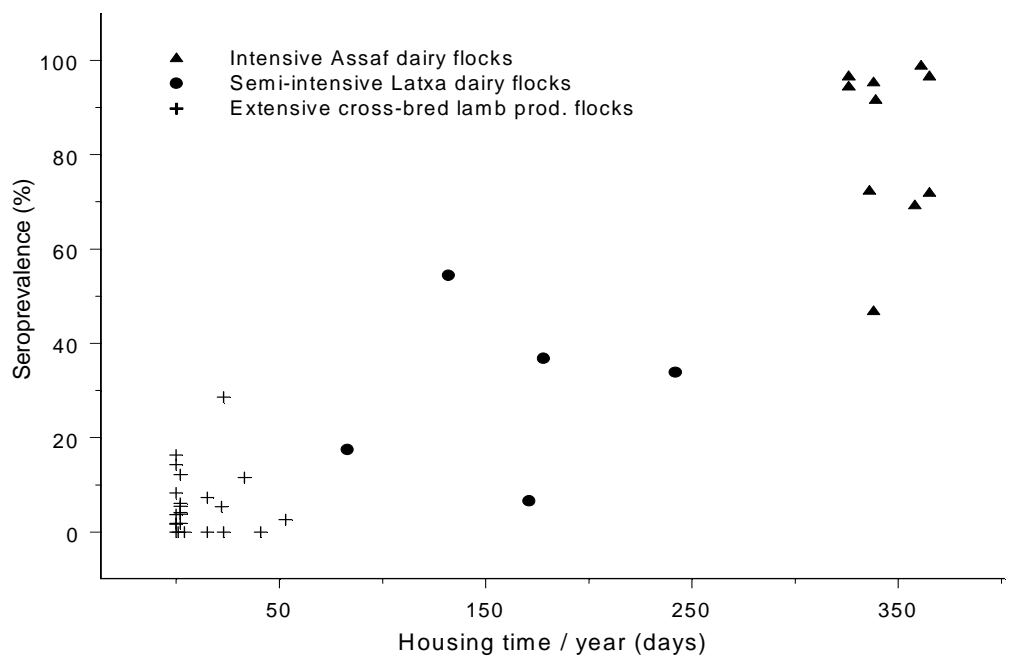

Figure III.2.2. Relationship between flock seroprevalence and housing time in Spanish extensively raised crossbred lamb-producing flocks, semi-intensively raised Latxa dairy flocks and intensively raised Assaf dairy flocks. $(n=38)$.

Over $50 \%$ of one-year-old and $25 \%$ of older seropositive ewes in Assaf flocks had ROD values above the maximum ROD values of seropositive Latxa ewes. In contrast, ROD was $<1$ in more than $50 \%$ seropositive Manchega cross-bred ewes (Tab.III.2.2).

\section{Discussion}

This is the first study comparing the MVV seroprevalence in intensive semi-intensive andextensive commercial sheep flocks in an MVV-endemic country and was carried out to provide some field evidence that horizontal transmission is the key route for MVV infection and that lactogenic transmission alone may be insufficient to insure MVV persistence in infected flocks, as suspected from previous experimental studies (Alvarez et al. 2005, Alvarez et al. 2006, Leginagoikoa et al. 2006a). The results obtained strongly suggest that in sheep production systems where sheep do not have close contact, MVV transmission is scarce and the opposite occurs when sheep are confined together most of the time. The latter is not a novel finding and has been amply reported (Blacklaws et al. 2004), but the former has not been generally recognised and suggests that lactogenic transmission is relatively inefficient. The $\mathrm{R}_{e}$ associated to lactogenic transmission could not be estimated since lambs raised with infected dams were exposed to both lactogenic and close direct horizontal infection except in one Assaf flock where lambs were raised under isolation with ovine colostrum and milk replacement. Interestingly, 
seroprevalence in one-year old sheep in this flock was $20 \%$, very similar to the experimentally estimated seroprevalence associated to naturally suckled colostrum from seropositive ewes (Alvarez et al. 2005). However, the existence of several extensive flocks with $0 \%$ seroprevalence is compatible with $R_{e}$ associated to colostrum and milk being below or close to one. Consequently, MVV control and eradication under such circumstances could be easy and inexpensive. The results in extensive flocks may help to explain the apparent absence of MVV in geographic areas such as Australasia, where most sheep are raised extensively. A further finding of this study was that antibody OD of seropositive sheep differed depending on flock seroprevalence and were greater in aged adults than in one year-old sheep. This could be related to greater virus challenge from possibly a larger variety of infectious strains to which hosts are exposed. Given the limited number of flocks investigated and the criteria used to select flocks it could be argued that the observed seroprevalence is biased and not representative of these sheep production systems and that MVV-transmission between sheep readily occurred and sheep did or did not become infected as a result of for example, genetic breed-associated susceptibility and resistance to MVV-infection. Given the limited number of flocks investigated and the criteria used to select flocks it could be argued that the observed seroprevalence is biased and not representative of these sheep production systems and that MVV-transmission between sheep readily occurred and sheep did or did not become infected as a result of for example, genetic breed-associated susceptibility and resistance to MVV-infection. Flock selection within intensive and extensive systems was not random and was limited to flocks under the care of two veterinary practitioners. As indicated before, the veterinarian responsible for the intensively raised flocks had expressed concern for MVV infection and the contrary was the case for the veterinarian looking after the extensive flocks and this could be a source of strong selection bias. However, similarly high SRLV-seroprevalence is typical for example in intensive dairy goat herds in California (Rowe et al. 1992) and in Icelandic sheep kept in close confinement in the winter (Palsson 1976) and similar low and null SRLV seroprevalence was reported in extensive flocks in Patagonia (Robles et al. 2003). Further bias might have been introduced by selecting the smaller flocks in the extensive system and those registered with the local milk-board among intensive flocks, but it is unlikely that either factor contributes greatly to explaining the enormous differences in MVV-seroprevalence in these two sheep production systems. Moreover, although certain alleles have been identified that confer goats and cows some degree of resistance to lentiviral infections (Ruff et al. 1993, Mirsky et al. 1998) and there are indications of inheritable susceptibility and resistance to MVV seroconversion in sheep (Berriatua et al. 2003) , there is no evidence or previous suggestions, that major differences in flock MVV-seroprevalence are attributable to genetic differences between sheep. Breed-associated differences in susceptibility to infection have been proposed. However, differences are not consistent and no reports exist of particular breeds that always remain free or 
virtually free of MVV infection after exposure to the virus. Resistance has also been linked to family lines within particular breeds, based on evidence that infection in flocks is often restricted to the progeny of infected ewes (Houwers 1990). From these arguments it is reasonable to conclude that it is very unlikely that the observed seroprevalence in extensive and intensive flocks was strongly confounded by selection bias and breed differences. In contrast, the observed seroprevalence in semi-intensively raised Latxa dairy flocks $(<30 \%)$ is unlikely to be typical of this sheep production system because selected flocks had all implemented some form of MVV control and can be considered low. Indeed, the estimated MVV-seroprevalence in the Basque Country was $55 \%$ in a large survey using the AGID test, which is less sensitive than the ELISA used here. The estimated seroprevalence in the Basque Country and the similarity in the age-specific seroprevalence patterns in some Assaf and Latxa flocks in the present study, suggest that the epidemiology of MVV-infection in these two production systems may not differ greatly. Moreover, seroprevalence differences between and within Assaf and Latxa flocks suggests that MVV-infection depends on additional factors, other than the degree of contact between infected and non-infected sheep. This is further supported by the finding that neither housing time nor any of the other housing variables investigated, explained differences in seroprevalence between intensive flocks. Other factors affecting MVV infection may include the sheep's genetic susceptibility, the virulence of MVV strains associated with a cytopathic effect (Lairmore et al. 1987), the presence of other diseases such as ovine Pulmonary Adenomatosis that increase the risk of MVV infection (Gonzalez et al. 1993) and other unrecorded management and production practices. Specifically, the animal to animal dynamics of SRLV horizontal infection is not well understood and little is known of certain husbandry aspects that affect the risk of MVV-infection. Although nose to nose contact between sheep is suspected to be a major risk factor for MVV infection, all the intensive flocks in this study used feeding troughs that allowed direct nose to nose contact between sheep. Furthermore, the lack of an association between seroprevalence in one year-old sheep and place of rearing (flock building or separate shed), suggests that indirect contact transmission of SRLV may not be very efficient. This has been investigated, with discrepancies. For example, no CAEV transmission between infected and noninfected does penned separately in the same building was found in a study (Adams et al. 1983), whereas in another, indirect CAEV-transmission between does in different pens in the same shed was reported and the risk of infection depended on the degree of separation between animals (Peretz et al. 1994). Finally, little is known concerning the effect of production pressure on MVV-infection, however it has been considered an important risk factor (Leginagoikoa et al. 2006a) and the relationship between milk production and MVV-incidence of seroconversion in these flocks warrants further investigation.

Control wise, the results of this study are optimistic for some intensive Assaf flocks with moderate seroprevalence similar to some semi-intensively Latxa flocks where it was shown that seroprevalence 
could be gradually reduced by selectively culling seropositives (Berriatua et al. 2003) but it is unlikely that selective culling alone would permit elimination of infection in intensive flocks with high MVVprevalence. Clearly more research is required to elucidate SRLV excretion from infected animals and contact transmission between animals and the ways to avoid it in order to better control this lentiviral infection.

\section{Acknowledgements}

This work was financially supported by grants AGL2003-08977-c03-03 of the Ministerio de Ciencia y Tecnología and SED2003011 and SED2005008 of the Departamento de Agricultura of the Basque Government. We are also indebted for this to study flock owners for allowing us to work on their farms and to veterinarians Javier Otaola Otxoa, José Angel Fuertes Miguélez and Pedro José Mora Fernández for their invaluable help in selecting and sampling their client flocks 



\section{ESTUDIO 3}

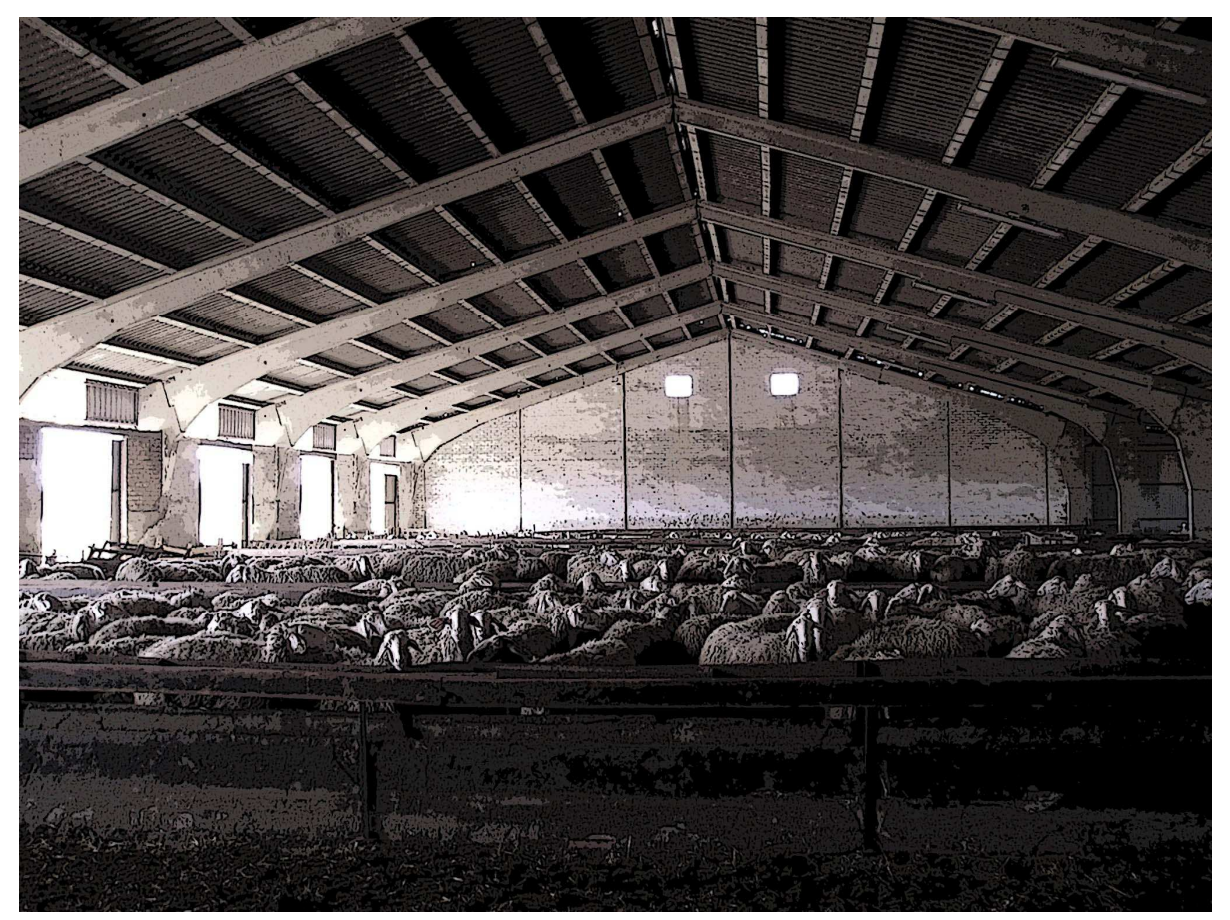

\section{Effects of housing on the incidence of visna/maedi virus infection in sheep flocks}

\footnotetext{
I. Leginagoikoa1 ${ }^{1}$ E. Minguijón' 1 , R.A. Juste' ${ }^{1}$, J.Barandika1

B. Amorena², D. de Andrés², J.J. Badiola³ ${ }^{3}$ L. Luján ${ }^{3}$, E. Berriatua ${ }^{4}$.

${ }^{1}$ Instituto Vasco de Investigación y Desarrollo Agrario-NEIKER, Derio, Bizkaia, Spain.

2 Instituto de Agrobiotecnología y Recursos Naturales, CESIC-UPNA, Pamplona, Spain

${ }^{3}$ Departamento de Patología Animal. Universidad de Zaragoza, Zaragoza, Spain.

${ }^{4}$ Enfermedades Parasitarias, Facultad de Veterinaria. Universidad de Murcia, Murcia, Spain.
}

Research in Veterinary Science 88 (2010) 415-421 



\section{Abstract}

The incidence of seroconversion to visna/maedi virus (VMV) infection and its relationship with management and sheep building structure was investigated in 15 dairy sheep flocks in Spain during 3-7 years. Incidence rate were 0.09 per sheep-year at risk in semi-intensive Latxa flocks and 0.44 per sheep-year at risk in intensive Assaf flocks and was greatest for the one year old Assaf replacement flock. Separate multivariable models developed for replacement and adult flocks indicated that in both cases seroconversion was strongly associated to direct contact exposure to infected sheep and to being born to a seropositive dam. The latter effect was independent of the mode of rearing preweaning and the risk of seroconversion was similar for sheep fed colostrum and milk from a seropositive or a seronegative dam. These results are further evidence of the efficiency of horizontal VMV transmission by close contact between sheep and also suggest a inheritable component of susceptibility and resistance to infection. In contrast, indirect aerogenous contact with seropositive sheep was not associated with seroconversion as evidenced in replacement sheep housed in separate pens in the same building as adult infected sheep for one year. Consequently, VMV may not be efficiently airborne over short distances and this is important for control of infection. Moreover, there was no relationship between seroconversion and shed open areas. The latter could be related to having examined few flocks in which high infection prevalence dominated the transmission process while ventilation, may depend on a variety of unrecorded factors whose relationship to infection needs to be further investigated.

\section{Introduction}

Visna/maedi virus (VMV) in sheep and caprine encephalitis virus (CAEV) are the small ruminant lentiviruses (SRLV) in the family Retroviridae. Infections with these viruses produce slow, progressive and fatal lymphoproliferative diseases in target organs such as lungs, mammary glands, brain and joints (Radostits et al. 2000), causing progressive wasting and economic losses, most commonly in sheep 2-3 years old and older (Houwers 1990, Keen et al. 1997a). Animals cannot be effectively vaccinated against SRLVs and VMV is prevalent in sheep populations worldwide with the notable exceptions of Australia and New Zealand (Brodie et al. 1998). Numerous studies have demonstrated that infection is widespread in Spain (Lujan et al. 1993, Berriatua et al. 2003, Benavides et al. 2006c) and is particularly relevant in indoor raised dairy sheep in the region of Castile-León where prevalence of infection is high and the otherwise 
rare clinical nervous disease (visna) may be diagnosed in lambs less than one year-old (Leginagoikoa et al. 2006b, Benavides et al. 2006c).

SRLVs are transmitted via colostrum and milk from mother to offspring and following contact with infected animals (Blacklaws et al. 2004). Understanding SRLV transmission dynamics is crucial in order to elaborate control strategies. Less than $30 \%$ of lambs naturally raised by infected dams may become infected with VMV during lactation (Alvarez et al. 2005, Alvarez et al. 2006) however, this percentage may change depending on horizontal exposure, which increases with the time spent with the dam, flock prevalence and housing time (De Boer et al. 1979, Berriatua et al. 2003, Leginagoikoa et al. 2006a). The mechanics of contact infection are poorly understood; nose to nose contact has been suggested to be a key behaviour facilitating VMV transmission and environmental or fomite exposure through common areas and equipment that involve oral or nasal contact such as feed and water troughs are likely to also play a major role in infection (Sigurdsson et al. 1953, Palsson 1976, Houwers 1990). As for other respiratory pathogens, transmission of VMV may also occur indirectly by airborne exposure. Sheep management and building characteristics that reduce close contact between sheep and increase ventilation should reduce VMV transmission, but this has received little scientific attention. Perez et al. 2009, recently showed that VMV seroprevalence in semi-intensive sheep flocks in Aragon housed at night, decreased with increasing shed open area (sides, ends and roof). In a previous smaller cross-sectional study in extensive and intensive sheep elsewhere in Spain, flock seroprevalence was strongly positively associated with the number of days spent indoors, which was highest in intensive dairy flocks, lowest in extensive flocks and intermediate in semi-intensive dairy flocks (Leginagoikoa et al. 2006b). However, the association between housing days and infection was not evident within a particular sheep rearing system; moreover, it was not possible to demonstrate a significant relationship between seroprevalence and a variety of sheep building characteristics including open shed area, flooring area or volume of shed available per sheep (Leginagoikoa et al. 2006b). Further VMV-antibody data from these sheep was later retrieved and this allowed a more in depth investigation of seroconversion and its relationship with management and structural characteristics of sheep buildings, using advanced multivariable statistical techniques. The present article presents the results obtained and discusses the potential role of management practices and housing design in the control of this major infection of indoor raised sheep. 


\section{Material and Methods}

\section{Study design and population}

The aim of the study was to describe the risk of VMV seroconversion and its relationship with flock husbandry and sheep building characteristics, in 15 dairy sheep flocks from Spain. They included 10 intensively raised and almost permanently housed Assaf flocks from Castile-León and five semi-intensive Latxa flocks housed for several months/year, mostly in winter, from the Basque region. Adult flock size was 211-700 sheep and 272-283 sheep in Assaf and Latxa flocks, respectively, and flock selection was based on available resources, flock size, flock owners and veterinary practitioners willing to participate in the study and previous epidemiological knowledge of VMV infection in these production systems, as previously described (Leginagoikoa et al. 2006b). All sheep in Latxa flocks were tested annually between 2000 and 2006, except sheep in one flock that were not tested in 2006 (Tab. III.3.1). In contrast, Assaf flocks were tested from 2004 to 2006 including all sheep the first year and only previously seronegative and all replacement ewes the following two years.

Table III.3.1. Annual VMV seroprevalence in Spanish Latxa and Assaf dairy sheep flocks in years $2000-2006$.

\begin{tabular}{lcccccc}
\hline Breed and production & Year & Sheep & & \multicolumn{3}{l}{ Flock } \\
\cline { 6 - 7 } system & & No. & $\%+$ +ve. & No. & \multicolumn{2}{c}{$\%+$ +ve. ranges } \\
\cline { 6 - 7 } & & & & & $\begin{array}{c}\text { 1 year old } \\
\text { replacements }\end{array}$ & $\geq 2$ yrs-old \\
\hline Latxa Semi-intensive & 2000 & 1369 & 39 & 5 & $3-46$ & $2-88$ \\
& 2001 & 1421 & 32 & 5 & $0-21$ & $4-82$ \\
& 2002 & 1431 & 28 & 5 & $0-15$ & $9-66$ \\
& 2003 & 1433 & 25 & 5 & $0-15$ & $8-53$ \\
& 2004 & 1570 & 24 & 5 & $0-15$ & $6-49$ \\
Assaf Intensive & 2005 & 1472 & 27 & 5 & $1-16$ & $9-53$ \\
& 2006 & 1141 & 25 & 4 & $0-25$ & $11-44$ \\
& 2004 & 3980 & 78 & 10 & $21-90$ & $46-99$ \\
& 2005 & 4860 & 80 & 10 & $12-96$ & $64-100$ \\
& 2006 & 5036 & 77 & 10 & $11-83$ & $58-100$ \\
\hline
\end{tabular}




\section{Management and housing characteristics of study flocks}

Every farm was visited on year 1 to interview the farmer to complete a flock management questionnaire and to measure sheep housing facilities and this information has been published (Leginagoikoa et al. 2006b). Briefly, during lactation replacement lambs in eleven flocks were naturally raised with their dams and lambs in the remaining four flocks were artificially reared with milk replacer from $24 \mathrm{~h}$-old. Moreover, lambs in the latter four flocks differed according to the way they were raised during the first $24 \mathrm{~h}$ of life and to the place where they were subsequently kept in until one year of age; lambs in three flocks spent their first $24 \mathrm{~h}$ of life with their dam naturally suckling colostrum and those in the other flock were separated from their dams at birth and received its colostrum by bottle, and after $24 \mathrm{~h}$ old, lambs in three flocks were taken to a separate building with no adult sheep and those in the remaining flock stayed in the same building (in separate pens) as their dams and rest of the adult sheep.

The median number of days-old at which lactation ended was 42 in intensive flocks and 37 days in semi-intensive flocks. Following weaning and until joining the adult flock at one year-old, replacement sheep were kept as a separate flock using different pastures and sheds to the adults except in three flocks where replacements and adults were raised in separate pens in the same shed, sharing airspace. Median (range) housing time in days for replacement and adult sheep, respectively, were $242(123-365)$ and 171(83-242) in Latxa flocks and 365 (290-365) and 338(326-365) in Assaf flocks. Similarly, stocking density (sheep/shed area in $\mathrm{m}^{2}$ ) for adult and replacement sheep were $1.1(0.6-2.0)$ for adults and $1.0(0.7-1.6)$ for replacements in Latxa flocks and $1.0(0.6-1.4)$ for adults and $1.1(0.6-2.2)$ for replacements in Assaf flocks. Details of shed volume/sheep and shed open areas per sheep used for ventilation can be obtained from Table III.3.2. All sheep sheds had natural horizontal ventilation with sides and ends open to a variable extent and the shed for the adult sheep in one flock also had a ridge opening on the roof.

\section{Blood sampling and VMV-antibody testing}

Sheep $\geq 1$ year-old were blood-sampled from the jugular vein with vacuum tubes with no anticoagulant and these were sent refrigerated to the laboratory and kept frozen at $20^{\circ} \mathrm{C}$ until tested for VMV antibodies, using an indirect commercial ELISA test (Elitest, Hyphen Biomed) following manufacturer's instructions. Optical densities were measured in an ELISA reader (Multiskan EX3, Labsystems) at $450 \mathrm{~nm}$ using $595 \mathrm{~nm}$ as reference wavelength and the results 
were interpreted as indicated by the manufacturer. The assay has sensitivity (se) and specificity (sp) and 95\% confidence intervals compared to the AGIDT and western-blotting of $99.4 \%$ (98.499.8) and 99.3\% (98.7-99.6), respectively (Saman et al. 1999).

Table III.3.2. VMV seroconversion incidence rates $(x 100)$ in one year old replacement Latxa and Assaf sheep according to the mode of rearing, housing time, stocking density and shed structural variables.

\begin{tabular}{|c|c|c|c|c|}
\hline & Semi-intensive & & Intensive Ass & \\
\hline & $\begin{array}{l}\text { No. of } \\
\text { sheep-years } 1\end{array}$ & $\begin{array}{l}\text { Incidence } \\
\text { rate }^{2}\end{array}$ & $\begin{array}{l}\text { No. of } \\
\text { sheep-years } 1\end{array}$ & $\begin{array}{l}\text { Incidence } \\
\text { rate }^{2}\end{array}$ \\
\hline Mode of rearing preweaning; & & & & \\
\hline With seronegative dam (-ve.) & 618 & 2 & 206 & 23 \\
\hline With seropositive dam (+ve.) & 278 & 5 & 281 & 37 \\
\hline Bottle-fed -ve. dam's colostrum ${ }^{3}$ & 326 & 7 & 319 & 52 \\
\hline Bottle-fed +ve. dam's colostrum ${ }^{3}$ & 429 & 24 & 79 & 31 \\
\hline Bottle-fed bovine colostrum ${ }^{3}$ & 255 & 6 & 0 & - \\
\hline Dam's serological status-age & & & & \\
\hline Seropositive-all ages & 878 & 15 & 600 & 34 \\
\hline Seronegative- 1 to 3 years old & 116 & 3 & 136 & 40 \\
\hline Seronegative - $\geq 4$ years old & 912 & 3 & 152 & 23 \\
\hline Place of rearing post weaning & & & & \\
\hline Shed with VMV-infected adults & 423 & 18 & 279 & 31 \\
\hline Shed with no adult sheep & 1733 & 7 & 2840 & 57 \\
\hline Replacement flock size & & & & \\
\hline $15-76$ & 1204 & 10 & 624 & 77 \\
\hline $77-280$ & 952 & 9 & 2500 & 49 \\
\hline Adult flock mean VMV seroprevalenc & & & & \\
\hline $0-50$ & 1553 & 6 & 68 & 29 \\
\hline $51-75$ & 478 & 15 & 706 & 24 \\
\hline $76-100$ & 125 & 34 & 2350 & 65 \\
\hline Housing days $x$ replacement flock me & prevalence $^{4}$ & & & \\
\hline $0-53$ & 1902 & 6 & 499 & 30 \\
\hline $54-340$ & 254 & 32 & 3056 & 56 \\
\hline Housing days $x$ adult flock mean VM & $n c e^{4}$ & & & \\
\hline $0-210$ & 1973 & 8 & 68 & 30 \\
\hline $211-365$ & 183 & 27 & 3056 & 56 \\
\hline Floor area /sheep $\left(m^{2}\right)$ & & & & \\
\hline $0.6-0.9$ & 1354 & 8 & 1907 & 58 \\
\hline $1-2.2$ & 802 & 12 & 1217 & 51 \\
\hline Shed volume /sheep $\left(m^{3}\right)$ & & & & \\
\hline $1.7-5.9$ & 1328 & 4 & 1989 & 65 \\
\hline $6-50.4$ & 828 & 18 & 1135 & 38 \\
\hline Shed open area /sheep $\left(m^{2}\right)$ & & & & \\
\hline $0.02-0.20$ & 931 & 4 & 1865 & 64 \\
\hline $0.21-0.86$ & 1225 & 14 & 1259 & 42 \\
\hline
\end{tabular}

${ }^{1}$ Sum of the years of follow-up of sheep until seroconvesion or until the end of the study if they remained seronegative.

2 Number of seroconverted sheep divided by number of seronegative sheep-years and multiplied by 100 .

3.Segregated from their dam at birth and taken to a separate pen with other similarly fed lambs.

${ }^{4}$ Arithmetic mean of flock seroprevalence at the start and end of the year of exposure. 


\section{Epidemiological and statistical analysis}

Epilnfo 2002 (CDC, Atlanta, USA) and SAS (SAS Institute) were used to do statistical analysis. Year-specific VMV seroconversion cumulative incidences were calculated as the percentage of seronegative sheep that seroconverted during a study year, and overall and variable level specific incidence rates were calculated dividing the number of seroconversions by the number of seronegative sheep-years. The later referred to the sum, over all sheep, of the years of followup for each animal until it seroconverted or until the end of the study if it did not seroconvert (i.e., while at risk) (Thrusfield 1995). Level-specific incidences rates and means for continuous variables were compared with the Yate's corrected chi-squared test and the non-parametric Kruskal-Wallis tests, respectively. Logistic regression was used to investigate the relationship between seroconversion over a 1 year period (yes or no) and independent sheep and flock variables as previously described (Berriatua et al. 2003). Independent fixed variables considered are shown in Tables III.3.2. and III.3.3. Horizontal contact transmission was assessed indirectly by multiplying the number of days sheep were housed by the arithmetic mean of the flock seroprevalence at the start and end of the year of exposure (between samplings). To estimate seroconversion incidence among replacement sheep it was assumed that none of the animals were congenitally infected and all were seronegative at birth. Continuous variables were categorised prior to their inclusion into the model according to quartiles, terciles and to the shape of the distribution when the relationship with the outcome was multimodal. Additionally, flock and year were incorporated as random variables to account for unexplained correlation between sheep belonging to the same flock and among those tested on the same year. A backward strategy was used and all independent variables were included in initial models and following, variables not associated with the outcome at a $10 \%$ level $(p<0.10)$ were removed. The maximum likelihood estimation model was used, Ps were from likelihood-ratio chi-squared test and $\alpha$ was $5 \%(p<0.05)$ level for a double-sided test

\section{Results}

Annual VMV seroprevalence in adult and replacement Latxa and Assaf dairy sheep

VMV seroprevalence during the study period ranged from $24 \%$ to $39 \%$ in Latxa sheep and from $77 \%$ to $80 \%$ in Assaf sheep $(p<0.05)$. However, seroprevalence varied significantly between 
flocks of a particular breed and production system $(p<0.05)$ (Tab.III.3.1), within flocks over time $(p<0.05)$ (results not tabulated) and was lower in one year-old replacement sheep compared to adult sheep $(p<0.05)($ Tab. III.3.1).

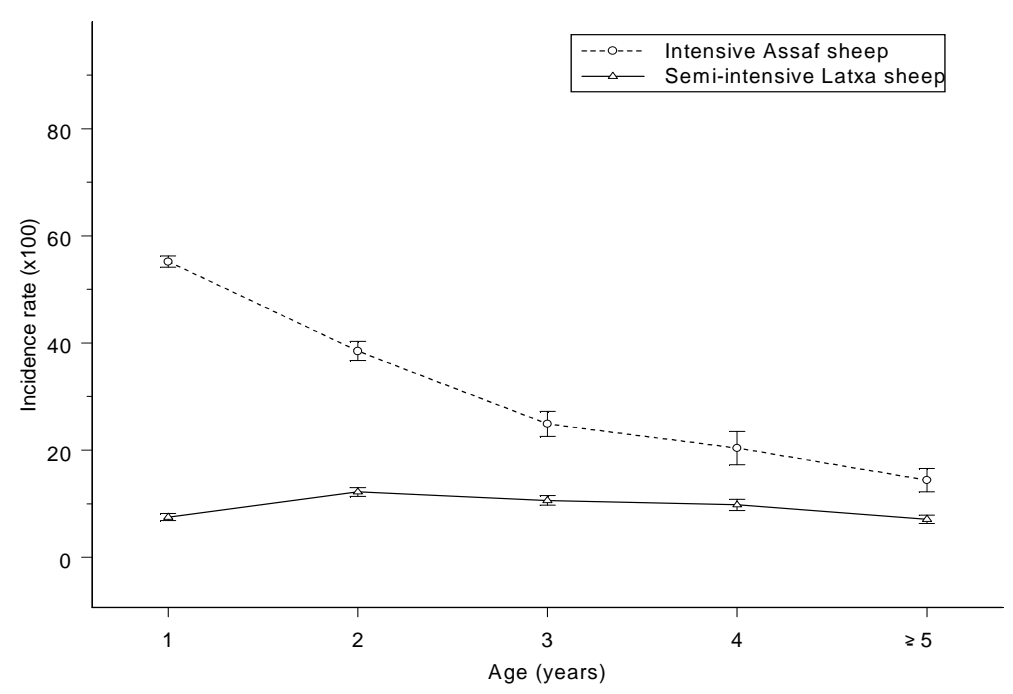

Figure III. 3.1. Age-specific VMV seroconversion incidence rate $(\mathrm{x} 100)$ in Spanish Latxa and Assaf dairy sheep flocks in years 2001-2006

\section{VMV seroconversion incidence rates in Latxa and Assaf dairy sheep}

The overall VMV seroconversion incidence rate was 0.44 (1675/3769) per sheep-year at risk in intensively raised Assaf sheep and 0.09 (606/6439) per sheep-year at risk in semi-intensive Latxa sheep $(p<0.05)$. Incidence varied significantly between flocks in the same production system and within some flocks over time $(p<0.05)$ (Tab.IIl.3.4). Similarly, the age-specific seroconversion incidence rate varied markedly between production systems; $60 \%$ of one year old Assaf sheep seroconverted during the first year of life compared to $<10 \% 1$ year-old Latxa sheep. Moreover, incidence markedly decreased with age in intensively raised Assaf sheep instead, it was similarly low among 1-4 year old semi-intensively raised Latxa sheep (Fig.Ill.3.1). 
Table III.3.3. VMV seroconversion incidence rates (x100) in 2 year old and older Latxa and Assaf sheep according to the mode of rearing, housing time, stocking density and shed structural variables.

\begin{tabular}{|c|c|c|c|c|}
\hline & \multicolumn{2}{|c|}{ Semi-intensive Latxa } & \multicolumn{2}{|c|}{ Intensive Assaf } \\
\hline & $\begin{array}{l}\text { No. of } \\
\text { sheep-years }{ }^{1}\end{array}$ & $\begin{array}{l}\text { Incidence } \\
\text { rate }^{2}\end{array}$ & $\begin{array}{l}\text { No. of } \\
\text { sheep-years }{ }^{1}\end{array}$ & $\begin{array}{l}\text { Incidence } \\
\text { rate }^{2}\end{array}$ \\
\hline \multicolumn{5}{|l|}{ Dam's serological status-age } \\
\hline Seropositive-all ages & 1414 & 18 & 188 & 47 \\
\hline Seronegative- 1 to 3 years old & 116 & 10 & 13 & 29 \\
\hline Seronegative - $\geq 4$ years old & 1893 & 6 & 44 & 32 \\
\hline \multicolumn{5}{|l|}{ Adult flock size } \\
\hline $167-254$ & 3851 & 11 & 332 & 13 \\
\hline 255-761 & 850 & 6 & 1709 & 23 \\
\hline \multicolumn{5}{|c|}{ Adult VMV adult flock mean VMV seroprevalence ${ }^{3}$} \\
\hline $0-50$ & 4173 & 9 & 0 & \\
\hline $51-75$ & 486 & 17 & 763 & 18 \\
\hline $76-100$ & 41 & 24 & 745 & 41 \\
\hline \multicolumn{5}{|c|}{ Housing days $X$ adult flock mean VMV seroprevalence ${ }^{3}$} \\
\hline $7-38$ & 2742 & 7 & 0 & \\
\hline $58-110$ & 1958 & 15 & 0 & \\
\hline 208-300 & 0 & & 1443 & 28 \\
\hline 323-365 & 0 & & 65 & 55 \\
\hline \multicolumn{5}{|l|}{ Floor area /sheep $\left(m^{2}\right)$} \\
\hline $0.6-0.9$ & 2268 & 10 & 1116 & 18 \\
\hline $1-2$ & 2433 & 10 & 925 & 27 \\
\hline \multicolumn{5}{|l|}{ Shed volume /sheep $\left(m^{3}\right)$} \\
\hline $3-7.9$ & 2268 & 10 & 1445 & 24 \\
\hline 8-17.4 & 2433 & 10 & 596 & 15 \\
\hline \multicolumn{5}{|l|}{ Shed open area /sheep $\left(m^{2}\right)$} \\
\hline $0.03-0.13$ & 1158 & 18 & 2012 & 21 \\
\hline $0.14-0.32$ & 3543 & 8 & 29 & 45 \\
\hline
\end{tabular}

1 Sum of the years of follow-up of sheep until seroconvertion or until the end of the study if they remained seronegative.

2 Number of seroconverted sheep divided by number of seronegative sheep-years and multiplied by 100 .

${ }^{3}$ Arithmetic mean of flock seroprevalence at the start and end of the year of exposure.

Unadjusted relationship between VMV-seroconversion and independent husbandry and sheep building variables

Tables III.3.2 and III.3.3 describe VMV seroconversion incidence rates in one year-old replacement and older sheep, respectively, according to mode of rearing, maternal VMV serological status and age, flock seroprevalence, housing time, stocking density and shed ventilation variables. Incidence rates varied significantly according to levels of all explanatory variables. $(p<0.05)$.

Bottle-feeding colostrum from a seropositive dam was associated with the greatest seroconversion incidence rate in Latxa flocks but this effect was not observed in Assaf flocks, where seroconversion was greatest in lambs bottle-fed colostrum from seronegative dams 
(Tab.III.3.2). Similarly, incidence was greatest among sheep born to seropositive ewes (Tab.III.3.2 and III.3.3), except for replacement sheep born to seronegative 1-3 year-old Assaf ewes which had a similar incidence as replacements born to seropositive dams (Tab. III.3.2 ). In both age groups seroconversion incidence was not associated to flock size and was positively associated to flock seroprevalence and to the product of flock seroprevalence by time spent indoors (Tab.III.3.2 and III.3.3). There was no consistency in the relationship between seroconversion and stocking density or sheep building variables in different groups of sheep; for example shed floor area was negatively associated with seroconversion in replacement Assaf sheep and similarly positively associated in Latxa replacements and adult Assaf sheep (Tab.III.3.2 and III.3.3)

Table III.3.4: Percentage of VMV seroconversion in Spanish Latxa and Assaf dairy sheep flocks in years 2000 to 2006.

\begin{tabular}{|c|c|c|c|c|c|c|c|c|c|}
\hline \multirow[t]{4}{*}{ Production system } & \multicolumn{3}{|l|}{ Sheep } & \multicolumn{6}{|c|}{ Flock } \\
\hline & \multirow[t]{3}{*}{ Year } & \multirow[t]{3}{*}{ No. } & \multirow{3}{*}{$\begin{array}{l}\% \text { sero- } \\
\text { conversions }\end{array}$} & \multirow[t]{3}{*}{$\mathrm{N}^{0}$} & \multicolumn{5}{|c|}{$\%$ seroconversions } \\
\hline & & & & & \multirow[t]{2}{*}{ Min. } & \multicolumn{3}{|c|}{ Quartiles } & \multirow[t]{2}{*}{ Max. } \\
\hline & & & & & & $25 \%$ & $50 \%$ & $75 \%$ & \\
\hline \multirow{6}{*}{$\begin{array}{l}\text { Latxa } \\
\text { Semi-intensive }\end{array}$} & 2001 & 1010 & 9 & 5 & 3 & 4 & 15 & 17 & 22 \\
\hline & 2002 & 1037 & 8 & 5 & 5 & 5 & 7 & 13 & 14 \\
\hline & 2003 & 1102 & 9 & 5 & 3 & 3 & 12 & 17 & 17 \\
\hline & 2004 & 1203 & 8 & 5 & 0 & 3 & 11 & 13 & 15 \\
\hline & 2005 & 1161 & 13 & 5 & 2 & 4 & 12 & 15 & 24 \\
\hline & 2006 & 926 & 10 & 4 & 1 & 1 & 6 & 14 & 19 \\
\hline Assaf & 2005 & 1823 & 46 & 10 & 14 & 28 & 40 & 88 & 95 \\
\hline Intensive & 2006 & 1946 & 43 & 10 & 9 & 21 & 49 & 68 & 83 \\
\hline
\end{tabular}

Multivariable relationship between VMV-seroconversion and husbandry and sheep building independent variables

Results from the logistic models investigating VMV-seroconversion variables in (a) one year-old replacement ewes and (b) two years older ewes are shown in table III.3.5. For sheep of both age groups VMV seroconversion was positively associated to the product of housing days by flock seroprevalence (odds ratio was greater for replacement compared to adult sheep) and to being born to a seropositive dam (Tab.III.3.5). Additionally, MV seroconversion was lower for replacement sheep raised with bovine colostrum and milk replacer compared to other sheep and was negatively associated to age in adult sheep. Finally, there was marginally significant 
variation in seroconversion between flocks and study years $(p=0.08-0.15)$ (Tab.III.3.5).

Table III.3.5. Estimates from the random-effects logistic-regression models of VMV seroconversion in intensive and semi-intensive dairy sheep in Spain (15 flocks; 2000-06). (a) one-year old replacement ewes $(n=2794)$ and $(b)$ two year-old and older ewes $(n=3675)$.

\begin{tabular}{lll}
\hline Variable & $\begin{array}{l}\text { Odds } \\
\text { ratio }\end{array}$ & $\begin{array}{l}95 \% \text { Confidence } \\
\text { Intervals }\end{array}$ \\
\hline
\end{tabular}

(a) One year-old replacement sheep

\section{Fixed-effects}

Mode of rearing preweaning

Naturally raised by seropositive dam

Naturally raised by seronegative dam

Bottle-fed colostrum from seropositive dam

Bottle-fed colostrum from seronegative dam

Bottle-fed bovine colostrum

Dam's age (yr.); MV status at last test

$\geq 4$; seronegative

1-3; seronegative

All ages; seropositive

1.00

1.92

1.03

2.59

0.29

1.00

1.99

4.11

$3.17, \quad 1.24$

$9.49, \quad 0.39$

$1.91, \quad 0.46$

$14.04,0.48$

$0.72, \quad 0.12$

0.4258

0.2689

0.9267

0.0079

Housing time $x$ replacement flock seroprevalence

$0-12$

$13-40$

44-113

146-225

Random effects: variance estimate and SE

Flock

Year

Residual

(b) Sheep $\geq 2$ years old

Fixed-effects

Age (yr.)

$\geq 4$

3

2

Housing time $x$ mean adult flock seroprevalence (0-1)

5-18

$25-67$

71-117

186-361

1.00

4.43

13.44

43.91

$8.26,2.37$

26.02, 6.95

$90.53,21.29$

$<0.0001$

0.1266

0.1219

0.1510

0.2279

1.0255

0.0282

0.1495

0.0656

$<0.0001$

1.00

1.37

1.85

$1.86,1.01$

$2.43,1.41$

0.0404

$1.00 \quad 2.17,0.90$

$1.40 \quad 3.63,1.19$

$2.08 \quad 7.56,1.68$

0.0216

3.56

0.0008

Dam's age (yr.); MV status at last test

$\geq 4$; $\quad$ seronegative

1.00

1-3; seronegative

All ages; seropositive

1.17

2.22

$2.10,0.66$

0.5914

Random effects: variance estimate and SE

Flock

0.174

$2.86,1.71$

$<0.0001$

Year

0.1842

0.1304

0.0911

Residual

* During the first $24 \mathrm{~h}$ of life and followed by milk-replacer until weaning 


\section{Discussion}

The present study aimed at investigating the role of housing on VMV infection in sheep. Results confirm that VMV infection is positively associated to housing time and direct contact with infected sheep and shows that this effect is greatest in the one year-old replacement flock. This suggests that naïve young sheep may be more susceptible to VMV infection and excrete more virus than previously exposed adults, but this has not been investigated. Although mode of rearing preweaning had a comparatively small effect on the risk of seroconversion in replacement sheep, probably many of them became infected preweaning lactogenically and from horizontal contact with their dam and other adults, and were the source of virus for their flockmates. This would explain the large seroconversion incidence in Assaf replacements that had been bottle-fed seronegative colostrum and raised only with other lambs preweaning. A previous study in Latxa sheep showed that 10-30\% of lambs may become infected from feeding colostrum from a seropositive dam (Alvarez et al. 2005, Alvarez et al. 2006) and the greatest risk of infection was for lambs bottle-fed colostrum from seropositive dams. The later was similarly observed in Latxa but not in Assaf replacements in this study. Moreover, the multivariable model indicated no differences in the risk of seroconversion between sheep bottle-fed seropositive colostrum and those naturally raised by seropositive ewes after adjusting for the effect of other variables on seroconversion, particularly horizontal contact with infected sheep. Berriatua et al. (2003), previously showed that seroconversion in housed sheep exposed to horizontal contact infection, was independent of mode of rearing preweaning.

The study also provides further epidemiological evidence that resistance and susceptibility to VMV infection has an inheritable component, as sheep from seronegative dams had a lower risk of seroconversion compared to offspring of seropositive dams after taking into account mode of rearing during lactation. The genetic basis of susceptibility and resistance to VMV infection is unknown although there is some evidence of genetic differences between sheep in susceptibility and resistance to other lentiviral infections of ruminants (Ruff et al. 1988, Mirsky et al. 1998).

To investigate post-weaning exposure of replacement sheep to infection from adults raised in separate pens in the same building, housing time was multiplied by seroprevalence in the adult flock. The variable was not associated to seroconversion suggesting that airborne transmission between pens several meters apart may not be efficient, as shown for other viral respiratory pathogens (Callan et al. 2002). Moreover, in contrast to some of the later viruses, SRLVs are not 
easily found in saliva and nose secretions (Gudnadottir et al. 1965, Houwers 1990) and under experimental conditions large to moderate doses are necessary to establish infection intranasally (Torsteinsdottir et al. 2003) and via the eye conjunctival space (Niesalla et al. 2008b). Indirect transmission farm studies are scarce and Adams et al. (1983), reported that a two meter separation between animal pens was sufficient to prevent SRLV transmission in goats. Peretz et al. (1994), showed that housing goats in separate buildings was superior in preventing SRLV contagion compared to separation by a wall and the later was more effective than a hurdle. VMV transmission may be enhanced by the concomitant presence of ovine pulmonary adenomatosis (Dawson et al. 1985, Gonzalez et al. 1993).

An attempt was made in this study to investigate the role of variables related to barn ventilation including stocking density and open areas but none of the variables were associated to seroconversion. Most farms provided adequate flooring space for their flocks. Greater open areas should facilitate shed ventilation and was associated with lower VMV seroprevalence in a previous study in 25 semi-extensively raised sheep flocks (Perez et al. 2009). The number of flocks analysed in the present study was smaller and seroprevalence in intensive flocks in the present study was very high and as infection pressure rises, ventilation offers progressively less reduction in aerosol concentration (Nardell et al. 1991). Moreover, flock VMV prevalence and incidence of infection greatly depend on factors other than ventilation, particularly the number of infected sheep culled and replaced by offspring of seronegative ewes (Berriatua et al. 2003). Further, larger studies are necessary to elucidate the role of building design and VMV infection. Such studies should additionally contemplate a number of factors that influence infectious aerosol formation, airflow and ventilation including outdoor and indoor temperature and relative humidity, prevailing winds, number and density of animals, animal activity and dust accumulation (Collins, Jr. 1990, Stark 1999, Callan et al. 2002, Lago et al. 2006, Nordlund 2008).

The present study improves our knowledge of factors associated with VMV infection in several ways; infection risk analysis should be carried out separately for replacement and adult sheep since younger sheep appear to be more susceptible to direct contact infection than adults and also, they are exposed to lactogenic infection. The importance of indirect exposure to aerosols from infected sheep remains unclear; the present study suggest the risk of infection may be low and detailed studies need to carried out to evaluate the potential role of improved barn ventilation to the reduce the risk of SRLV infection in indoor raised small ruminants 


\section{Acknowledgements}

This study was funded by the Ministerio de Ciencia y Tecnología of Spain through Grants MEC AGL2003-08977-C03-03/GAN and AGL2007-66874-C04-03/GAN. 



\title{
ESTUDIO 4
}

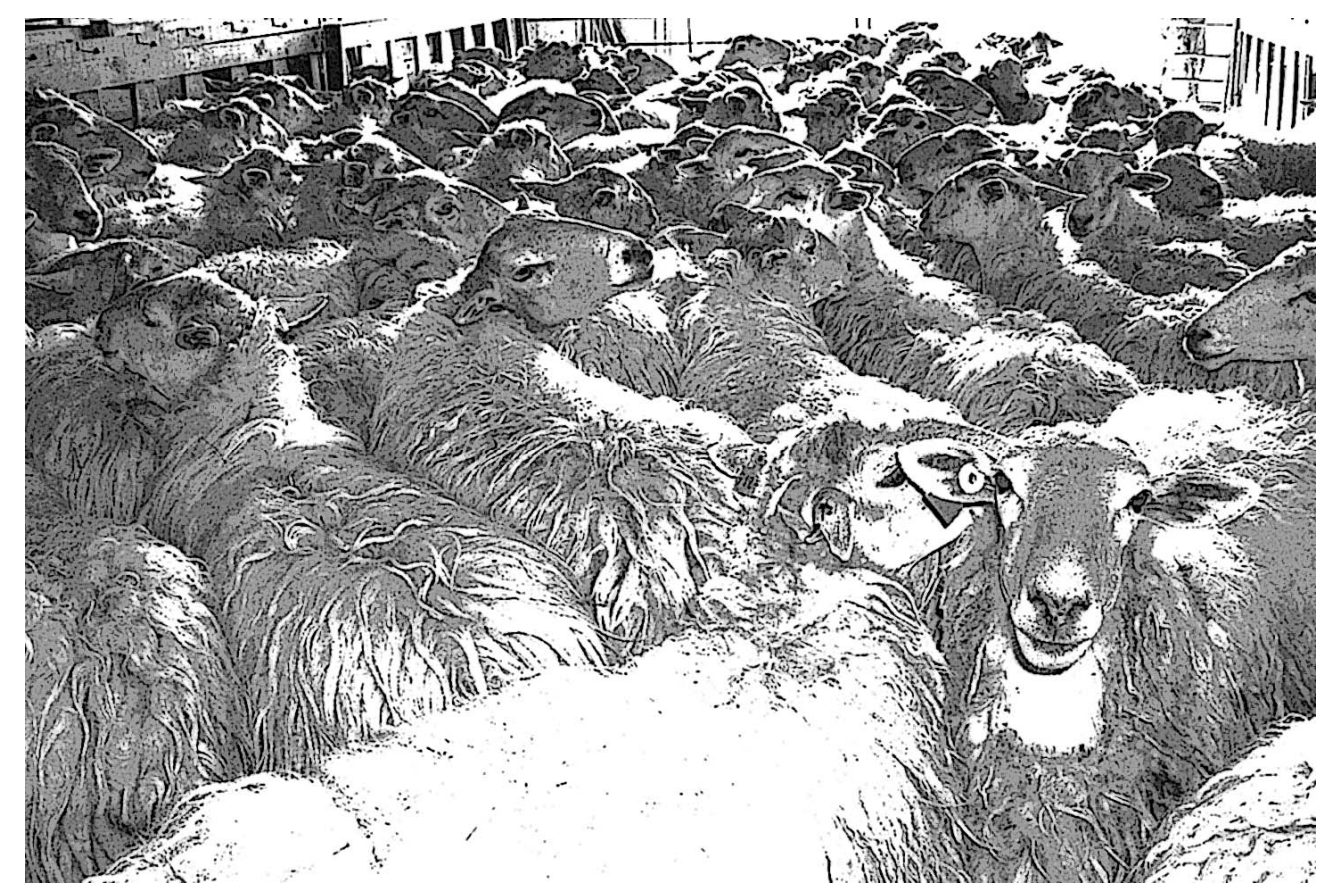

\section{Improvements in the detection of small ruminant lentivirus infection in the blood of sheep by PCR}

\author{
I. Leginagoikoa1', E. Minguijón'1, E. Berriatua², R.A. Juste ${ }^{1}$ \\ ${ }^{1}$ Instituto Vasco de Investigación y Desarrollo Agrario-NEIKER, Derio, Bizkaia, Spain. \\ ${ }^{2}$ Enfermedades Parasitarias, Facultad de Veterinaria. Universidad de Murcia, Murcia, Spain
}

Journal of Virological Methods 156 (2009) 145-149 



\begin{abstract}
The polymerase chain reaction on blood samples has been considered a complement to serological methods for the detection of small ruminant lentiviruses (SRLV) infections in sheep and goats. This is a report on the results of a study to evaluate the use of the same blood sample for the detection of infected animals by ELISA and PCR. A comparison between the results obtained by applying PCRs targeting LTR and gag sequences on blood clot, serum and peripheral blood leucocytes was made. In addition to simplifying sampling and laboratory work, the use of blood clot samples with the gagPCR improved remarkably the detection of infected animals. Finally, this study has shown the existence of a cell-free viremia in the serum of SRLV-infected sheep.
\end{abstract}

\title{
Introduction
}

Maedi-visna is a disease of sheep caused by a group of viruses defined as small ruminant lentivirus (SRLV) that belong to the genus Lentivirus of the Retroviridae family. This disease affects small ruminants causing chronic inflammatory lesions in the lung, joints, mammary glands, and brain (Narayan et al. 1982, Radostits et al. 2000). The infection is widespread in many countries (Brodie et al. 1998, Peterhans et al. 2004, Gufler et al. 2007) and its transmission occurs mainly by the respiratory route and also from dam to offspring via infected colostrum and milk (Berriatua et al. 2003, Leginagoikoa et al. 2006a, Leginagoikoa et al. 2006b). The infection by SRLV results characteristically in a life-long infection and a maintained humoral immune response. In the absence of effective treatments or vaccines, the control and eradication of the infection rely on sound epidemiological information and accurate detection of infected animals. There are several serological techniques available for detection of specific antibodies against SRLV, the most commonly used being the agar gel immunodiffusion test (AGID) and, with higher sensitivity, the enzyme-linked immunosorbent assay (ELISA) (Saman et al. 1999). However, antibody detection methods may have limited sensitivity related to antigenic variation in SRLVs, to the existence of infected animals that do not develop a humoral immune response and to interference with colostrum acquired antibodies in young animals. Following primary infection, SRLVs undergo a short-lived cell associated viral replication period (Juste et al. 1998) and remain integrated in the DNA of circulating antigenpresenting monocytes as a provirus(Narayan et al. 1982, Ryan et al. 2000) and an early antibody response may (Juste et al. 1998) or may not (Sihvonen 1981) take place. When infected cells reach target tissues, they mature to macrophages and viral gene expression takes place (Clements et al. 
1996). Because of this, using PCR or RT-PCR to amplify proviral DNA and CDNA from reversetranscribed viral RNA, respectively, in peripheral blood leucocytes (PBLs) is a useful complement to existing serological methods to detect infection. SRLV PCRs have been developed with specific and degenerate oligonucleotide primers across the genome, including the LTR region and the gag, pol and env genes. However, there appears to be considerable variability in their sensitivity due to strain sequence differences and to low viral load in the circulation (De Andres et al. 2005).

A further important diagnostic issue is the type of sample in which to perform the assays; commonly, SRLV investigations in infected flocks imply taking and processing at least two blood samples from each individual, in order to obtain white blood cells for PCR testing and serum for antibody analysis, respectively. However, it has been shown that infection with the human immunodeficiency virus type 1 (HIV-1), which is another member of the lentivirus genus, can be diagnosed by PCR testing of serum and blot clot samples from a single extraction tube, thus reducing sampling and sample processing costs (Boriskin et al. 1995). Being able to diagnose SRLV infection in a single clotted blood sample would be equally advantageous. It would open the possibility of using clotted blood samples obtained for serological diagnosis of other infections including those collected in large scale disease control programs such as for brucellosis. Since the use of a testing matrix other than PBLs has so far not been examined for SRLV PCR in vivo, a study was designed to compare the results of testing serum, PBLs and blood clot with an LTR and a gag-PCR tests (Extramiana et al. 2002, Daltabuit-Test et al. 2006) with procedures aimed at detecting proviral DNA and viral RNA.

\section{Material and Methods}

Animals and samples

Fifty sheep, including an equal number of SRLV seropositive and seronegative animals, from a Latxa breed flock that had been monitored for Maedi Visna infection during the last 10 years, were selected on the basis of their serological status in the last control. Blood was taken from the jugular vein in 10 $\mathrm{mL}$ tubes without anticoagulant to obtain both serum and blood clot, and in EDTA-coated $10 \mathrm{~mL}$ tubes to obtain PBLs. Serum was split into two $1 \mathrm{~mL}$ aliquots. The blood clot was cut into two halves that were taken to two separate vials. PBLs were obtained following lysis of red blood cells by adding $0.015 \mathrm{M}$ ammonium chloride to whole blood (1:2, v:v) as described previously (Extramiana et al. 2002). In the first stage, samples from 10 ELISA positive animals subset were used for the comparison of two different viral nucleic acids extraction procedures. In the second stage, the 
remaining 40 samples were incorporated to the study and processed using the most effective nucleotide extraction method.

\section{Serology}

The serum samples were tested for the presence of anti-SRLV antibodies using an indirect commercial ELISA (ELITEST-MVV, HYPHEN BioMed, France) that has sensitivity and specificity compared to AGID and Western blotting of 99.4\% (98.4-99.8) and 99.3\% (98.7-99.6), respectively (Saman et al. 1999). The sera were processed and the results were interpreted as indicated by the manufacturer.

\section{DNA and RNA extraction method comparison}

\section{Phenol-chloroform extraction}

Nucleic acids from the samples were purified by the method described by (Chomczynski et al. 1987). Five hundred microliters of denaturing solution (4 M guanidinium thiocyanate, $25 \mathrm{mM}$ sodium citrate $\mathrm{pH} 7,0.5 \%$ sarcosyl, $0.1 \mathrm{M}$ 2-mercaptoethanol) were added to $200 \mu \mathrm{L}$ of the serum sample or PBLs obtained from half of EDTA-treated blood. Three milliliters of denaturing solution were added to one of the blood clot samples and $500 \mu \mathrm{L}$ from the mixture was used later. $500 \mu \mathrm{L}$ of $2 \mathrm{M}$ sodium acetate treated with diethylpyrocarbonate (DEPC) was added and vortexed; $500 \mu \mathrm{L}$ of phenol-chloroformisoamyl alcohol solution (25:24:1, v:v:v) were added to the tube that was then vortexed and left for 15 min on ice. After centrifugation at $12,000 \times g$ for $10 \mathrm{~min}$ at $4^{\circ} \mathrm{C}$ the upper phase was transferred to another tube and $500 \mu \mathrm{L}$ of chloroformisoamyl alcohol (24:1, v:v) was added and vortexed. After 15 min on ice the samples were centrifuged as above and the upper phase was transferred to a new tube to which $2.5 \mu \mathrm{L}$ of RNA from phage MS2 [Roche Diagnostics, Germany] were added. Nucleic acids were precipitated with $500 \mu \mathrm{L}$ of isopropanol at $-20{ }^{\circ} \mathrm{C}$ overnight. After sedimentation by centrifugation at $12,000 \times \mathrm{g}$ for $20 \mathrm{~min}$, the pellet was washed twice with $1 \mathrm{~mL}$ of $75 \%$ ethanol in DEPC-treated Milli-Q water and kept for $10 \mathrm{~min}$ on ice, centrifuged as above and the supernatant discarded. Once the pellet was dry it was resuspended on $38 \mu \mathrm{L}$ of $50 \mathrm{mM}$ sodium acetate $10 \mathrm{mM}$ $\mathrm{MgCl} 2 \mathrm{DEPC}$-treated, heated at $65^{\circ} \mathrm{C}$ and stored at $-80^{\circ} \mathrm{C}$ until PCR was carried out. DNA and RNA concentrations were determined for each sample with a NanoDrop ND-1000 spectrophotometer [Thermo Fisher Scientific, USA]. 
Commercial kit extraction

Viral nucleic acid was obtained from $200 \mu \mathrm{L}$ of serum using the Qiamp MinElute Virus Spin kit [Qiagen Iberia, Spain] following manufacturer's instructions. Elution was made in $50 \mu \mathrm{L}$ of RNase free water. One aliquot of $30 \mathrm{mg}$ of blood clot or all the PBLs obtained from half of EDTA-treated blood, were used with the Kit Allprep DNA-RNA [Qiagen Iberia, Spain] for cell and tissue samples following manufacturer's instructions. Finally, the RNA was eluted with $35 \mu \mathrm{L}$ of RNase-free water and DNA with $100 \mu \mathrm{L}$ of elution buffer. The DNA and RNA concentrations were determined for each sample with a NanoDrop ND-1000 spectrophotometer [Thermo Fisher Scientific, USA].

\section{Polymerase chain reaction (PCR)}

The detection of LTR on Maedi Visna provirus was carried out using the PCR method described by Extramiana et al. (2002). It uses the forward 5'-TGACACAGCAAATGTAACCGCAAG-3' and the reverse 5-CCACGTTGGGCGCCAGCTGCGAGA-3 primers that specifically amplify a $291 \mathrm{bp}$ fragment. For each sample, two $25 \mu \mathrm{L}$ PCR reactions containing $50 \mathrm{ng}$ of DNA were carried out. The samples were considered positive when at least one of two replicates was positive and all the controls gave the expected results.

gag-targeted polymerase chain reaction (gag-PCR)

Detection of the gag gene on Maedi Visna provirus was carried out with the forward 5'GGGACGCCTGAAGTAAGGTA-3' and reverse 5'CAAAATCCTCGGACACAAG-3 primers, as described by Daltabuit-Test et al. (2006), that specifically amplify a 748 bp fragment of the gag gene. For each sample, two $25 \mu \mathrm{L}$ PCR reactions containing $50 \mathrm{ng}$ of DNA were carried out. The samples were considered positive when at least one of two replicates amplified the expected fragment size and all the controls gave the expected results.

gag-targeted reverse transcription and polymerase chain reaction (gag-RT-PCR)

The gag primers described previously were used to amplify cDNA from transcribed SRLV RNA (Daltabuit-Test et al. 2006) using the commercial kit One step RT-PCR [Qiagen Iberia, Spain]. The reaction volume was $25 \mu \mathrm{L}$ and contained $50 \mathrm{ng}$ of RNA and $0.625 \mu \mathrm{L}$ of RNase inhibitor [Promega Biotech Iberica, Spain] to protect the RNA. Similarly, samples were considered positive when a 748 bp DNA fragment was obtained in at least one of the two replicates. For the 10 seropositive samples 
used for comparing the two extraction methods, PCR was carried out before and after the treatment of the eluted RNA with deoxyribonuclease [DNA-free, Ambion, Applied Biosystems, Spain] following manufacturer's instructions. For the rest of the samples RT-gag-PCR was carried out only on nondeoxyribonuclease (DNase)-treated samples.

\section{Results and controls}

Each batch of samples included a negative extraction control and a negative PCR control. DNA and RNA obtained from a frozen lung sample of a sheep affected by respiratory maedi were used as positive controls. The PCRs were run in a 1.5\% (w:v) agarose gel in Tris-borate-EDTA buffer (TBE) that was stained with $0.5 \mathrm{mg} / \mathrm{mL}$ of ethidium bromide in TBE for $20 \mathrm{~min}$, washed in distilled water for $10 \mathrm{~min}$ and visualized on an ultraviolet transilluminator. The glyceraldehyde-3-phosphate dehydrogenase housekeeping gene was used as a control to verify the effectiveness of DNase treatments by PCR (negative result expected) and to confirm RNA amplification by RT-PCR (positive result expected).

\section{Statistical analysis}

The relationship between ELISA and PCR results was investigated and the degree of agreement was estimated using the kappa statistic (Dohoo et al. 2003b). Inferential value of the comparison of the frequencies of positive results according to each variable was estimated with the Chi square or Fisher exact tests. Additionally, as a measure of the relative performance of each method, complementary sensitivity (CS) (Juste et al. 2005) was calculated as the ratio of positive results in only one method to the total number of positive results in the other method. This variable was meant to represent the additional detection efficacy of one method over the other, assuming both were highly specific.

\section{Results}

Comparison of proviral DNA detection in serum, PBLs and blood clot samples by LTR-PCR and gagPCR using two different extraction methods (Tab. III.4.1)

Serum: None of the ten seropositive serum samples were positive for SRLV DNA by any of the two PCR techniques and extraction methods.

PBLs: The percentage of PCR-positive samples was $50 \%$ and $56 \%$ for the gag test using the commercial and phenol-chloroform extraction methods, respectively, and $30 \%$ and $25 \%$ for the LTR 
test on similarly extracted DNA.

Blood clot: The percentage of PCR-positive blood clot samples were $100 \%$ and $80 \%$ for the gag test following kit and phenol-chloroform extraction and $60 \%$ and $40 \%$ for the LTR-PCR test on DNA extracted by the latter methods, respectively.

Overall, there were highly significant differences in the frequency of PCR-positives among the three types of samples taken together and in each pair-wise comparison $(p<0.0001)$. Also, the gagtargeted PCR reactions yielded a significantly greater proportion of positive results $(47 \%)$ than the LTR PCRs $(26 \%)(p=0.0002)$. There were no significant differences in the frequencies of positive results regarding whether the nucleic acids were purified using the phenol-chloroform (33\%) or the commercial kit $(40 \%)(p=0.2894)$.

Table III.4.1. Comparison of two methods of extraction of DNA and RNA in serum, PBLs and blood clot from 10 serologically positive sheep. Percent positive samples, in parentheses number of samples examined when different from 10.

\begin{tabular}{|c|c|c|c|c|c|c|c|c|}
\hline \multirow[t]{3}{*}{ Sample } & \multicolumn{2}{|l|}{$\mathrm{PCR}^{\mathrm{a}}$} & \multirow{2}{*}{\multicolumn{2}{|c|}{$\frac{\text { RT-PCR a }^{a}}{g a g}$}} & \multicolumn{2}{|l|}{$\mathrm{PCR}^{b}$} & \multirow{2}{*}{\multicolumn{2}{|c|}{$\begin{array}{l}\text { RT-PCR b } \\
\text { gag }\end{array}$}} \\
\hline & \multirow[t]{2}{*}{$\overline{L T R}$} & \multirow[t]{2}{*}{ gag } & & & \multirow[t]{2}{*}{$\overline{\mathrm{LTR}}$} & \multirow{2}{*}{$\overline{g a g}$} & & \\
\hline & & & RNA DNase - & $\overline{\text { RNA DNase + }}$ & & & RNA DNase - & $\overline{\text { RNA DNase + }}$ \\
\hline Serum & 0 & 0 & 30 & 10 & 0 & 0 & 10 & 0 \\
\hline PBLs & 30 & 50 & 0 & 0 & $25(8)$ & $56(9)$ & 70 & 0 \\
\hline Blood Clot & 60 & 100 & 30 & 0 & 40 & 80 & 80 & 0 \\
\hline
\end{tabular}

a Commercial kit: Comercial kits were different for serum and for PBLs and blood clot. The former yielded a mixed DNARNA solution, while separate aliquots for RNA and DNA are obtained from PBLs and blood clot.

b Phenol-chloroform

Comparison of viral RNA detection in serum, PBLs and blood clot by gag-RT-PCR using two different extraction methods (Tab. III.4.1)

Serum: After extraction with the commercial kit, $30 \%$ of the samples were positive to gag-RTPCR. However, when the samples were treated with DNase prior to reverse transcription, only one remained positive. This was the same single serum sample (10\%) detected as positive using the phenol-chloroform extraction method before DNase digestion. (Tab. III.4.1)

PBLs: None of the samples extracted with the commercial kit were positive and $70 \%$ were positive by the phenol-chloroform extraction method although they became negative after digestion with DNase 
Blood clot: Thirty percent of the samples processed with the commercial kit were positive whereas $80 \%$ of them were positive with the phenol-chloroform method. All became negative after digestion with DNase.

Overall, there were no significant differences between the frequencies of positives among the three types of samples taken together $(p=0.2219)$ or in each pair-wise comparison. There were slightly significant differences in the frequencies of positive results regarding whether the nucleic acids were purified using the phenol-chloroform $(26 \%)$ or the commercial kit $(12 \%)(p=0.0310)$, and significant differences depending on whether there was a DNase digestion $(2 \%)$ step or not $(37 \%)(p<0.0001)$.

Comparison of results in PBLs and blood clot in seronegative and seropositive animals using the commercial kit (Tab. III.4.2.)

The proportion of PBL samples from seropositive ewes that were LTR-PCR and gag-PCR positive were $44 \%$ and $64 \%$, respectively, whereas only $4 \%$ of them were positive by gag-RT-PCR. None of 25 seronegative animals were PCR positive in PBLs.

Blood clot: Seropositive ewes were positive in $52 \%$ of the blood clot samples by LTR-PCR, $92 \%$ by gag-PCR and $20 \%$ by gag-RT-PCR. Twenty-four percent of the seronegative samples were positive in gag-PCR but none in LTR or in gag-RT-PCR.

Table III.4.2. ELISA and LTR and gag-PCR results comparison in PBLs and blood clot of 25 SRLV ELISApositive and 25 SRLV ELISA-negative sheep. In parentheses absolute frequency of positives. Kappa: agreement index, CS: complementary sensitivity.

\begin{tabular}{llccccc}
\hline & & ELISA $^{+}(\mathrm{n}=25)$ & ELISA - $(\mathrm{n}=25)$ & Kappa & CS ELISA & CS PCR \\
\hline LTR-PCR & PBLs & $44 \%$ & $0 \%$ & 0.522 & $127.3 \%$ & $0.0 \%$ \\
& Blood clot & $52 \%$ & $0 \%$ & 0.588 & $92.3 \%$ & $0.0 \%$ \\
gag-PCR & PBLs & $64 \%$ & $0 \%$ & 0.684 & $56.3 \%$ & $0.0 \%$ \\
& Blood clot & $92 \%$ & $24 \%$ & 0.689 & $6.9 \%$ & $24.0 \%$ \\
& & LTR-PCR ${ }^{+}(\mathrm{n}=24)$ & LTR-PCR - $(\mathrm{n}=76)$ & Kappa & CS LTR-PCR & CS gag-PCR \\
\hline gag-PCR & PBLs & $100 \%(11)$ & $15 \%(6)$ & 0.733 & $0.0 \%$ & $54.6 \%$ \\
& Blood clot & $100 \%(13)$ & $43 \%(16)$ & 0.501 & $0.0 \%$ & $123.1 \%$ \\
\hline
\end{tabular}


Agreement between PCR and ELISA ( Tab. III.4.2)

In the comparison between ELISA and gag-PCR, the best agreement was obtained when the PCR was used on blood clot samples (kappa $=0.689)$ and on PBLs samples (kappa $=0.684)$. The ELISA CS was $56.3 \%$ for PBLs and $6.9 \%$ for blood clot, while the gag-PCR CS was $0 \%$ for PBLs and $24 \%$ for blood clot. The agreement between the ELISA and the LTR-PCR test was lower than for the gagPCR, and kappa was 0.588 and 0.522 for blood clot and PBLs samples, respectively. The ELISA CS was $127.3 \%$ for PBLs and $92.3 \%$ for blood clot whereas the CS for the PCR was $0 \%$ in both sample types. It is necessary to emphasize that the best agreement values between ELISA and PCR were obtained in the samples of blood clot for both PCRs. Comparing gag and LTR-PCR test, the gagPCR CS was $54.6 \%$ in PBLs and $123.1 \%$ in blood clot however, the LTR-PCR CS was $0 \%$ in both cases but the degree of agreement between the techniques was substantial (kappa $=0.733)$ in PBLs samples and moderate $(k a p p a=0.501)$ in blood clot samples.

\section{Discussion}

This study is one of the few where a one-step PCR method has shown higher sensitivity than an ELISA for detection of SRLV infected sheep and goats (Rimstad et al. 1993, Brinkhof et al. 2008). In addition to showing that PCRs improve the sensitivity of SRLV infection diagnosis, it provides further evidence that SRLV viremia is a frequent phenomenon in natural infections and may happen in the absence of a humoral immune response. Several authors have reported the existence of seronegative animals as tested by ELISA, that are PCR-positive (Wagter et al. 1998, Gil et al. 2006) and the percentage of PCR-positives reached up to $34 \%$ and included animals in the prepatent stage of infection following recent exposure (Wagter et al. 1998). In the current study, SRLV infection was investigated with a gag-PCR and an ELISA and six (24\%) seronegative ewes were PCR-positive whilst two (8\%) ewes were ELISA-positive and PCR-negative in PBLs or blood clot samples. These animals remained seropositive when tested again for SRLV antibodies 1 year later, ruling out a possible failure in the serology. Longitudinal studies with newborn lambs until the age of 10 months revealed that $19-23 \%$ of the lambs were at least once LTR-PCR positive and did not seroconvert (Alvarez et al. 2006, Leginagoikoa et al. 2006b).

When comparing the ELISA and PCR techniques, the CS of ELISA was lower for blood clot compared to PBL samples and for the gag-PCR than for the LTR-PCR. The CS of PCR was higher than zero only when gag-PCR on blood clot samples was performed. In such case the value of CS of 
PCR was three times that of ELISA. The lack of an absolute concordance between ELISA and PCR techniques most likely reflects that the variables detected by ELISA (SRLV antibodies) and PCR (proviral SRLV sequences) are different and somewhat independent from each other. Previous studies have shown variable results in agreement between PCR and serological techniques. Age, thus time from first exposure to infection, seems to result in increased concordance between LTRPCR and ELISA (Alvarez et al. 2006, Leginagoikoa et al. 2006b).

Strain variation, a feature that characterizes small ruminant lentiviruses, hampers the design of primers that allow both a high sensitivity and specificity in PCR technique (De Andres et al. 2005). Several studies have described the use of PCR in different target regions and some obtained good results with primers in LTR (Zanoni et al. 1992, Extramiana et al. 2002, Angelopoulou et al. 2006a). However, other investigators showed the gag-PCR to be more sensitive than the LTR-PCR (Zanoni et al. 1990a, Reddy et al. 1993, Brinkhof et al. 2008). The former is a structural highly conserved gene coding for immunogenic proteins, used commonly for serological diagnosis and this may also explain the higher diagnostic agreement between the ELISA and the gag-PCR techniques.

The use of blood clot not only allows to perform serologic and molecular diagnosis in a single sample, thus reducing sampling and laboratory work but it improves remarkably the sensitivity of the proviral SRLV gag and LTR PCR and this is a result that had not been reported previously. Since the amount of nucleic acid used as PCR template, and the extraction method in blood clot and PBLs were the same, some other factors would be related to this result. It is known that SRLV does not need cell division to replicate itself, instead macrophage activation results in viral replication (Narayan et al. 1982, Gendelman et al. 1986). One possible explanation would be that the activation of the monocytes in the coagulation cascade (Kumar et al. 2008) could stimulate viral expression and result in a higher viral load. Nevertheless the detection of viral RNA did not increase as should be expected in such a case. The influence of methodological differences between gag-PCR and RT-PCR could lead to a lower sensitivity of RT-PCR. In fact, the commercial kit used for nucleic acid extraction on PBLs and blood clot yielded two aliquots from each sample, one of them enriched DNA that was used for PCR and the other enriched in RNA, used in RT-PCR. This difference of template in addition to the use of a commercial kit for RT-PCR in one step, resulted in a higher sensitivity of PCR on DNA over RT-PCR using non-DNase treated RNA. RNA degradation on blood clotting might as well influence although GAPDH-RT-PCR in DNase digested samples yielded positive results. Strikingly, the inhibitory effect of haemoglobin on Taq polymerase activity reported previously (Panaccio et al. 
1991, Wilson 1997) was not observed in this study on blood clot samples. Ammonium chloride is used widely to obtain PBLs and perform subsequent PCR and to our knowledge no inhibitory effect has been reported in relation to PCR. In this case it was verified that the results obtained after washing the buffycoat with sterile water were the same when ammonium chloride was used. It would be of interest to study the mechanism involved in the improvement of the detection of SRLV in blood clot over PBLs as well as to study the diagnostic implications of using blood clot samples for other viral infections.

The detection of cell-free viral RNA in serum from individual animals as shown in the present study is novel and, to the best of our knowledge, has not been reported previously. The results of the study provide further evidence that highest SRLV diagnostic sensitivity is achieved by using a combination of PCR and antibody-ELISA. This is of utmost importance to maximise the validity of experimental and epidemiological studies and the success of infection control programs. It would be desirable to carry out follow-up studies on infected animals to better understand the dynamics of ELISA and PCR positive animals and particularly to ascertain whether immunologically silent infections are a feature of SRLV pathogenesis or just a temporary finding associated to early or reactivated infections.

\section{Conclusions}

An SRLV gag-PCR test performed on blood clots appears to be a highly sensitive method for detecting SRLV in vivo. It supports strongly the existence of frequent cell-associated viremia that is important for diagnostic purposes and provides further insight into the dynamics of SRLV infection.

\section{Acknowledgements}

Technical assistance in flock management from Josune Arranz and Dr. Ina Beltrán de Heredia is acknowledged. This work has been funded by grants from the Spanish Ministry of Education and Science (AGL2006-13410-C06-03) and the Department of Agriculture, Fisheries and Food of the Basque Government (SEC2006011 and SED2007009). Esmeralda Minguijon salary is partially covered by the INIA program for incorporation of $\mathrm{PhD}$ graduates into agricultural research centres. Iratxe Leginagoikoa has enjoyed a fellowship from the Foundation Candido Iturriaga y Maria Dañobeitia 
IV. 1.RESUMEN 

En esta tesis doctoral se presenta una investigación sobre la epidemiología y el diagnóstico de la infección por el virus Maedi Visna en ovino, concretamente sobre la transmisión de VMV en distintos sistemas de producción y sobre el empleo de la reacción en cadena de la polimerasa (PCR) para detectar el VMV libre e integrado en células, en diversas matrices sanguíneas. Las hipótesis epidemiológicas de partida son consecuencia de resultados de estudios experimentales y epidemiológicos previos de nuestro grupo de trabajo que indican la mayor importancia de la transmisión horizontal del VMV frente a la vía lactógena en el mantenimiento de la infección en rebaños ovinos. Los resultados de esta tesis confirman dicha conclusión y mejoran el conocimiento de la transmisión del virus en rebaños ovinos. Por otro lado, las aportaciones relativas al diagnóstico también suponen un avance en la búsqueda de una metodología que maximice el éxito de detectar el virus y facilite el estudio de la infección.

El primer trabajo presenta los resultados de un estudio de transmisión horizontal del VMV en un grupo de 191 ovinos de raza Latxa sometidos a una presión de infección horizontal alta o baja. El grupo, formado por corderos de 1 año de edad con una seroprevalencia inicial de VMV de 15\% aproximadamente, se dividió en dos lotes. El lote de alta presión de infección (grupo H) incluyó a las hembras que se incorporaron como reposición a un rebaño de ovejas latxas adultas en producción lechera cuya seroprevalencia de VMV fue 42-66\%. El lote de baja presión de infección (grupo L) lo integraron corderos machos que se mantuvieron aislados de otros ovinos en una nave bien ventilada. Durante los tres años que duró el estudio se sangraron los animales cada 6 meses y se analizaron anticuerpos mediante ELISA (enzyme-linked immunosorbent assay) y secuencias de ADN de virus integrado en monocitos con una PCR de las secuencias repetitivas largas terminales (LTRPCR). Al final del experimento la seroprevalencia no varió en el grupo $L$ y fue $57 \%$ en el grupo $H$. La concordancia de los resultados de ambas técnicas medida con el coeficiente kappa, osciló con la edad entre 0,63 (buena) al año de edad y 0,94 (muy buena) a los cuatro años de edad. La seroincidencia acumulada fue máxima para el grupo $\mathrm{H}$ durante los primeros seis meses en el rebaño adulto y fue disminuyendo hasta ser nula a los cuatro años de edad. De estos resultados se deduce la importancia fundamental de la transmisión horizontal por contacto con animales infectados y su estrecha relación con el manejo y las condiciones de estabulación del rebaño. Además, el trabajo demuestra por primera vez la presencia continuada de viremia en adultos detectable mediante PCR. 
Como consecuencia de los resultados de la experiencia anterior se planteó la hipótesis que dio lugar al segundo trabajo de la tesis: "Si el contagio horizontal es clave en la infección por el VMV cabe esperar que el virus sea poco prevalente en rebaños en cría extensiva en pastoreo y potencialmente muy prevalente en rebaños en estabulación intensiva". Para confirmar esta hipótesis se planteó un estudio de prevalencia e incidencia de Maedi Visna de tres años de duración en 38 rebaños de tres sistemas de explotación ovino característicos en España: el de ovino latxo lechero en régimen semi-intensivo del País Vasco, el de de ovino Assaf lechero intensivo de Castilla-León, y el de producción de cordero Manchego cruzado en régimen extensivo en Castilla la Mancha.La encuesta serológica realizada el primer año reveló una seroprevalencia de $5 \%$ en los rebaños extensivos, $25 \%$ en los rebaños semi-intensivos y $77 \%$ en los rebaños intensivos y la seroprevalencia se correlacionó positivamente con el tiempo de estabulación. Sin embargo, se observaron variaciones en la seroprevalencia entre rebaños de un mismo sistema productivo que no se relacionaron con las características estructurales de las instalaciones estudiadas y en concreto con el área de nave abierta, considerada indicativa del grado de ventilación de la nave.

La baja o nula seroprevalencia observada en algunos rebaños extensivos, asociada a la escasa transmisión horizontal, es compatible con resultados anteriores de nuestro grupo que indican que la transmisión lactógena es incapaz por si sola de mantener el VMV en la población. El hallazgo sugiere además que muy probablemente sería sencillo y barato eliminar el virus de rebaños en producción extensiva.

Durante los dos años siguientes del trabajo anterior se investigó la incidencia de seroconversion a VMV en los rebaños intensivos y semi-intensivos y los resultados de dicho análisis dieron lugar al tercer trabajo de esta tesis. La tasa de seroconversión fue 0,09 ovejas-año en el sistema semi-intensivo latxo y 0,44 ovejas-año en el sistema intensivo Assaf. Se observó variabilidad significativa en la incidencia de seroconversion entre rebaños del mismo sistema productivo y según la edad. De este modo la incidencia fue máxima en las corderas de rebaños intensivos durante el primer año de vida y aumentó de forma gradual según la edad en rebaños semi-extensivos. En el análisis multivariable de regresión logística la seroconversión se asoció positivamente al producto de la prevalencia del rebaño y los días de estabulación y fue mayor para las hijas de madres seropositivas que para las de madres seronegativas, independientemente del modo de cría durante la lactancia, con madre seropositiva o seronegativa. Estos resultados corroboran la estrecha relación entre la seroconversión y la presión de infección horizontal en el rebaño y aportan más evidencia 
que sugiere de la existencia de un componente heredable de resistencia/susceptibilidad a la infección por el VMV. Por el contrario, en el análisis multivariable de la incidencia de seroconversión tampoco demostró asociación entre ésta y las variables relacionadas con las características estructurales de las instalaciones, ni con el modo de cría de la reposición durante la lactancia. La ausencia de relación entre las instalaciones y la incidencia de infección podría asociarse al número relativamente escaso de rebaños estudiados y a la naturaleza compleja de la ventilación que depende de factores no determinados en este estudio y que sería importante investigar. Por otro lado, otros trabajos anteriores han demostrado que en rebaños con intensa transmisión horizontal, la transmisión lactógena no aumenta significativamente el riesgo de infección en la vida del animal.

Los resultados del trabajo descritos en el capítulo 1 sugirieron que el análisis de anticuerpos anti-VMV mediante ELISA es un buen método para estudiar la infección por VMV en ovejas adultas, aunque la PCR permitió detectar algunos animales infectados y seronegativos. La mayoría de los protocolos de PCR descritos en la literatura se basan en la detección de ADN de VMV integrado en los monocitos en vez de ARN de virus libre. Además muchos asumen que la sensibilidad de la técnica mejora si la prueba se realiza en ADN de monocitos previamente separados de los hematíes. Sin embargo, apenas existen trabajos en los que se haya comparado la validez diagnóstica de protocolos de PCR con métodos de aislamiento y purificación de ADN diferentes. En el cuarto trabajo de ésta tesis se compara la sensibilidad respecto al ELISA de protocolos de PCR distintos según las secuencias de VMV objetivo, el tipo de muestra sanguínea y el método de purificación de ADN empleado. Como material de partida se escogieron 25 animales ELISA-seronegativos y 25 ELISA-seropositivos de los que se tomaron muestras de suero, coágulo sanguíneo y células blancas. Se extrajo el ADN y ARN de las muestras mediante kit comerciales de columnas de sílice y el método clásico de extracción fenólica y se analizó la presencia de virus libre (ARN) y asociado a monocitos (DNA) con las técnicas de PCR basadas en las secuencias LTR y gag del virus. En una primera selección de 10 muestras de animales seropositivos se obtuvo una mayor proporción de resultados positivos con la PCR-gag que con la PCR-LTR y en ADN de coagulo sanguíneo extraído mediante kit comercial que en otras matrices. No se detectó ADN proviral en las muestras de suero pero se detectó RNA de virus libre en un animal seropositivo. Los resultados de los análisis realizados en las muestras de los 50 ovinos confirmaron los resultados preliminares indicando un porcentaje de gag-PCR-positivos de $68 \%$ en células blancas y $92 \%$ en coágulo sanguíneo $(p<0.05)$. Esta técnica permitió detectar provirus en $25 \%$ de las muestras seronegativas y con ella se obtuvo la 
mejor correlación entre los resultados de ELISA y PCR. No existen estudios anteriores sobre el empleo de protocolos de PCR basados en ADN de coágulo sanguíneo y en esta tesis se plantean posibles razones para explicar la buena sensibilidad asociada a este protocolo. Se trata en cualquier caso de un hallazgo de clara utilidad práctica por que además de mejorar la sensibilidad de la prueba, evita la necesidad de purificar leucocitos para aislar el ADN molde y hace accesible al diagnóstico la muestra de sangre coagulada que es la de elección en las campañas de saneamiento de enfermedades ovino. 
IV. 2. SUMMARY 

This $\mathrm{PhD}$ dissertation presents an investigation of the epidemiology and diagnosis of maedivisna virus (MVV) infection, focusing on MVV transmission in specific sheep production systems and on the use of the polymerase chain reaction to detect cell-free and integrated virus in various blood fractions. The epidemiological hypothesis tested were raised following results from previous investigations by our research group indicating the greater relative importance of horizontal compared to lactogenic MVV transmission and our results confirm this finding and further improve our knowledge of MVV transmission in sheep flocks. Similarly, the results from the diagnostic experiments are an important step forward in our search for a diagnostic methodology that maximises sensitivity to detect and investigate MVV infection.

The first chapter presents results from a study of the horizontal transmission of MVV in sheep raised under high and low MVV infection pressure. A group of 191 one year-old sheep with a 15\% seroprevalence was divided into two experimental groups. The high pressure group (group $\mathrm{H}$ ) included the females, introduced as replacement sheep in an adult milking flock with a $66 \% \mathrm{MVV}$ seroprevalence, whilst the low infection group (L-group) consisted of castrated males that remained isolated from other sheep in a well ventilated barn. Sheep were blood tested and analysed for MVVantibodies and DNA sequences by ELISA and PCR, respectively, on a six-monthly basis during three years. Seroprevalence did not change in the L-group and was $57 \%$ in group $\mathrm{H}$ at the end of the experiment. The degree of agreement between diagnostic tests measured by the kappa coefficient, was 0.63 at the start of the experiment in one year-old sheep and was very good thereafter reaching a maximum 0.95 at 4 years old. Cumulative incidence of seroconversion was highest in group $\mathrm{H}$ in the six months after their introduction to the adult flock and subsequently diminished to $0 \%$ at four years old. These results confirm the efficiency of horizontal MVV transmission under high infection pressure and point out for the first time to the presence of persistent MVV viremia detected by PCR in adult sheep.

Result from the previous experiment prompted the following hypothesis: "If horizontal contagion is key in MVV infection prevalence would be expected to be low in extensively raised sheep and high in intensive housed sheep". This was tested in 38 sheep flocks from 3 important sheep production systems in Spain: permanently housed intensive Assaf dairy sheep flocks, semiintensive Latxa dairy sheep flocks and extensively raised lamb producing Manchega cross flocks. A cross-sectional survey carried out during the first year of the project indicated seroprevalence was 
$77 \%, 25 \%$ and $5 \%$, in intensive, semi-intensive and extensive flocks, respectively. However seroprevalence varied within sheep systems and this was not associated with variables related to sheep building structure including shed open area, taken as indicative of shed ventilation. The low and null seroprevalence in extensive flocks as a result of low horizontal transmission is in agreement with previous findings indicating that lactogenic transmission alone is unable to maintain the virus in the population. The low prevalence also suggests that it would be relatively simple and inexpensive to eliminate MVV from extensive flocks.

Intensive and semi-intensive flocks from the previous experiment were analysed by ELISA for two more consecutive years and this allowed to estimate seroconversion incidence which was 0.09 sheep-years in semi-intensive Latxa dairy flocks and 0.44 sheep-years in intensive Assaf dairy sheep $(p<0.05)$, as shown in chapter 3 of this theses. Incidence however, varied significantly between flocks in the same production system and with age; incidence was highest in Assaf replacement sheep following their introduction to the adult flock and increased gradually with age in semi-intensive flocks. Logistic regression models indicated that seroconversion was associated to the product of flock prevalence and housing days and was greater for the progeny of seropositive sheep compared to that of seronegative sheep, independent of mode of rearing preweaning, with a seropositive or a seronegative dam. These results confirm the close relationship between seroconversion and horizontal infection pressure and provide further evidence for the existence of an inheritable component of susceptibility/resistance to infection. In contrast, multivariable models failed to show a relationship between seroconversion and building structure or the sheep's mode of rearing preweaning. The lack of an association between seroconversion and building variables may be related to having studied few flocks and to ventilation being a complex phenomenon dependent on factors not accounted for in this study that merit further investigation. As for the absence of an association between mode of rearing preweaning and seroconversion, the result confirms those from a previous investigation which lead to the conclusion that when horizontal transmission is strong lactogenic infection does not increase significantly the overall, lifetime, risk of infection.

From the work carried out in chapter 1 it could be concluded that analysing antibodies antiMVV by ELISA is a good approach to investigating infection in adult sheep, although the PCR test allowed detecting a few infected yet seronegative sheep and this important from a control point of view. Most of the PCR tests described in the literature are designed to detect integrated MVV DNA sequences rather than free virus RNA and rely on using DNA template from previously purified white 
blood cells to maximise diagnostic sensitivity. However, there are few studies in the literature to support the need for this extra purification step. The fourth chapter of this thesis investigates the validity with respect to the ELISA, of several PCR protocols using different primers and target sequences and different sample matrices and DNA purification methods. Clotted and blood and blood with anticoagulant were collected from 25 seropositive and 25 seronegative sheep and serum, blood clot and white blood cells were extracted. RNA and DNA were purified from these samples using commercial silica-based kits and the traditional phenol extraction method and used as templates for PCRs targeting LTR and gag sequences. Preliminary results in samples from ten sheep indicated a greater proportion of gag-PCR-positive compared to LTR-PCR-positive sheep and better sensitivity using DNA purified from blood by commercial kits than otherwise. Moreover, MVV-RNA was detected in sera from one sheep in contrast, no proviral DNA was detected in serum from any of the animals. Finally, results obtained in samples from the 50 animals investigated confirmed previous results and the proportion of gag-PCR-positives was $68 \%$ when using DNA from purified white blood cells and $92 \%$ when using blood clot $(p<0.05)$. The gag-PCR in DNA from blood clot allowed detecting provirus in $25 \%$ seronegative sheep and had a better agreement with the ELISA than other PCR protocols. There are no previous studies investigating the use of PCR protocols based on DNA from blood clot and several reasons are proposed to explain the good sensitivity associated to this protocol. Whatever the reasons maybe, it's a finding with clear practical implications since in addition to increasing test sensitivity, the protocol saves purifying white blood cells and opens to the possibility of using clotted blood samples which are the most common sample obtained from sheep in official disease control programs. 

IV. 3.LABURPENA 

Doktorautza Tesi honetan, ardiengan, Maedi Visna birusaren infekzioari buruzko, epidemiologia eta diagnostikoaren inguruan egindako ikerketa aurkezten da. Zehatz mehatz, produkzio sistema ezberdinetan VMV-ren transmisioa ikertu da eta baita PCR-ren erabilera, VMV libre zein zeluletan integratutakoa detektatzeko, odol matrize ezberdinetan.

Irteerako hipotesi epidemiologikoak, gure lan taldearen aurretiko lan esperimental eta edpidemiologikoen emaitzen ondorio dira, non azpimarratzen den VMVren transmisio horizontalaren garrantzia, transmisio laktogenoarekin alderatuta, artaldeetan infekzioaren mantenitzeari dagokionez. Tesi honen emaitzek ondorio hau baieztatzen dute eta artaldeengan, birusaren transmisioaren ezagutza hobetezen dute. Bestalde, diagnostikoaren inguruko aportazioek ere aurrerapen bat suposatzen dute, birusa detektatzeko unean arrakasta areagotu dezaketen metodologia baten bilaketan eta beraz, infekzioaren ikerketa erraztuko dutena.

Lehenengo lanean, VMV-ren transmisio horizontal altu edo baxu baten eraginpean jarritako, Latxa arrazako 191 artalderengan lortutako emaitzak aurkezten dira. Taldea, \%15-eko haserako seroprebalentzia zuten urtebeteko bildotsek osatzen zuten eta bi sailetan banatu ziren. Infekzio presio altuko lotea ( $\mathrm{H}$ taldea), erreposizio gisa, esne-produkzioan zegoen artalde latxa helduekin bat sartutako emeak osatzen zuten, VMV-ren seroprebalentzia \%42-66-koa zelarik. Infekzio presio baxuko taldea ( $\mathrm{L}$ taldea), beste ardiengandik aislaturik eta ondo aireztatutako nabe batean eduki ziren bildots arrek osatzen zuten. Ikerketak iraun zuen hiru urteetan, animaliei sei hilabetero atera zitzaien odola. ELISA teknikaren bidez antigorputzak aztertu ziren eta baita monozitoetan integratutako birusaren ADN-aren sekuentziak, sekuentzia errepikakor luze terminalaren PCR baten bitartez.

Esperimentuaren amaieran, $\mathrm{L}$ taldearen seroprebalentzia ez zen aldatu, $\mathrm{H}$ taldearena aldiz \%57-ekoa izan zen. Bi tekniken emaitzen arteko bat-etortzeak, kappa koefizientearekin neurtuta, adinarekin oszilatu zuela ikusi zen, urtebetekoengan 0,63-koa (ona) eta lau urtekoengan 0,94-koa (oso ona) izan zelarik. Akumulatutako serointzidentzia maximoa izan zen $\mathrm{H}$ taldearentzat, lehenengo sei hilabeteetan artalde helduarentzat eta gutxiagotzen joan zen nulua izan arte lau urteren buruan. Emaitza hauekin, infektatutako animaliekin izandako kontaktu bidezko transmizio horizontalak duen garrantzia azpimarratzen da, artaldeen maneiu zein ukuiluratze kondizioekin duen lotura estua kontutan harturik. Gainera, lan honek lehenengo aldiz aurkezten du, PCR bidez detektagarria den biremiaren presentzia iraunkorra, ardi helduengan. 
Aurreko esperientzian lortutako emaitzen ondorio gisa, bigarren lanari lekua eman zion hipotesia planteatu zen: "Kutsatze horizontala gakoa baldin bada VMV infektatzeko, hazkuntza estentsiboan diarduten artaldeengan birusaren prebalentzia txikia izango dela espero da eta are handiagoa hazkuntza intentsiboan dauden artaldeengan". Hipotesi hau baieztatzeko, VMV-ren prebalentzia eta intzidentzia ikertuko zituen lan bat planteatu zen, hiru urtetako iraupena izango zuena, 38 artalderengan, Espainia mailan, bereizgarriak diren hiru ardi explotazio sistema ezberdinengan parte hartzen dutenengan: sistema semi-intentsiboan diarduten Euskal Herriko esneardi latxena; sistema intentsiboan, Gaztela eta Leon-en diarduten Assaf esne-ardiena eta sistema estentsiboan, Gaztela eta Mantxa-ko, Mantxako bildots gurutzatuena.

Lehenengo urtean burututako galdeketa serologikoak, artalde estentsiboengan \%5-eko seroprebalentzia zegoela ezagutzera eman zuen, \%25-ekoa artalde semi-intensiboengan eta \%77koa artalde intentsiboengan, seroprebalentzia eta ukuiluratze denbora positiboki korrelazionatzen zirela ikusi zelarik. Hala eta guztiz ere, produkzio sistema bereko artaldeengan, seroprebalentzian aldaketak nabarmendu ziren, ikertutako instalazioen ezaugarri estrukturalekin bat etzetozela ikusi zen, batipat nabe irekien eremuan, nabearen aireztatze graduarekin zuen zerikusia adierazgarria kontsideratu baitzen.

Zenbait artalde estentsiborengan nabarmendu zen seroprebalentzia baxua edo nulua, transmisio horizontal eskasarekin lotuta, gure lan taldeak lortutako emaitzekin bat dator, transmisio laktogenoa bere kabuz soilik, populazioan VMV mentenitzeko gai ez dela ondorioztatzean. Aurkikuntza honek, gainera, aditzera ematen du, beharbada errazagoa eta merkeagoa litzatekeela birusa produkzio estentsiboan dagoen artaldeengandik kanporatzea.

Aurreko lanaren ondorengo bi urteetan, artalde intentsibo eta semi-intensiboengan VMV-ren serokonbertsioaren intzidentzia ikertu zen, eta analisi horren emaitzek Tesi honen hirugarren lana osatu zuten. Serokonbertsio tasa 0,09 ardi/urtekoa izan zen artalde latxa semi-intentsiboengan eta 0,44 ardi/urtekoa sistema intentsiboan ziarduten Assaf ardiengan. Aldakortasun adierazgarria nabarmendu zen adinaren arabera eta produkzio sistema bereko artaldeengan, serokonbertsio intzidentziari dagokionez. Honela, intzidentzia maximoa izan zen sistema intentsiboko urtebeteko bildots emeengan eta gradualki haundiagotzen joan zen sistema semi-estentsiboetako ardien adinarekin bat. Erregresio logistikoaren analisi multibariablearen bitartez, serokonbertsioa positiboki erlazionatu zen artaldearn prebalentziaren produktuarekin eta ukuiluratze egunekin eta handiagoa 
izan zen ama seropositiboen alabentzat, ama seronegatiboekin alderatuta, edoskitze garaian izandako hazkuntza motatik at, ama seropositbo zein seronegativo. Emaitza hauek, serokonbertsioaren eta artaldean dagoen infekzio horizontalaren presioaren arteko lotura estua baieztatzen dute eta VMV-ren infekzioarekiko erresistentea/sentikorra den osagai heredagarri baten existentzia nabarmentzen dute. Bestalde, serokonbertsio intzidentziaren analisi multibariableetan, etzen baieztatu inongo loturarik, honen eta eraikinen ezaugarri estrukturalen bariableen artean, ezta ere edoskitze garaiko hazkuntza motarekin ere ez. Eraikin eta infekzio intzidentziaren arteko lotura falta hori, ikertutako artalde kopuru txikiarekin bat datorrela esan daiteke eta baita aireztatze mota konplexuarekin, lan honetan zehaztu ez diren zenbait faktoreren menpe daudelarik, baina hauek ikertzea garrantzitsua izango litzatekeelarik. Bestalde, aurretiko zenbait lanetan baieztatu dute, transmisio horizontal handiko artaldeengan, animaliaren bizitzan zehar, transmisio laktogenoa era esanguratsuan ez dela areagotzen.

Lehenengo kapituluan aurkezten diren emaitzek zera iradokitzen dute: ELISA bitartez aztertutako anti-VMV antigorputzen analisia metodo on bat dela ardi helduengan VMV-ren infekzioa ikusteko, nahiz eta PCR-aren bitartez, infektatuta zeuden zenbait animalia seronegatibo detektatu ziren. Litertaturan deskribatzen diren PCR-ren protokolo gehienak, monozitoetan integraturik dagoen VMV-ren ADN-a detektatzen saiatzen dira, birus librearen ARN-a detektatu ordez. Gainera, askok bere gain hartzen dute, teknikaren sentsibilitatea areagotu egiten dela baldin eta proba, hematiengandik separatuta dagoen monozitoen ADN-rengan egiten bada. Dena den, gutxi dira lanak, ADN ezberdinen isolamendu eta purifikaziorako PCR protokoloen baliogarritasuna baieztatzen dutenak. Tesi honen laugarren lanean, ELISA-ren eta PCR-aren arteko sentsiblitatea konparatzen da. PCR-ari dagokionez, VMV-ren sekuentzia ezberdinak, odol lagin mota eta ADN-aren purifikaziorako erabilitako metodo ezberdinak kontutan hartuaz. Lagin gisa 25 animalia ELISAseronegatibo eta beste 25 animalia ELISA-seropositiboren odola, koagulua eta zelula zuriak hartu ziren. Lagin hauetatik ADN-a eta ARN-a atera ziren, kit komertzialak zekartzan silizesko zutabeak erabiliaz eta extrakzio fenolikoaren metodo klasikoa aplikatuz. Honela, birus librearen (ARN) eta monozitoei lotutakoaren (ADN) presentzia ikertu zen, birusaren LTR eta gag sekuentzietan oinarritutako PCR baten bitartez. Lehendabizi hautatutako 10 animalia seropositiboren laginak aztertu ondoren, emaitza positibo gehiago detektatu ziren PCR-gag-arekin PCR-LTR-arekin baino, era berean, koaguluetatik kit komertzialen bidez ateratako ADN laginetatik lortu ziren emaitza positibo gehiago. Serum laginetan etzen detektau birusaren DNA-a, nahiz eta animlia 
seropositiboarengan birus librearen ARN-a detektatu zen. 50 ardirengan egindako analisien emaitzek, lortutako emaitza horiek baieztatu zituzten, zelula zurietan \%68-ko PCR-gag bidezko emaitza positiboak eta koaguluetan \%92-koa lortuaz $(p>0,05)$. Teknika honen bitartez, lagin seronegatiboen \%25ek probirusa zutela detektatu zen, ELISA eta PCR-ren emaitzen arteko korrelaziorik onena lortuaz. Odol koaguluen ADN-an oinarritzen diren PCR protokoloen erabilera deskribatzen duen lanik ez da existitzen eta tesi honetan, metodo honen sentsibilitate ona erakusten duten zenbait arrazoi posible planteatzen dira. Praktikotasun handiko aurkikuntza da, izan ere, sentsibilitatea hobetzeaz gain, ADN-a isolatzeko leukozitoak purifikatzeko beharra saihesten du eta diagnostikoari begira, odol koagulua lagin eredugarri gisa kokatzen $\mathrm{du}$, ardien saneamendu kanpainetan gertatzen den bezala. 
V. DISCUSIÓN GENERAL 

La importancia relativa de la transmisión horizontal en el Maedi Visna ya descrita anteriormente (Palsson 1976, De Boer et al. 1979, Houwers et al. 1987b, Houwers 1990, Berriatua et al. 2003, Alvarez et al. 2005) se confirma cuantitativamente en los estudios presentados en esta tesis.

En el primero de los trabajos de esta tesis se describe por primera vez situaciones de alta y baja incidencia de transmisión horizontal en ganado estabulado, asociadas a presiones de infección altas y bajas, respectivamente. A la vez de corroborar la eficacia de la transmisión horizontal este resultado plantea incógnitas sobre los mecanismos y condiciones necesarias para que esta forma de transmisión tenga lugar. La baja o nula tasa de infección descrita en los rebaños extensivos del segundo trabajo demuestra que efectivamente es necesaria la estabulación durante largos periodos de tiempo para que la transmisión horizontal tenga lugar. El cuarto de los trabajos aporta evidencia epidemiológica de la necesidad de un contacto estrecho entre animales para que ocurra el contagio horizontal y de que el contacto indirecto a través de aerosoles es posiblemente poco eficaz en la transmisión del virus. Sería de gran interés llevar acabo estudios experimentales para poder confirmar este hallazgo y valorar los modos y mecanismos precisos asociados al contagio horizontal entre animales mantenidos en el mismo corral. En este sentido es de gran interés la posibilidad actual de de detectar virus en una variedad de matrices incluidos los aerosoles como se está llevando a cabo en nuestro laboratorio Es de gran interés también el descubrimiento de diferentes matrices de alta utilidad diagnóstica como es el coagulo sanguíneo frente a la sangre con anticoagulante y la posibilidad de detectar el virus a través de muestras de aerosoles como se está llevando a cabo en nuestro laboratorio.

Las diferencias significativas encontradas en los valores de seroconversión en los dos grupos estudiados dentro de un mismo rebaño en el primer trabajo se relacionan con diferentes factores entre los que destaca la utilización de un manejo diferente y la exposición a diferentes presiones de infección. Ambos grupos, al inicio del estudio con un año de edad, presentaron una prevalencia similar cercana al 15\%; en el grupo de los machos solo seroconvirtió un animal, sin embargo las hembras pasaron a una prevalencia del $57 \%$ a los tres años de edad, la incidencia de seroconversión en este grupo fue máxima a los seis meses de la incorporación al rebaño adulto disminuyendo progresivamente hasta los cuatro años de edad. La eficacia del contacto horizontal reflejada en la incidencia de seroconversión se presenta en edades mas tempranas que en los estudios descritos anteriormente (Adams et al. 1983, Robinson et al. 1986, Berriatua et al. 2003) 
probablemente por que el ELISA y la PCR permiten detectar la infección en fases previas a las que lo hace la IDGA utilizado en estos estudios. Otro factor que puede influir en las diferencias de seroconversión es el sexo ya discutido en otros estudios (Simmard et al. 1991, Ayelet et al. 2001, Arsenault et al. 2003) pero que también se atribuye a los diferentes manejos utilizados con machos y hembras. El hecho de que la edad media de los machos infectados sea menor que la de las hembras puede ser un factor que favorezca la transmisión horizontal ya que el riesgo de infección de los corderos es mayor cuando se exponen a ovejas infectadas durante más tiempo que cuando se exponen a las que se han infectado recientemente. (Sihvonen 1980, Radostits et al. 2000).También el estrés productivo al que se someten las ovejas lecheras podría favorecer la infección tanto por una mayor excreción del virus por parte de las ovejas infectadas como por una mayor susceptibilidad para infectarse como consecuencia a una respuesta inmune debilitada, hecho que aún no se ha conseguido relacionar directamente. El riesgo de seroconversión al año de edad fue independiente de haber tenido algún resultado PCR positivo durante los muestreos realizados en el primer año de vida probablemente por que haya animales infectados que presenten una seroconversión tardía (Sihvonen 1980, Houwers et al. 1987b, Rimstad et al. 1993). La correlación entre el ELISA y la PCR fue muy buena y mucho mejor que la observada en los primeros seis meses de vida (Alvarez et al. 2006) lo que sugiere que la viremia asociada a células aumenta con la edad y el ELISA recombinante utilizado presenta una sensibilidad similar a la LTR-PCR pudiendo utilizarse como método diagnóstico de rutina en estudios epidemiológicos en ovejas adultas.

En el estudio de seroprevalencia frente al MV realizado en tres sistemas de explotación ovina diferentes en España se demuestra la importancia del contacto estrecho y del manejo en la transmisión de la enfermedad, observándose una correlación positiva entre los días que se estabulan al año las ovejas y la seroprevalencia del rebaño adulto. No se ha podido cuantificar la importancia relativa de la transmisión lactógena por el contacto estrecho que mantienen los corderos con sus madres salvo en un rebaño de ovejas Assaf que se amamantaron con calostro ovino y lactoreemplazante y que presentaron una prevalencia al año de edad del $20 \%$ muy similar a la atribuida a la ingestión de calostro de forma natural en estudios experimentales previos realizados en Neiker (Alvarez et al. 2005). Estos resultados demuestran en condiciones de campo que la transmisión lactógena por si sola es insuficiente para mantener la infección.Esto es así porque pese a que en los rebaños extensivos los corderos están más tiempo en contacto con las madres y se destetan más tarde, el tiempo de estabulación anual de las ovejas adultas es mucho menor por lo 
que la transmisión horizontal resulta poco eficiente y no permite la extensión de la infección.Por el contrario, en los rebaños intensivos las diferencias en los valores de seroprevalencia de los corderos de un año de edad están relacionadas con el tipo de manejo hasta su destete, pero tras mantenerse el primer año con el resto de ovejas la prevalencia aumenta significativamente igualándose prácticamente a la prevalencia del rebaño adulto. Las diferencias en los valores de seroprevalencia observadas entre los rebaños dentro de un mismo sistema productivo sugieren que existen otros factores que influyen en la transmisión del MV que no se han tenido en cuenta en el estudio, tanto relacionados con el manejo, como con algún componente genético de resistencia-susceptibilidad relacionado con ciertas líneas familiares ya sugerido anteriormente (Houwers 1990) y que necesita estudiarse en mayor profundidad.

Las medidas de control que se basan en la eliminación de animales seropositivos y reemplazo con animales seronegativos son fácilmente aplicables a los rebaños de los sistemas extensivos de cruces de Manchega y semi-intensivo de oveja Latxa e incluso también en rebaños con prevalencias moderadas en el sistema intensivo Assaf.

El problema se presenta en los rebaños con prevalencias muy altas, superiores al $80 \%$, donde es difícil obtener reposición a partir de madres seronegativas y en los que la alternativa pasa por la compra de animales libres de la enfermedad lo que parece bastante difícil de encontrar dentro de este sistema productivo, pero la confirmación epidemiológica de la existencia de un componente genético de susceptibilidad y resistencia a la seroconversión (capítulo 3) permite plantear la posibilidad de alcanzar un control satisfactorio del VMV mediante la cría selectiva de animales resistentes a la infección y al desarrollo de la enfermedad, por lo que es interesante seguir investigando para conocer si existen genotipos relacionados con la resistencia y susceptibilidad a la infección.

El análisis de la incidencia de seroconversión frente a MV en rebaños lecheros intensivos y semi-intensivos demostró la asociación positiva con el tiempo de estabulación y el contacto con animales infectados sobre todo en corderos de reposición de un año de edad sugiriendo que estos sean más susceptibles a infectarse que los animales adultos.

En los corderos que se criaron con sus madres, el tipo de manejo antes del destete no tuvo mucha importancia sobre los valores de seroconversión de la reposición al entrar en el rebaño adulto, probablemente por que la mayoría de los corderos se infectan durante el primer año de vida a través del calostro y por el contacto con la madre sobre todo en los rebaños de prevalencia alta 
donde la presión de infección es mayor. Sin embargo este índice fue muy alto para los corderos que tomaron calostro de madres seronegativas y que no mantuvieron contacto con otras ovejas adultas durante el primer año. El producto del tiempo de estabulación y la seroprevalencia del rebaño utilizado para conocer la importancia relativa de la transmisión horizontal después del destete en corderos que se estabulan en la misma nave en cubículos diferentes no mostró relación entre las variables reflejando poca eficiencia en la transmisión por vía aerógena lo que hace necesario un estudio mas a fondo sobre el tema, en particular profundizando en la determinación de la presencia del virus y la cuantificación del mismo en el ambiente. En el estudio realizado en el sistema ovino de Aragón (Perez et al. 2009) se relacionó la seroprevalencia con la razón entre las variables días de estabulación y área abierta de la nave, la cual representa el grado de confinamiento de los animales. En nuestros trabajos no se ha conseguido relacionar las variables relativas a las instalaciones con la prevalencia e incidencia del rebaño, tal vez por que el número de rebaños utilizados no ha sido suficiente y por que las seroprevalencias en el sistema intensivo Assaf son muy elevadas. Seria por ello necesario seguir investigando sobre los factores ambientales asociados a las instalaciones como por ejemplo el grado de ventilación necesaria que minimicen la posibilidad de transmisión aerógena.

El hecho que la raza sea un factor que favorezca la infección ha sido muy discutido, en nuestros estudios las diferencias de seroprevalencia observadas en las razas estudiadas están íntimamente relacionadas con el sistema productivo y el manejo utilizado así que no podemos determinar la importancia de este factor en la infección del MV.

Aunque en nuestros trabajos se ha observado una relación positiva de los valores de densidad óptica del ELISA con la seroprevalencia del rebaño y la edad de los animales que sugiere que podría utilizarse como medida indirecta de la infección del rebaño, el uso del ELISA como técnica de diagnóstico de rutina presenta limitaciones en los casos en los que se presenta seroconversión tardía o en los que ésta no se llega a producir (De Andres et al. 2005). Se ha demostrado que la combinación con técnicas moleculares como la PCR es una estrategia eficaz para la detección de la infección del MV (De Andres et al. 2005, Gil et al. 2006, Brinkhof et al. 2010).La muestra mas utilizada en los estudios de PCR realizados ha sido tradicionalmente la de leucocitos de sangre periférica separados de los eritrocitos y del plasma. Sin embargo, en nuestro trabajo se demuestra que el coagulo sanguíneo es la matriz más eficiente para la detección de la infección del MV, ya que permite detectar mayor número de positivos y obtener mejores valores de concordancia ente el ELISA y la PCR que la muestra de linfocitos de sangre periférica en las tres 
PCR utilizadas. Además, presenta incluso mayor sensibilidad que el ELISA utilizado ya que, mediante la variante gag-PCR, detecta la infección incluso en animales seronegativos. De los trabajos publicados hasta el momento algunos obtienen mejores resultados utilizando como secuencia diana la LTR (Zanoni et al. 1992, Extramiana et al. 2002, Angelopoulou et al. 2006a) y otros con la gag (Zanoni et al. 1990a, Reddy et al. 1993, Brinkhof et al. 2008). En concreto, en nuestro caso, la gag-PCR en coagulo sanguíneo se mostró capaz de detectar provirus en mayor numero de animales seropositivos que la LTR y proporciono mejores resultados de concordancia con el ELISA que podrían explicarse porque en la secuencia gag se encuentran las proteínas inmunógenas que se utilizan para el diagnóstico serológico.

Los LVPR tienen tropismo por las células de la línea monocito-macrófago y el hecho de que se obtengan mejores resultados en coagulo sanguíneo que en linfocitos de sangre periférica (Narayan et al. 1983, Gendelman et al. 1985) puede ser por que los monocitos se activen en la cascada de coagulación estimulando la expresión vírica (Kumar et al. 2008). Si esto fuese así habría que esperar un aumento de la cantidad de virus libre. Puesto que esto no se ha observado en nuestro ensayo cabría pensar la RT-PCR utilizada todavía tiene una limitada sensibilidad. Una observación interesante de estas investigaciones es que por primera vez se ha detectado virus libre en el suero sanguíneo. El hecho de que la frecuencia de detección haya sido baja concuerda con la baja cantidad de virus libre que caracteriza a los LVPR (Brodie et al. 1992). Aún así, este trabajo puede tener una gran importancia práctica en tanto en cuanto que demuestra que se puede utilizar una misma muestra para la detección de anticuerpos y de virus sobre todo en aplicación a campañas de saneamiento para la erradicación de la enfermedad suponiendo una reducción del gasto en la toma de muestras y en el trabajo laboratorial.

Como resultado de los diferentes trabajos realizados en esta Tesis Doctoral se han podido concretar perfilar mejor diferentes aspectos del diagnóstico, la epidemiología y el control del Maedi Visna generándose hipótesis y cuestiones que abren nuevas puertas para continuar investigando sobre esta enfermedad. 

VI. CONCLUSIONES GENERALES 

1- La tasa de seroconversión anual en ganado sometido ambientes de alta prevalencia es comparativamente alta durante el primer año de contacto y se reduce posteriormente hasta ser nula a los cuatro años de edad.

2- La estrecha correlación entre los resultados de PCR y ELISA a partir del año de edad indica que la viremia es un fenómeno muy frecuente en animales adultos con infección subclínica.

3- La demostración por primera vez de la presencia de virus libre en suero indica que la viremia no va ligada exclusivamente a células con virus integrado.

4- La estrecha relación entre la seroprevalencia y el sistema productivo confirman epidemiológicamente la importancia fundamental de la transmisión horizontal del VMV como un efecto de las diferencias en tiempo y condiciones de estabulación frente a la similitud de encalostramiento y lactancia en todos los sistemas.

5- Las diferencias de seroprevalencia en rebaños del mismo sistema productivo sugieren que la transmisión horizontal no solo depende del tiempo de estabulación y que otros factores de manejo podrían jugar un papel fundamental en la transmisión del virus.

6- La elevada tasa de infección en progenie amamantada con calostro procedente de ovejas infectadas confirma resultados previos sobre la eficacia de la transmisión lactógena en determinadas circunstancias.

7- La asociación positiva entre la seroconversión y el estado serológico materno independientemente del modo de cría durante la lactancia, similar a la observada en un estudio epidemiológico anterior, refuerza la hipótesis de la existencia de un componente genético de susceptibilidad y resistencia a la infección. 
8- El coágulo sanguíneo es la muestra de elección para el diagnóstico virológico porque proporciona la sensibilidad más alta en las pruebas de PCR y porque su utilización reduce el trabajo de toma de muestras y de laboratorio. 
VII. BIBLIOGRAFIA 

Abril F, Alpuente P, Ramo A, Ruz JM y Adeva R. 2004. Estudio serológico del Visna-Maedi en las razas ovinas: Rasa Aragonesa, Ojinegra, Cartera y Maellana, en la provincia de Teruel y comparación de las pruebas de diagnóstico serológico entre IDGA y ELISA. XXIX Jornadas Cientificas VIII Internacionales de la Sociedad Española de Ovinotecnia y Caprinotecnia (SEOC). Lleida. Septiembre. 2004.

Abril-Galve F, Lozano-Tena MF y Martinez-Orte E. 1994. Estudio epidemiológico de la enfermedad Visna-Maedi en el ganado ovino. Mundo Ganadero, 2:46-50.

Adams DS, Klevjer-Anderson P, Carlson JL, McGuire TC y Gorham JR. 1983. Transmission and control of caprine arthritis-encephalitis virus. Am J Vet Res, 44(9):1670-5.

Agnarsdottir G, Thorsteinsdottir H, Oskarsson T, Matthiasdottir S, St Haflidadottir B, Andresson OS y Andresdottir $V$. 2000. The long terminal repeat is a determinant of cell tropism of maedi-visna virus. $J$ Gen Virol, 81(Pt 8):1901-5.

Alba A, Allepuz A, Serrano E y Casal J. 2008. Seroprevalence and spatial distribution of maedi-visna virus and pestiviruses in Catalonia (Spain). Small Rum Res, 78:80-6.

Ali Al Ahmad MZ, Chebloune Y, Bouzar BA, Baril G, Bouvier F, Chatagnon G, Leboeuf B, Pepin M, Guibert JM, Russo P, Manfredi E, Martin J y Fieni F. 2007a. Lack of risk of transmission of caprine arthritis-encephalitis virus (CAEV) after an appropriate embryo transfer procedure. Theriogenology, 69(4):408-15.

Ali Al Ahmad MZ, Fieni F, Martignat L, Chatagnon G, Baril G, Bouvier F y Chebloune Y. 2005. Proviral DNA of caprine arthritis encephalitis virus (CAEV) is detected in cumulus oophorus cells but not in oocytes from naturally infected goats. Theriogenology, 64(7):1656-66.

Ali Al Ahmad MZ, Fieni F, Pellerin JL, Guiguen F, Cherel Y, Chatagnon G, Bouzar AB y Chebloune Y. 2007b. Detection of viral genomes of caprine arthritis-encephalitis virus (CAEV) in semen and in genital tract tissues of male goat. Theriogenology, 69(4):473-80.

Alvarez V. 2005. Estudio epidemiológico y experimental de la transmisión y control del virus MaediVisna en ovino lechero de raza Latxa del País Vasco. Tesis Doctoral. Facultad de VeterinariaUniversidad de León.

Alvarez V, Arranz J, Daltabuit-Test M, Leginagoikoa I, Juste RA, Amorena B, De Andres D, Lujan L, Badiola JJ y Berriatua E. 2005. Relative contribution of colostrum from Maedi-Visna virus (MVV) infected ewes to MVV-seroprevalence in lambs. Res Vet Sci, 78(3):237-43.

Alvarez V, Daltabuit-Test M, Arranz J, Leginagoikoa I, Juste RA, Amorena B, De Andres D, Lujan L, Badiola JJ y Berriatua E. 2006. PCR detection of colostrum-associated Maedi-Visna virus (MVV) infection and relationship with ELISA-antibody status in lambs. Res Vet Sci, 80(2):226-34. 
Ameztoy JM, Santamaría C y Muñoz P. 1998. Seroprevalencia de maedi-visna en explotaciones ovinas del centro y sur de Navarra. Medicina Veterinaria, 15(1):28-31.

Amorena B, Monleón E, Pacheco C, Pérez M, Monzón M, Gracia E y Rota C. 1997. Tendencias actuales en los métodos de diagnóstico de interés epidemiológico. Med Vet, 14(5):305-18.

Anderson BC, Bulgin MS, Scott-Adams D y Duelke B. 1985. Firm udder in periparturient ewes with lymhocitic accumulations, retrovirus infection, and milk unavailable at the teat. $J$ Am Vet Med Assoc, 186(4):391-3.

Anderson RM y May RM. 1992, Infectious Diseases of Humans: dynamics and control. Second edition Oxford University Press.Oxford, United Kingdom.

Andresdottir V, Skraban R, Matthiasdottir S, Lutley R, Agnarsdottir G y Thorsteinsdottir H. 2002. Selection of antigenic variants in maedi-visna virus infection. $J$ Gen Virol, 83(Pt 10):2543-51.

Angelopoulou K, Brellou GD, Greenland T y Vlemmas I. 2006a. A novel deletion in the LTR region of a Greek small ruminant lentivirus may be associated with low pathogenicity. Virus Res, 118(1-2):17884.

Angelopoulou K, Brellou GD y Vlemmas I. 2006b. Detection of maedi-visna virus in the kidneys of naturally infected sheep. J Comp Pathol, 134(4):329-35.

Angelopoulou K, Poutahidis T, Brellou GD, Greenland T y Vlemmas I. 2007. A deletion in the R region of long terminal repeats in small ruminant lentiviruses is associated with decreased pathology in the lung. Vet $J, 175(3): 346-55$.

Arsenault J, Dubreuil P, Girard C, Simard C y Belanger D. 2003. Maedi-visna impact on productivity in Quebec sheep flocks (Canada). Prev Vet Med, 59(3):125-37.

Artigas C, Vendrell JP y Mejías JM. 1999. Estudio seroepidemiológico frente a Chlamydiosis, Visna Maedi y Toxoplasmosis en 64 rebaños de la sierra norte de Sevilla. XXIV Jornadas Cientificas,III Internacionales de la Sociedad Española de Ovinotecnia y Caprinotecnia.(SEOC). Soria. 1999.

Ayelet G, Roger F, Tibbo M y Tembely S. 2001. Survey of maedi-visna (MV) in ethiopian highland sheep. Vet J, 161(2):208-10.

Barlough J, East NE, Rowe JD, van Hoosear K, DeRock E, Bigornia L y Rimstad E. 1994. Doublenested polymerase chain reaction for detection of Caprine Arthritis-Encephalitis Virus proviral DNA in blood, milk, and tissues of infected goats. J Virol Methods, 50(1-3):101-13.

Barros SC, Andresdottir V y Fevereiro M. 2005. Cellular specificity and replication rate of Maedi Visna virus in vitro can be controlled by LTR sequences. Arch Virol, 150(2):201-13. 
Barros SC, Ramos F, Duarte M, Fagulha T, Cruz B y Fevereiro M. 2004. Genomic characterization of a slow/low maedi visna virus. Virus Genes, 29(2):199-210.

Benavides J, Fuertes M, Garcia-Pariente C, Ferreras MC, Garcia Marin JF y Perez V. 2006a. Natural cases of visna in sheep with myelitis as the sole lesion in the central nervous system. J Comp Pathol, 134(2-3):219-30.

Benavides J, Garcia-Pariente C, Carmen FM, Fuertes M, Francisco Garcia-Marin J y Perez V. 2006b. Diagnosis of clinical cases of the nervous form of Maedi-Visna in 4- and 6-month-old lambs. Vet $\mathrm{J}$, 174(3):655-8.

Benavides J, Gomez N, Gelmetti D, Ferreras MC, Garcia-Pariente C, Fuertes M, Garcia-Marin JF y Perez V. 2006c. Diagnosis of the nervous form of Maedi-Visna infection with a high frequency in sheep in Castilla y Leon, Spain. Vet Rec, 158(7):230-5.

Berriatua E, Alvarez V, Extramiana AB, Gonzalez L, Daltabuit-Test M y Juste RA. 2003. Transmission and control implications of seroconversion to Maedi-Visna virus in Basque dairy-sheep flocks. Prev Vet Med, 60(4):265-79.

Biescas E. 2006. Contribución al estudio serológico, lesional, diagnóstico y preventivo del Maedi Visna ovino. Tesis Doctoral. Facultad de Veterinaria-Universidad de Zaragoza.

Biescas E, Lujan L, Cáncer J, Perez M, Bolea R, Bernal MC, Abril F, Malo JM y Badiola JJ. 2004. Campaña de sondeo serológico y control del Maedi-Visna en Aragón: resultados 2002-2003. XXIX Jornadas Cientificas VIII Internacionales de la Sociedad Española de Ovinotecnia y Caprinotecnia.(SEOC) Lleida. Septiembre. 2004..

Biescas E, Preziuso S, Bulgin MS y DeMartini JC. 2005. Ovine lentivirus-associated leucomyelitis in naturally infected North American sheep. J Comp Pathol, 132(2-3):107-16.

Bird P, Blacklaws BA, Reyburn HT, Allen D, Hopkins J, Sargan DR y Mc-Connell I. 1993. Early events in immune evasion by the lentivirus Maedi-Visna ocurring within infected lymphoid tissue. $J$ Virol, 67(9):5187-97.

Bird P, Reyburn HT, Blacklaws BA, Allen D, Nettleton P, Yirrell DL, Watt N, Sargan DR y McConnell I. 1995. The restricted IgG1 antibody response to maedi visna virus is seen following infection but not following immunization with recombinant gag protein. Clin Exp Immunol, 102(2):274-80.

Biront $P$ y Deluyker H. 1985. Control programme for maedi/visna in Belgium. En: Sharp, J. M. y HoffJorgensen R. editor. Slow Viruses in Sheep, goats and cattle. pp. 123-6. Commission of the European Communities. Luxembourg. 
Blacklaws BA, Berriatua E, Torsteinsdottir S, Watt NJ, De Andres D, Klein D y Harkiss GD. 2004. Transmission of small ruminant lentiviruses. Vet Microbiol, 101(3):199-208.

Blacklaws BA, Bird P, Allen D y McConnell I. 1994. Circulating cytotoxic T lymphocyte precursors in maedi-visna virus-infected sheep. J Gen Virol, 75 ( Pt 7):1589-96.

Bolea R. 1998. Estudios de la presencia del virus Maedi-Visna en la glándula mamaria ovina. Tesis Doctoral.Facultad de Veterinaria- Universidad de Zaragoza.

Bolea R, Monleon E, Carrasco L, Vargas A, De Andres D, Amorena B, Badiola JJ y Lujan L. 2006. Maedi-visna virus infection of ovine mammary epithelial cells. Vet Res, 37(1):133-44.

Boriskin Y, Booth JC, Fernando S, Carrington D, Evans MR, Hay P y Coates AR. 1995. The detection of HIV-1 proviral DNA by PCR in clotted blood specimens. J Virol Methods, 52(1-2):87-94.

Boshoff CH, Dungu B, Williams R, Vorster J, Conradie JD, Verwoerd DW y York DF. 1997. Detection of Maedi-Visna virus antibodies using a single fusion transmembrane-core p25 recombinant protein ELISA and a modified receiver-operating characteristic analysis to determine cut-off values. $J$ Virol Methods, 63(1-2):47-56.

Brahic M y Haase AT. 1981. Lentivirinae:Maedi/Visna virus group infections. Comparative diagnosis of viral diseases. Academic Press.

Braun U, Camenzind D, Meli M, Boni J y Ossent P. 2001. Clinical findings and diagnostic procedure in a dairy sheep with visna. Schweiz Arch Tierheilkd, 143(11):550-3.

Brinkhof JM, Moll L, van Maanen C y Houwers DJ. 2010. Use of serology and polymerase chain reaction for the rapid eradication of small ruminant lentivirus infections from a sheep flock: A case report. Res Vet Sci, 88(1):41-3.

Brinkhof JM y van Maanen C. 2007. Evaluation of five enzyme-linked immunosorbent assays and an agar gel immunodiffusion test for detection of antibodies to small ruminant lentiviruses. Clin Vaccine Immunol, 14(9):1210-4.

Brinkhof JM, van Maanen C, Wigger R, Peterson K y Houwers DJ. 2008. Specific detection of small ruminant lentiviral nucleic acid sequences located in the proviral long terminal repeat and leader-gag regions using real-time polymerase chain reaction. J Virol Methods, 147(2):338-44.

Brodie SJ, De la Concha-Bermejillo A, Koeing G, Snowder GD y DeMartini JC. 1994. Maternal factors associated with prenatal transmission of Ovine Lentivirus. J Infect Dis, 169(3):653-7. 
Brodie SJ, De la Concha-Bermejillo A, Snowder GD y Demarquest J. 1998. Current concepts in the epizootiology, diagnosis, and economic importance of ovine progressive pneumonia in North America: A review. Small Rum Res, 27(1):1-17.

Brodie SJ, Marcom KA, Pearson LD, Anderson BC, De la Concha-Bermejillo A, Ellis JA y DeMartini JC. 1992. Effects of virus load in the pathogenesis of lentivirus-induced lymphoid interstitial pneumonia. J Infect Dis, 166(3):531-41.

Brodie SJ, Pearson LD, Snowder GD y DeMartini JC. 1993. Host-virus interaction as defined by amplification of viral DNA and serology in lentivirus-infected sheep. Arch Virol, 130(3-4):413-28.

Brodie SJ, Pearson LD, Zink MC, Bickle HM, Anderson BC, Marcom KA y DeMartini JC. 1995. Ovine lentivirus expression and disease. Virus replication, but not entry, is restricted to macrophages of specific tissues. Am J Pathol, 146(1):250-63.

Brulisauer F, Vogt HR, Perler L y Rufenacht J. 2005. Risk factors for the infection of Swiss goat herds with small ruminant lentivirus: a case-control study. Vet Rec, 157(8):229-33.

Bulgin MS. 1990. Ovine Progressive Pneumonia,Caprine Arthritis-Encephalitis, and related Lentiviral diseases of sheep and goats. Vet Clin North Am Food Anim Pract, 6(3):691-704.

Callan RJ y Garry FB. 2002. Biosecurity and bovine respiratory disease. Vet Clin North Am Food Anim Pract, 18(1):57-77.

Caporale VP, Lelli R y Rutili D. 1985. Isolation of Visna.Maedi virus from the choroid plexus of an apparently healthy sheep in Italy. Vet Res Commun, 9:115-22.

Capucchio MT, Sanna E, Sanna MP, Farigu S, Minelli R y Guarda F. 2003. Maedi-visna virus detection in ovine third eyelids. J Comp Pathol, 129(1):37-43.

Carey N y Dalziel RG. 1993. The biology of maedi-visna virus--an overview. Br Vet J, 149(5):437-54.

Carrozza ML, Mazzei M, Bandecchi P, Arispici M y Tolari F. 2003. In situ PCR-associated immunohistochemistry identifies cell types harbouring the Maedi-Visna virus genome in tissue sections of sheep infected naturally. J Virol Methods, 107(2):121-7.

Carruth LM, Hardwick JM, Morse BA y Clements JE. 1994. Visna virus Tat protein: a potent transcription factor with both activator and suppressor domains. J Virol, 68(10):6137-46.

Celer V, Jr., Zanoni RG y Peterhans E. 1993. Comparison of various antigens in the diagnosis of caprine arthritis-encephalitis virus using the ELISA test. Vet Med (Praha), 38(4):237-44. 
Celer VJ, Celer V, Nejedla E, Bertoni G, Peterhans E y Zanoni RG. 2000. The detection of proviral DNA by semi-nested polymerase chain reaction and phylogenetic analysis of Czech Maedi-Visna isolates based on gag gene sequences. $J$ Vet Med B Infect Dis Vet Public Health, 47(3):203-15.

Chebloune Y, Sheffer D, Karr BM, Stephens E y Narayan O. 1996. Restrictive type of replication of ovine/caprine lentiviruses in ovine fibroblast cell cultures. Virology, 222(1):21-30.

Cheevers WP, Beyer JC y Hotzel I. 2001. Plasmid DNA encoding caprine interferon gamma inhibits antibody response to caprine arthritis-encephalitis virus (CAEV) surface protein encoded by a coadministered plasmid expressing CAEV env and tat genes. Vaccine, 19(23-24):3209-15.

Cheevers WP, Snekvik KR, Trujillo JD, Kumpula-McWhirter NM, Pretty On Top KJ y Knowles DP. 2003. Prime-boost vaccination with plasmid DNA encoding caprine-arthritis encephalitis lentivirus env and viral SU suppresses challenge virus and development of arthritis. Virology, 306(1):116-25.

Chomczynski P y Sacchi N. 1987. Single-step method of RNA isolation by acid guanidinium thyocianate-phenol-chloroform extraction. Anal Biochem, 162:156-9.

Christodoulopoulos G. 2005. Mik production and milk fat content in commercial Karagouniko breed flocks infected by Maedi in Greece. Proceedings of the Sixth International Sheep Veterinary Congress, pp. 344-5.

Christodoulopoulos G. 2006. Maedi-Visna: Clinical review and short reference on the disease status in Mediterranean countries. Small Rum Res, 62(1-2):47-53.

Clements JE, Gdovin SL, Montelaro RC y Narayan O. 1988. Antigenic variation in lentiviral diseases. Ann Rev Immunol, 6:139-59.

Clements JE y Zink MC. 1996. Molecular biology and pathogenesis of animal lentivirus infections. Clin Microbiol Rev, 9(1):100-17.

Coffin JM. 1996. Retroviridae: The viruses and their replication. En: Fields, B. N., Knipe, D. M. y Howley, P. M. editores. Fields Virology. ed. III. pp. 1767-835. Lippincot-Raven Publishers. Philadelphia.

Collins ER, Jr. 1990. Ventilation of sheep and goat barns. Vet Clin North Am Food Anim Pract, 6(3):635-54.

Cordier G, Cozon G, Greenland T, Rocher F, Guiguen F, Guerret S, Brune J y Mornex JF. 1990. In vivo activation of alveolar macrophages in ovine lentivirus infection. Clin Immunol Immunopathol, 55(3):355-67. 
Cortez RC, Fieni F, Roux C, Russo P, Guibert JM, Guiguen F, Chebloune Y, Pepin M y Pellerin JL. 2006. Detection of ovine lentivirus in the cumulus cells, but not in the oocytes or follicular fluid, of naturally infected sheep. Theriogenology, 66(5):1131-9.

Cottereau A, Laval A y Jeanpert A. 1977. Identification de Maedi dans lést de la France. Bull Acad Vét de France, 50:223-32.

Cross RF, Smith CK y Moorhead PD. 1975. Vertical transmission of Progressive Pneumonia of Sheep. Am J Vet Res, 36(4 Pt.1):465-8.

Cutlip RC, Howard D y Lehmkuhl HD. 1986a. Erradication of Ovine Progressive Pneumonia from sheep flocks. J Am Vet Med Assoc, 188(9):1026-7.

Cutlip RC, Jackson TA y Laird GA. 1977. Immnunodifusion Test for Ovine Progressive Pneumonia. Am J Vet Res, 38(7):1081-4.

Cutlip RC, Jackson TA y Lehmkuhl HD. 1979. Lesions of Ovine Progressive Pneumonia: Interstitial Pneumonitis and Encephalitis. Am J Vet Res, 40(10):1370-4.

Cutlip RC y Laird GA. 1976. Isolation and Charecterization of a virus associated with Progressive Pneumonia (Maedi) of Sheep. Am J Vet Res, 37(12):1377-82.

Cutlip RC, Lehmkuhl HD, Brogden KA y Bolin SR. 1985a. Mastitis associated with Ovine Progressive Pneumonia virus infection in sheep. Am J Vet Res, 46(2):326-8.

Cutlip RC, Lehmkuhl HD, Brogden KA y Sacks JM. 1986b. Breed susceptibility to ovine progressive pneumonia (Maedi/Visna) virus. Vet Microbiol, 12:283-8.

Cutlip RC, Lehmkuhl HD y Jackson TA. 1981. Intrauterine transmission of ovine progressive pneumonia virus. Am J Vet Res, 42(10):1795-7.

Cutlip RC, Lehmkuhl HD, Schmerr MJF y Brogden KA. 1988. Ovine progressive pneumonia(Maedi/Visna) in sheep. Vet Microbiol, 17:237-50.

Cutlip RC, Lehmkuhl HD, Whipp SC y Mc-Clurkin AW. 1982. Effects on ovine fetuses of exposure to ovine progressive pneumonia virus. Am J Vet Res, 43(1):82-5.

Cutlip RC, Lehmkuhl HD, Wood RL y Brogden KA. 1985b. Arthritis associated with ovine progressive pneumonia. Am J Vet Res, 46(1):65-8.

Daltabuit-Test M. 2005. Desarrollo y aplicación de técnicas de diagnóstico serológico y molecular para el estudio de la transmisión calostral y horizontal del virus Maedi-Visna (VMV) en ovino. Tesis Doctoral. Facultad de Veterinaria-Universidad de Zaragoza. 
Daltabuit-Test M, De la Concha-Bermejillo A, Espinosa LE, Loza RE y Aguilar SA. 1999. Isolation of caprine arthritis encephalitis virus from goats in Mexico. Can J Vet Res, 63(3):212-5.

Daltabuit-Test M, Juste RA y Berriatua E. 2006. Desarrollo de una técnica de PCR para detectar Virus Maedi Visna (VMV) libre e integrado en células y aplicación al estudio de la infección calostral en corderos. An Vet Murcia, 22:57-66.

Dawson M. 1980. Maedi/Visna: a review. Vet Rec, 106:212-6.

Dawson M. 1987. Pathogenesis of maedi-visna. Vet Rec, 120:451-4.

Dawson M, Done SH, Venables C y Jenkins CE. 1990. Maedi/Visna and Sheep Pulmonary Adenomatosis: a study of concurrent infection. Br Vet J, 146(6):531-8.

Dawson M, Venables C y Jenkins CE. 1985. Experimental infection of a natural case of Sheep Pulmonary Adenomatosis with Maedi/Visna virus. Vet Rec, 116:588-9.

De Andres D, Klein D, Watt NJ, Berriatua E, Torsteinsdottir S, Blacklaws BA y Harkiss GD. 2005. Diagnostic tests for small ruminant lentiviruses. Vet Microbiol, 107(1-2):49-62.

De Andres X, Reina R, Ciriza J, Crespo H, Glaria I, Ramirez H, Grillo MJ, Perez MM, Andresdottir V, Rosati S, Suzan-Monti M, Lujan L, Blacklaws BA, Harkiss GD, De Andres D y Amorena B. 2009. Use of $B 7$ costimulatory molecules as adjuvants in a prime-boost vaccination against Visna/Maedi ovine lentivirus. Vaccine, 27(34):4591-600.

De Boer GF. 1970. Antibody formation in Zwoegerziekte, a slow infection in sheep. J Immunol, 104(2):414-22.

De Boer GF, Terpstra C y Houwers DJ. 1979. Studies in epidemiology of Maedi/Visna in sheep. Res Vet Sci, 26:202-8.

De la Concha-Bermejillo A. 1997. Maedi-Visna and ovine progressive pneumonia. Vet Clin North Am Food Anim Pract, 13(1):13-33.

De la Concha-Bermejillo A, Brodie SJ, Magnus-Corral S, Bowen RA y DeMartini JC. 1995a. Pathologic and serologic responses of isogeneic twin lambs to phenotypically distinct lentiviruses. $J$ Acquir Immune Defic Syndr Hum Retrovirol, 8(2):116-23.

De la Concha-Bermejillo A, Juste RA, Kretschmer R y Aguilar SA. 1995b. Ovine lentivirus infection: an animal model for pediatric HIV infection? Arch Med Res, 26(4):345-54.

De la Concha-Bermejillo A, Magnus-Corral S, Brodie SJ y DeMartini JC. 1996. Venereal shedding of ovine lentivirus in infected rams. Am J Vet Res, 57(5):684-8. 
de la Cruz M, Serrano E, Montoro V, Marco J, Romeo M, Baselga R, Albizu I y Amorena B. 1994. Etiology and prevalence of subclinical mastitis in the Manchega sheep at mid-late lactation. Small Rum Res, 14(2):175-80.

DeMartini JC, Bowen RA, Carlson JO y De la Concha-Bermejillo A. 1991. Strategies for the genetic control of ovine lentivirus infections. En: Axford, R. F. E. editor. Breeding for disease resistance in farm animals. pp. 293-314. CABI.

DeMartini JC, De la Concha-Bermejillo A, Carlson JO y Bowen RA. 2000. Diseases caused by Maedi-Visna and other ovine lentiviruses. En: Axford, R. F. E. S., Bishop, S. C., Nicholas, F. W. y Owen, J. B. editores. Breeding for disease resistance in farm animals. pp. 301-24. CABI.

DeMartini JC, Halsey W, Boshoff C, York D y Howell MD. 1999. Comparison of a maedi-visna virus CA-TM fusion protein ELISA with other assays for detecting sheep infected with North American ovine lentivirus strains. Vet Immunol Immunopathol, 71(1):29-40.

Dohoo I, Martin W y Stryhn H. 2003a. Measures of association. pp. 121-38. AVC Inc., Charlottetown. Canada.

Dohoo I, Martin W y Stryhn H. 2003b. Screening and diagnostics tests. En: Dohoo, I., Martin, W. y Stryhn, H. editores. Veterinary Epidemiologic Research. pp. 85-120. AVC Inc., Charlottetown. Canada.

Dohoo IR, Heaney DP, Stevenson RG, Samagh BS y Rhodes CS. 1987. The effects of Maedi/Visna virus infection on productivity in ewes. Prev Vet Med, 4:471-84.

Dukes TW, Greig AS y Corner AH. 1979. Maedi/Visna in Canadian Sheep. Can J Comp Med, 43(3):313-20.

East NE, Rowe JD, Madewell BR y Floyd K. 1987. Serologic prevalence of caprine arthritisencephalitis virus in California goat dairies. J Am Vet Med Assoc, 190(2):182-6.

Elder JH, Lerner DL, Hasselkus-Light CS, Fontenot DJ, Hunter E, Luciw PA, Montelaro RC y Phillips TR. 1992. Distinct subsets of retrovirus encode dUTPase. J Virol, 66(3):1791-4.

Ellis JA y DeMartini JC. 1985. Immunopathologic and Morphometric changes in Pulmonary Lymph Nodes of sheep with Progressive Pneumonia. Vet Pathol, 22:32-41.

Ellis T, Robinson W y Wilcox G. 1983. Effect of colostrum deprivation of goat kids on the natural transmission of caprine retrovirus infection. Aust Vet J, 60(11):326-9.

Ellis TM, Carman H, Robinson WF y Wilcox GE. 1986. The effect of colostrum-derived antibody on neo-natal transmission of caprine arthritis-encephalitis virus infection. Aust Vet J, 63(8):242-5. 
Eltahir YM, Dovas Cl, Papanastassopoulou M, Koumbati M, Giadinis N, Verghese-Nikolakaki S y Koptopoulos G. 2006. Development of a semi-nested PCR using degenerate primers for the generic detection of small ruminant lentivirus proviral DNA. J Virol Methods, 135(2):240-6.

Espi A, Prieto JM y Alvarez M. 2001. Situación sanitaria del ovino en Asturias: seroprevalencia de la enfermedad de la frontera, Maedi Visna, Aborto enzootico, Agalaxia contagiosa, Fiebre $Q$ y Leptospirosis. XXVI Jornadas Científicas de la Sociedad Española de Ovinotecnia y Caprinotecnia (SEOC). Sevilla..

Esteban-Muñoz C, Tejon-Tejon D. 1986. Catalogo de razas autóctonas Españolas, I. Especies ovina y caprina. (ISBN: 8474790905).

Extramiana AB, Gonzalez L, Cortabarria N, Garcia M y Juste RA. 2002. Evaluation of a PCR technique for the detection of Maedi-Visna proviral DNA in blood, milk and tissue samples of naturally infected sheep. Small Rum Res, 44(2002):109-17.

Fevereiro M, Barros S y Fagulha T. 1999. Development of a monoclonal antibody blocking-ELISA for detection of antibodies against Maedi-Visna virus. J Virol Methods, 81(1-2):101-8.

Fournier D, Campbell JR y Middleton DM. 2006. Prevalence of maedi-visna infection in culled ewes in Alberta. Can Vet J, 47(5):460-6.

García I, Vega GS, Asensio A, Agundo R y De la Fuente R. 1994. A serological survey of MVV in Comunidad de Madrid. $3^{\circ}$ European Society for Veterinary Virology (ESVV) congress. Interlaken (Suiza).

Gates NL, Winward MS, Gorham RJ y Shen DT. 1978. Serologic survey of prevalence of Ovine Progressive Pneumonia in Idaho Range Sheep. J Am Vet Med Assoc, 173(12):1575-7.

Gendelman HE, Narayan O, Kennedy-Stoskopf S, Kennedy PGE, Ghotbi Z, Clements JE, Stanley F y Pezeshkpour G. 1986. Tropism of Sheep Lentiviruses for monocytes: susceptibility to infection and virus gene expression increase dirung maturation of monocytes and macrophages. J Virol, 58(1):6774.

Gendelman HE, Narayan O, Molineaux S, Clements JE y Ghotbi Z. 1985. Slow, persistent replication of lentiviruses: role of tissue macrophages and macrophage precursors in bone marrow. Proc Natl Acad Sci USA, 82:7086-90.

Georgsson G, Houwers DJ, Palsson PA y Pétursson G. 1989. Expression of viral antigens in the central nervous system of visna-infected sheep:an immunohistochemical study on experimental visna induced by virus strains of increased neurovirulence. Acta.Neuropathol., 77:299-306. 
Georgsson G, Petursson G, Miller A, Nathanson N y Palsson PA. 1978. Experimental visna in foetal Icelandic sheep. J Comp Pathol, 88:597-605.

Giangaspero M, Gruner L, Nishikawa H, Tabbaa D y Vacirca G. 1993. Lungworms, maedi visna and mixed infections with respiratory viruses in Syrian Awassi sheep. Vet Res Commun, 17(5):371-4.

Gil A, Rola M y Kuzmak J. 2006. Application of PCR technique in diagnosis of small ruminant lentivirus infection in sheep and goats. Pol J Vet Sci, 9(4):213-7.

Gjerset B, Jonassen CM y Rimstad E. 2007. Natural transmission and comparative analysis of small ruminant lentiviruses in the Norwegian sheep and goat populations. Virus Res, 125(2):153-61.

Gjerset B, Rimstad E, Teige J, Soetaert K y Jonassen CM. 2008. Impact of natural sheep-goat transmission on detection and control of small ruminant lentivirus group $\mathrm{C}$ infections. Vet Microbiol, 135(3-4):231-8.

Glaria I, Reina R, Crespo H, de A, X, Ramirez H, Biescas E, Perez MM, Badiola J, Lujan L, Amorena $B$ y De Andres D. 2009. Phylogenetic analysis of SRLV sequences from an arthritic sheep outbreak demonstrates the introduction of CAEV-like viruses among Spanish sheep. Vet Microbiol, 138(12):156-62.

Gonzalez B, Reina R, Garcia I, Andrés S, Glaria I, Alzueta M, Mora MI, Jugo BM, Arrieta-Aguirre I, de la Lastra JM, Rodriguez D, Rodriguez JR, Esteban M, Grillo MJ, Blacklaws BA, Harkiss GD, Chebloune Y, Lujan L, De Andres D y Amorena B. 2005. Mucosal immunization of sheep with a Maedi-Visna virus (MVV) env DNA vaccine protects against early MVV productive infection. Vaccine, 23(34):4342-52.

Gonzalez L. 1989a. El Maedi o neumonía progresiva en el conjunto de las enfermedades respiratorias crónicas del ganado ovino en la Comunidad Autónoma Vasca. Tesis Doctoral. Facultad de Veterinaria. Universidad de Zaragoza.

Gonzalez L. 1989b. Lentivirus de los pequeños rumiantes: Maedi-Visna y Artritis Encefalitis Caprina.

Gonzalez L, Badiola JJ y Gelabert JL. 1984. Neumonía progresiva (MAEDI) en el ganado ovino del País Vasco. Med Vet, 1(5-6):277-82.

Gonzalez L, Juste RA, Cuervo LA, Idigoras I y Saez dO. 1993. Pathological and epidemiological aspects of the coexistance of maedi-visna and sheep pulmonary adenomatosis. Res Vet Sci, 54:1406.

Greenwood PL, North RN y Kirkland PD. 1995. Prevalence, spread and control of caprine arthritisencephalitis virus in dairy goat herds in New South Wales. Aust Vet J, 72(9):341-5. 
Grego E, Bertolotti L, Quasso A, Profiti M, Lacerenza D, Muz D y Rosati S. 2007. Genetic characterization of small ruminant lentivirus in Italian mixed flocks: evidence for a novel genotype circulating in a local goat population. J Gen Virol, 88(Pt 12):3423-7.

Grego E, Lacerenza D, Reina R, Profiti M y Rosati S. 2009. Serological characterization of the new genotype $\mathrm{E}$ of small ruminant lentivirus in roccaverano goat flocks. Vet Res Commun, 33(Suppl 1):137-40.

Grego E, Profiti M, Giammarioli M, Giannino L, Rutili D, Woodall C y Rosati S. 2002. Genetic heterogeneity of small ruminant lentiviruses involves immunodominant epitope of capsid antigen and affects sensitivity of single-strain-based immunoassay. Clin Diag Lab Immunol, 9(4):828-32.

Griffin DE, Narayan O y Adams RJ. 1978. Early immune responses in Visna, a slow viral disease of sheep. J Infect Dis, 138(3):340-50.

Gudmundsson B, Bjarnadottir H, Kristjansdottir S y Jonsson JJ. 2003. Quantitative assays for maedivisna virus genetic sequences and mRNA's based on RT-PCR with real-time FRET measurements. Virology, 307(1):135-42.

Gudnadottir M. 1974. Visna-Maedi in sheep. Prog Med Virol, 18:336-49.

Gudnadottir M y Kristinsdottir K. 1967a. Complement-fixing antibodies in sera of sheep affected with visna and maedi. J Immunol, 98(4):663-7.

Gudnadottir M y Palsson PA. 1965. Host-virus interaction in Visna infected sheep. J Immunol, 95(6):1116-20.

Gudnadottir M y Palsson PA. 1967b. Transmission of Maedi by inoculation of a virus grown in tissue culture from Maedi-affected lungs. J Infect Dis, 117(1):1-6.

Gufler H, Gasteiner J, Lombardo D, Stifter E, Krassnig R y Baumgartner W. 2007. Serological study of small ruminant lentivirus in goats in Italy. Small Rum Res, 73(1-3):169-73.

Guven MN. 1985. Maedi-visna eradication programme in Ireland. En: Sharp, J. M. y Hoff-Jorgensen, R. editores. Slow viruses in sheep, goats and cattle. pp. 283-9. Commission of the European Communities. Luxembourg.

Haase AT. 1986. Pathogenesis of lentivirus infections. Nature, 322:130-6.

Henriques AM, Fevereiro M, Prazeres DM y Monteiro GA. 2007. Development of a candidate DNA vaccine against Maedi-Visna virus. Vet Immunol Immunopathol, 119(3-4):222-32. 
Herrmann LM, Cheevers WP, Marshall KL, McGuire TC, Hutton MM, Lewis GS y Knowles DP. 2003. Detection of serum antibodies to ovine progressive pneumonia virus in sheep by using a caprine arthritis-encephalitis virus competitive-inhibition enzyme-linked immunosorbent assay. Clin Diagn Lab Immunol, 10(5):862-5.

Herrmann-Hoesing LM, Lehmkuhl HD y Cutlip RC. 2009. Minimum intravenous infectious dose of ovine progressive pneumonia virus (OPPV). Res Vet Sci, 87(2):329-31.

Herrmann-Hoesing LM, Palmer GH y Knowles DP. 2007a. Evidence of proviral clearance following postpartum transmission of an ovine lentivirus. Virology., 362(1):226-34.

Herrmann-Hoesing LM, White SN, Lewis GS, Mousel MR y Knowles DP. 2007b. Development and validation of an ovine progressive pneumonia virus quantitative PCR. Clin Vaccine Immunol, 14(10):1274-8.

Herrmann-Hoesing LM, White SN, Mousel MR, Lewis GS y Knowles DP. 2008. Ovine progressive pneumonia provirus levels associate with breed and Ovar-DRB1 . Immunogenetics, 60(12):749-58.

Hoff-Jorgensen R. 1978. Maedi-Visna in Danish sheep. Bull Off int Epiz, 89(7-8):527-30.

Hoff-Jorgensen R. 1985. Control programme for lentivirus infections in Danish sheep and goats. En: Sharp, J. M. y Hoff-Jorgensen, R. editores. Slow viruses in sheep, goats and cattle. pp. 133-7. Commission of the European Communities. Luxembourg.

Houwers DJ. 1990. Economic importance, epidemiology and control. Maedi Visna and related diseases. pp. 83-117.

Houwers DJ, König CD, Bakker J, De Boer MJ, Pekelder JJ, Sol J, Vellema P y De Vries G. 1987a. Maedi-Visna control in sheep III: results and evaluation of a voluntary control program in the Nethelands over a period of four years. Vet Q, 9(1):29S-36S.

Houwers DJ, König CD, De Boer GF y Schaake J. 1983. Maedi-Visna control in sheep. I. Artificial rearing of colostrum-deprived lambs. Vet Microbiol, 8:179-85.

Houwers DJ, Schaake J y De Boer GF. 1984. Maedi-Visna controlin sheep.II. Half-yearly serological testing with culling of positive ewes and progeny. Vet Microbiol, 9:445-51.

Houwers DJ y Van der Molen EJ. 1987b. A five -year serological survey of natural transmission of Maedi-Visna virus in a flock of sheep, completed with post mortem investigation. $J$ Vet Med, 34:42131.

Houwers DJ, Visscher AH y Defise PR. 1989. Importance of ewe lamb relationship and breed in the epidemiology of maedi-visna virus infections. Res Vet Sci, 46:5-8. 
Huffman EM, Kirk JH, Winward L y Gorham JR. 1981. Serologic prevalence of Ovine Progressive Pneumonia in a Western Range flock of sheep. J Am Vet Med Assoc, 178(7):708-10.

Johnson LK, Meyer AL y Zink MC. 1992. Detection of ovine lentivirus in seronegative sheep by in situ hybridization, PCR, and cocultivation with susceptible cells. Clin Immunol Immunopathol, 65(3):25460.

Juste RA, Garrido JM, Geijo M, Elguezabal N, Aduriz G, Atxaerandio R y Sevilla I. 2005. Comparison of blood polymerase chain reaction and enzyme-linked immunosorbent assay for detection of Mycobacterium avium subsp. paratuberculosis infection in cattle and sheep. $J$ Vet Diagn Invest, 17(4):354-9.

Juste RA, Gelabert JL y Saez de Ocariz C. 1987. Aspectos epizootiologicos de algunas enfermedades del ganado ovino latxo en la CAPV: I-Metodología y enfermedades crónicas (Maedi y Paratuberculosis). Volumen extra n7.ITEA.II Jornadas sobre produccion animal., pp. 230-5.

Juste RA, Kwang J y De la Concha-Bermejillo A. 1998. Dynamics of cell-associated viremia and antibody response during the early phase of lentivirus infection in sheep. Am J Vet Res, 59(5):563-8.

Juste RA, Ott TL, Bazer FW, Kwang J y De la Concha-Bermejillo A. 1997. Effects of two patterns of interferon-TAU treatment on lambs experimentally infected with ovine lentivirus. 3rd European Workshop on Ovine and Caprine Retroviruses.

Juste RA, Ott TL, Kwang J, Bazer FW y Concha-Bermejillo A. 1996. Effects of recombinant interferon-tau on ovine lentivirus replication. J Interferon Cytokine Res, 16(12):989-94.

Juste RA, Ott TL, Kwang J, Bazer FW y De la Concha-Bermejillo A. 2000. Effects of recombinant ovine interferon-tau on ovine lentivirus replication and progression of disease. J Gen Virol, 81(Pt 2):525-32.

Kajikawa O, Lairmore MD y DeMartini JC. 1990. Analysis of antibody responses to phenotypically distinct Lentiviruses. J Clin Microbiol, 28(4):764-70.

Karanikolaou K, Angelopoulou K, Papanastassopoulou M, Koumbati- Artopiou M, Papadopoulos O y Koptopoulos G. 2005. Detection of small ruminant lentiviruses by PCR and serology tests in field samples of animals from Greece. Small Rum Res, 58(2):181-7.

Katzman M y Sudol M. 1994. In vitro activities of purified visna virus integrase. J Virol, 68(6):3558-69.

Keen JE, Hungerford LL, Littledike ET, Wittum TE y Kwang J. 1997a. Effect of ewe ovine lentivirus infection on ewe and lamb productivity. Prev Vet Med, 30:155-69. 
Keen JE, Hungerford LL, Wittum TE, Kwang J y Littledike ET. 1997b. Risks factors for seroprevalence of ovine lentivirus in breeding ewe flocks in Nebraska,USA. Prev Vet Med, 30:81-94.

Keen JE, Kwang J y Rosati S. 1995. Comparison of Ovine Lentivirus detection by conventional and recombinant serological methods. Vet Immunol Immunopathol, 47:295-309.

Kenigswald G y Van-Straten M. 2009. The effect of maedi visna virus (MVV) positive serology on milk and meat production in Israeli "Assaf" sheep herd. 7Th International Sheep Veterinary Congress.Norway.

Kennedy PGE, Narayan O, Ghotbi Z, Hopkins J, Gendelman HE y Clements JE. 1985. Persistent expression of la antigen and viral genome in Visna-Madi induced inflammatory disease. J Exp Med, 162:1970-82.

Kennedy RC, Eklund CM, López C y Hadlow WJ. 1968. Isolation of a virus from the lungs of Montana sheep affected with Progressive Pneumonia. Virology, 35:483-4.

Kennedy-Stoskopf S y Narayan O. 1986. Neutralizing antibodies to visna lentivirus: mechanisms of action and possible role in virus persistance. $J$ Virol, 59(1):37-44.

Kennedy-Stoskopf S, Narayan O y Strandberg JD. 1985. The mammary gland as a target organ for infection with caprine arthritis-encephalitis virus. J Comp Pathol, 95(4):609-17.

Khaled Al-Qudah, Ahmad M.Al-Majali y Zuahir Bani Ismail. 2006. Epidemiological studies on caprine arthritis-encephalitis virus infection in Jordan. Small Rum Res, 66:181-6.

Klein JR, Martin S, Griffing S, Nathanson N, Gorham RJ, Shen DT, Pétursson G, Georgsson G, Palsson PA y Lutley R. 1985. Precipitating antibodies in experimental Visna and natural progressive pneumonia of sheep. Res Vet Sci, 38:129-33.

Kleinbaum DG, Kupper LL, Muller KE y Nizam A. 1998, Applied Regression Analysis and Other Multivariable Methods. Third Edition Duxbury Press.Pacific Grove, California.

Knowles DP, Evermann JF, Shropshire C, VanderSchalie J, Bradway D, Gezon HM y Cheevers WP. 1994. Evaluation of agar gel immunodiffusion serology using caprine and ovine lentiviral antigens for detection of antibody to caprine arthritis-encephalitis virus. J Clin Microbiol, 32(1):243-5.

Kristbjornsdottir HB, Andresdottir V, Svansson V, Torsteinsdottir S, Matthiasdottir S y Andresson OS. 2004. The vif gene of maedi-visna virus is essential for infectivity in vivo and in vitro. Virology, 318(1):350-9. 
Krogsrud J. 1985. Control of maedi in Norway. En: Sharp, J. M. y Hoff-Jorgensen, R. editores. Slow viruses in sheep, goats and cattle. pp. 139-44. Commission of the European Communities. Luxembourg.

Krogsrud J y Udnes H. 1978. Maedi(Progressive Pneumonia in sheep).Diagnosis, epizootiology, prevention and control programme in Norway. Bull Off int Epiz, 89:451-64.

Kumar V, Abbas A y Fausto N. 2008. Hemodynamic disorders, thromboembolic disease, and shock. Robbins \& Cotran Pathologic basis of Disease. ed. 7. pp. 127-43. Elsevier-Saunders. Amsterdam.

Kwang J, Keen JE, Cutlip RC y Littledike ET. 1993. Evaluation of an ELISA for detection of Ovine Progressive Pneumonia antibodies using a recombinant transmembrane envelope protein. $J$ Vet Diagn Invest, 5(2):189-93.

Kwang J y Torres JV. 1994. Oligopeptide-based enzyme immunoassay for ovine lentivirus antibody detection. J Clin Microbiol, 32(7):1813-5.

Lacerenza D, Giammarioli M, Grego E, Marini C, Profiti M, Rutili D y Rosati S. 2006. Antibody response in sheep experimentally infected with different small ruminant lentivirus genotypes. Vet Immunol Immunopathol, 112(3-4):264-71.

Lago A, McGuirk SM, Bennett TB, Cook NB y Nordlund KV. 2006. Calf respiratory disease and pen microenvironments in naturally ventilated calf barns in winter. J Dairy Sci, 89(10):4014-25.

Lago N, Cienfuegos S, Pato J, Panadero R, López C, Vázquez L, Dacal V, Arnes Y y Fernández G. 2009. Estudio de la prevalencia de la enfermedad de Maedi-Visna en las explotaciones de ovino de carne de Galicia. 34 Congreso Nacional de la Sociedad de Ovinotecnia y Caprinotecnia.Huesca.

Lairmore MD, Akita GY, Russell HI y DeMartini JC. 1987. Replication and cytopathic effects of ovine lentivirus strains in alveolar macrophages correlate with in vivo pathogenicity. $J$ Virol, 61(12):4038-42.

Lairmore MD, Poulson JM, Adducci TA y DeMartini JC. 1988. Lentivirus-induced lymphoproliferative disease. Comparative pathogenicity of phenotypically distinct ovine lentivirus strains. Am J Pathol, 130(1):80-90.

Lamara A, Fieni F, Mselli-Lakhal L, Tainturier D y Chebloune Y. 2001. Efficient replication of caprine arthritis-encephalitis virus in goat granulosa cells. Virus Res, 79(1-2):165-72.

Larruskain A, Minguijon E, Garcia-Etxebarria K, Moreno B, Arostegui I, Juste RA y Jugo BM. 2010. MHC class II DRB1 gene polymorphism in the pathogenesis of Maedi-Visna and pulmonary adenocarcinoma viral diseases in sheep. Immunogenetics, 62(2):75-83. 
Larsen HJ, Hyllseth B y Krogsrud J. 1982. Experimental Maedi virus infection in sheep: early cellular and humoral immune response following parenteral inoculation. Am J Vet Res, 43(3):379-89.

Legastelois I, Cottin V, Mornex JF y Cordier G. 1997. Alveolar macrophages from sheep naturally infected by visna-maedi virus contribute to IL-8 production in the lung. Vet Immunol Immunopathol, 59(1-2):131-9.

Leginagoikoa I, Daltabuit-Test M, Alvarez V, Arranz J, Juste RA, Amorena B, De Andres D, Lujan LL, Badiola JJ y Berriatua E. 2006a. Horizontal Maedi-Visna virus (MVV) infection in adult dairy-sheep raised under varying MVV-infection pressures investigated by ELISA and PCR. Res Vet Sci, 80(2):235-41.

Leginagoikoa I, Juste RA, Barandika J, Amorena B, De Andres D, Lujan L, Badiola J y Berriatua E. 2006b. Extensive rearing hinders Maedi-Visna Virus (MVV) infection in sheep. Vet Res, 37(6):767-78.

León L y Prats J. 1996. Encuesta serológica de la infección por el virus Maedi/Visna en la población ovina de Moratalla (Murcia). XXI Jornadas Científicas de la Sociedad Española de Ovinotecnia y Caprinotecnia (SEOC). Logroño., pp. 119-27.

Lerondelle C, Godet M y Mornex JF. 1999. Infection of primary cultures of mammary epithelial cells by small ruminant lentiviruses. Vet Res, 30(5):467-74.

Lerondelle C, Greenland T, Jane M y Mornex JF. 1995. Infection of lactating goats by mammary instillation of cell-borne caprine arthritis-encephalitis virus. J Dairy Sci, 78(4):850-5.

Lerondelle C y Ouzrout R. 1990. Expression of maedi-visna virus in mammary secretions of a seropsitive ewe. Dev Biol Stand, 72:223-7.

Leroux C, Lerondelle C, Chastang J y Mornex JF. 1997. RT-PCR detection of lentiviruses in milk or mammary secretions of sheep or goats from infected flocks. Vet Res, 28(2):115-21.

Light MR, Schipper IA, Molitor TW, Tilton JE y Slanger WD. 1979. Progressive Pneumonia in sheep: incidence of natural infection and establishment of clean flocks. J Anim Sci, 49(5):1157-60.

Lucam F. 1942. La "Bouhite" ou "lymphomatose pulmonaire maligne du Mouton". Recl Med Vet, 118:273.

Lujan L y Badiola JJ. 2001. Maedi-Visna. Ovis, 72 .

Lujan L, Badiola JJ, García Marín JF, Moreno B, Vargas MA, Fernández de Luco D y Pérez V. 1993. Seroprevalence of Maedi-Visna infection in sheep in the north-east of Spain. Prev Vet Med(15):18190. 
Lujan L, Bergara I, Collie DDS y Watt NJ. 1994. Ovine Lentivirus (Maedi-Visna virus) protein expression in sheep alveolar macrophages. Vet Pathol, 31:695-703.

Lujan L, García Marín JF, Fernández de Luco D, Vargas A y Badiola JJ. 1991. Pathological changes in the lungs and mammary glands of sheep and their relationship with Maedi-Visna infection. Vet $\operatorname{Rec}, 20: 51-4$.

Lutley R, Pétursson G, Palsson PA, Georgsson G, Klein JR y Nathanson N. 1983. Antigenic drift in Visna: virus variation during long-term infection of Icelandic sheep. J Gen Virol, 64(Pt 7):1433-40.

MAPA. 2004. Encuestas ganaderas 2004. Subdirección general de estadisticas agroalimentarias. 24-25.

Marsh H. 1923. Progressive pneumonia in sheep. J Am Vet Med Assoc, 62:458-73.

McGuire TC, Adams DS, Johnson GC, Klevjer-Anderson P, Barbee DD y Gorham JR. 1986. Acute arthritis in caprine arthritis-encephalitis virus challenge exposure of vaccinated or persistently infected goats. Am J Vet Res, 47(3):537-40.

McNeilly TN, Baker A, Brown JK, Collie D, Maclachlan G, Rhind SM y Harkiss GD. 2008. Role of alveolar macrophages in respiratory transmission of Visna/maedi virus. J Virol, 82(3):1526-36.

McNeilly TN, Tennant P, Lujan L, Perez M y Harkiss GD. 2007. Differential infection efficiencies of peripheral lung and tracheal tissues in sheep infected with Visna/maedi virus via the respiratory tract. J Gen Virol, 88(Pt 2):670-9.

Menzies P. 2006. The Ontario Sheep Health Program: A structured health management program for intensively reared flocks. Small Rum Res, 62(1-2):95-9.

Mirsky ML, Olmstead C, Da Y y Lewin HA. 1998. Reduced bovine leukaemia virus proviral load in genetically resistant cattle. Anim Genet, 29(4):245-52.

Mitchell DT. 1915. Investigations into jaagsiekte or chronic catarrhal pneumonia of sheep. Dir. Vet.Educ.Res.(3rd and 4th Report. Union of South Africa):585.

Molina RM, Trigo FJ y Cutlip RC. 1986. Estudio serológico de la neumonía progresiva ovina en México. Veterinaria México, 17:269-73.

Monleón E, Pacheco C, Lujan L, Bolea R, Luco DF, Vargas A, Alabart JL, Badiola JJ y Amorena B. 1997. Effect of in vitro Maedi-Visna virus infection on adherence and phagocytosis of staphylococci by ovine cells. Vet Microbiol, 57:13-28. 
Murphy FA, Gibbs EPJ, Horzinek MC y Studdert MJ. 1999. Retroviridae. Veterinary Virology. ed. Third edition. pp. 363-87. Academic Press.

Narayan O y Clements JE. 1989. Biology and pathogenesis of lentiviruses. J Gen Virol, 70 ( Pt 7):1617-39.

Narayan O, Clements JE, Kennedy-Stoskopf S, Sheffer D y Royal W. 1987. Mechanisms of escape of visna lentiviruses from immunological control. Contrib Microbiol Immunol, 8:60-76.

Narayan O, Kennedy-Stoskopf S, Sheffer D, Griffin DE y Clements JE. 1983. Activation of caprine arthritis-encephalitis virus expression during maturation of monocytes to macrophages. Infect Immun, 41(1):67-73.

Narayan O, Silverstein AM, Price D y Johnson RT. 1974. Visna virus infection of American lambs. Science, 183(130):1202-3.

Narayan O, Wolinsky JS, Clements JE, Strandberg JD, Griffin DE y Cok LC. 1982. Slow virus replication: the role of macrophages in the persistence and expression of visna viruses of sheep and goats. J Gen Virol, 59(Pt 2):345-56.

Narayan O, Zink MC, Gorrell MD, McKentee M, Sharma D y Adams R. 1992. Lentivirus induced arthritis in animals. J.Rheumatol., 19:25-32.

Nardell EA, Keegan J, Cheney SA y Etkind SC. 1991. Airborne infection. Theoretical limits of protection achievable by building ventilation. Am Rev Respir Dis, 144(2):302-6.

Nathanson N, Martin JR, Georgsson G, Palsson PA, Lutley R y Petursson G. 1981. The effect of post-infection immunization on the severity of experimental visna. J Comp Pathol, 91:185-91.

Nathanson N, Panitch H, Palsson PA, Petursson G y Georgsson G. 1976. Pathogenesis of visna: II. Effect of immunosuppression upon early central nervous system lesion. Lab Invest, 35(5):441-51.

Niesalla $H$, de A, X, Barbezange C, Fraisier C, Reina R, Arnarson H, Biescas E, Mazzei M, McNeilly TN, Liu C, Watkins C, Perez M, Carrozza ML, Bandecchi P, Solano C, Crespo H, Glaria I, Huard C, Shaw DJ, de B, I, De Andres D, Tolari F, Rosati S, Suzan-Monti M, Andresdottir V, Torsteinsdottir S, Petursson G, Badiola J, Lujan L, Pepin M, Amorena B, Blacklaws BA y Harkiss GD. 2008a. Systemic DNA immunization against ovine lentivirus using particle-mediated epidermal delivery and modified vaccinia Ankara encoding the gag and/or env genes. Vaccine, 27(2):260-9.

Niesalla H, McNeilly TN, Ross M, Rhind SM y Harkiss GD. 2008b. Experimental infection of sheep with visna/maedi virus via the conjunctival space. J Gen Virol, 89(Pt 6):1329-37.

Niesters HG. 2002. Clinical virology in real time. J Clin Virol, 25 Suppl 3:3-12. 
Nordlund KV. 2008. Practical considerations for ventilating calf barns in winter. Vet Clin North Am Food Anim Pract, 24(1):41-54.

Oliver RE, Gorham JR, Parish SF, Hadlow WJ y Narayan O. 1981a. Ovine progressive pneumonia: pathologic and virologic studies on the naturally occurring disease. Am J Vet Res, 42(9):1554-8.

Oliver RE, Gorham JR, Perryman LE y Spencer GR. 1981b. Ovine progressive pneumonia: experimental intrathoracic, intracerebral, and intra-articular infections. Am J Vet Res, 42(9):1560-4.

Ouzrout $\mathrm{R}$ y Lerondelle C. 1990. Expression du virus Visna-Maedi dans les sécrétions mammaries d'une brebis séropositive lors d'une gestation puis d'une induction artificielle de lactation. Ann Rech Vet, 21:69-73.

Palfi V, Glavits R y Hajtos I. 1989. Testicular lesions in rams infected by maedi/visna virus. Acta Vet Hungarica, 37(1-2):97-102.

Palsson PA. 1976. Maedi and visna in sheep. En: Kimberlin, R. H. editor. Slow virus diseases of animals and man. pp. 17-43.

Palsson PA, Georgsson G, Petursson G y Nathanson N. 1977. Experimental Visna in Icelandic lambs. Acta Vet Scand, 18(1):122-8.

Panaccio M y Lew A. 1991. PCR based diagnosis in the presence of $8 \%(\mathrm{v} / \mathrm{v})$ blood. Nucleic Acids Res, 19(15):1151.

Pasick J. 1998a. Maedi-visna virus and caprine arthritis-encephalitis virus: distinct species or quasispecies and its implications for laboratory diagnosis. Can J Vet Res, 62(4):241-4.

Pasick J. 1998b. Use of a recombinant maedi-visna virus protein ELISA for the serologic diagnosis of lentivirus infections in small ruminants. Can J Vet Res, 62(4):307-10.

Payne JH, Bainbridge T, Pepper WJ, Pritchard GC, Welchman DdB, and Scholes SFE. 2004. Emergence of an apparently neurotropic maedi-visna virus infection in Britain. Vet Rec, 154 (3): 94.

Pekelder JJ, Houwers DJ y Elving L. 1991. Effect of maedi-visna virus infection on lamb growth. Vet Rec, 129(16):368.

Peluso.R., Haase AT, Stowring L, Edwards M y Ventura P. 1985. A Trojan Horse mechanism for the spread of Visna virus in monocytes. Virology, 147:231-6.

Pepin M, Vitu C, Russo P, Mornex JF y Peterhans E. 1998. Maedi-visna virus infection in sheep: a review. Vet Res, 29(3-4):341-67. 
Peretz G, Bugnard F y Calavas D. 1994. Study of a prevention programme for caprine arthritisencephalitis. Vet Res, 25(2-3):322-6.

Perez M, Biescas E, de A, X, Leginagoikoa I, Salazar E, Berriatua E, Reina R, Bolea R, De Andres D, Juste RA, Cancer J, Gracia J, Amorena B, Badiola JJ y Lujan L. 2009. Visna/maedi virus serology in sheep: Survey, risk factors and implementation of a successful control programme in Aragon (Spain). Vet J.

Perk K. 1988. Ungulate lentiviruses: Pathogenesis and relationship to AIDS. Adv Vet Sci Comp Med, 32:97-128.

Perk K, Yaniv A, Gazit A y DeMartini JC. 1996. Evaluation of vaccines for ovine lentivirus infection. AIDS Res Hum Retroviruses, 12(5):425-6.

Peterhans E, Greenland T, Badiola J, Harkiss G, Bertoni G, Amorena B, Eliaszewicz M, Juste RA, Krassnig R, Lafont JP, Lenihan P, Petursson G, Pritchard G, Thorley J, Vitu C, Mornex JF y Pepin M. 2004. Routes of transmission and consequences of small ruminant lentiviruses (SRLVs) infection and eradication schemes. Vet Res, 35(3):257-74.

Peterson K, Brinkhof JM, Houwers DJ, Colenbrander B y Gadella BM. 2007. Presence of prolentiviral DNA in male sexual organs and ejaculates of small ruminants. Theriogenology, 69(4):43342.

Petursson G, Andresdottir V, Andresson O, Torsteinsdottir S, Georgsson G y Palsson PA. 1991. Human and ovine lentiviral infections compared. Comp Immunol Microbiol Infect Dis, 14(4):277-87.

Petursson G, Georgsson G y Palsson PA. 1990. Maedi-visna virus. En: Dinker, Z. y Morein, B. editores. Virus infections of ruminants. pp. 431-40. Elsevier Science Publishers. Amsterdam.

Petursson G, Matthiasdottir S, Svansson V, Andresdottir V, Georgsson G, Martin AH, Agnarsdottir G, Gisladottir E, Arnadottir S, Hognadottir S, Jonsson SR, Andresson OS y Torsteinsdottir S. 2005. Mucosal vaccination with an attenuated maedi-visna virus clone. Vaccine, 23(24):3223-8.

Pisoni G, Bertoni G, Puricelli M, Maccalli M y Moroni P. 2007a. Demonstration of coinfection with and recombination by caprine arthritis-encephalitis virus and maedi-visna virus in naturally infected goats. J Virol, 81(10):4948-55.

Pisoni G, Moroni $P$, Turin $L$ y Bertoni G. 2007b. Compartmentalization of small ruminant lentivirus between blood and colostrum in infected goats. Virology, 369(1):119-30.

Pisoni G, Quasso A y Moroni P. 2005. Phylogenetic analysis of small-ruminant lentivirus subtype B1 in mixed flocks: evidence for natural transmission from goats to sheep. Virology, 339(2):147-52. 
Ploumi K, Christodoulou V, Vainas E, Lymberopoulos A, Xioufis A, Giouzeljiannis A, Paschaleri E y Ap D, I. 2001. Effect of maedi-visna virus infection on milk production in dairy sheep in Greece. Vet Rec, 149(17):526-7.

Power C, Richardson S, Briscoe M y Pasick J. 1995. Evaluation of two recombinant Maedi-visna virus proteins for use in an enzyme-linked immunosorbent assay for the detection of serum antibodies to ovine lentiviruses. Clin Diag Lab Immunol, 2(5):631-3.

Preziuso S, Sanna E, Sanna MP, Loddo C, Cerri D, Taccini E, Mariotti F, Braca G, Rossi G y Renzoni G. 2003. Association of Maedi Visna virus with Brucella ovis infection in rams. Eur $J$ Histochem, 47(2):151-8.

Pritchard GC y Done SH. 1990. Concurrent Maedi-Visna virus infection and Pulmonary Adenomatosis in a commercial breeding flock in East Anglia. Vet Rec, 127:197-200.

Quérat G, Barban V, Sauze N, Filippi P, Vigne R, Russo P y Vitu C. 1984. Highly lytic and persistent Lentiviruses naturally present in sheep with Progressive Pneumonia are genetically distinct. J Virol, 52(2):672-9.

Radostits OM, Gay CC, Blood DC y Hinchcliff KW. 2000, Veterinary Medicine. 9 W.B.Saunders.London.

Ramirez H, Roman BS, Glaria I, Reina R, Hernandez MM, de A, X, Crespo H, Hichou B, Cianca S, Goni C, Grandas A, Garcia-Pastor L, Vijil LE, Quintin F, Grillo MJ, De Andres D y Amorena B. 2009. Antibody-based diagnosis of small ruminant lentivirus infection in seminal fluid. Theriogenology, 72(8):1085-96.

Ravazzolo AP, Nenci C, Vogt HR, Waldvogel A, Obexer-Ruff G, Peterhans E y Bertoni G. 2006. Viral load, organ distribution, histopathological lesions, and cytokine mRNA expression in goats infected with a molecular clone of the caprine arthritis encephalitis virus. Virology, 350(1):116-27.

Reddy PG, Sapp WJ y Heneine W. 1993. Detection of caprine arthritis-encephalitis virus by polymerase chain reaction. J Clin Microbiol, 31(11):3042-3.

Reina R, Barbezange C, Niesalla H, de A, X, Arnarson H, Biescas E, Mazzei M, Fraisier C, McNeilly TN, Liu C, Perez M, Carrozza ML, Bandecchi P, Solano C, Crespo H, Glaria I, Huard C, Shaw DJ, de B, I, De Andres D, Tolari F, Rosati S, Suzan-Monti M, Andresdottir V, Torsteinsdottir S, Petursson G, Lujan L, Pepin M, Amorena B, Blacklaws BA y Harkiss GD. 2008a. Mucosal immunization against ovine lentivirus using PEI-DNA complexes and modified vaccinia Ankara encoding the gag and/or env genes. Vaccine, 26(35):4494-505.

Reina R, Berriatua E, Lujan L, Juste RA, Sanchez A, De Andres D y Amorena B. 2008b. Prevention strategies against small ruminant lentiviruses: An update. Vet J, 182(1):31-7. 
Reina R, Grego E, Profiti M, Glaria I, Robino P, Quasso A, Amorena B y Rosati S. 2009. Development of specific diagnostic test for small ruminant lentivirus genotype E. Vet Microbiol, 138(34):251-7.

Reina R, Mora MI, Glaria I, Garcia I, Solano C, Lujan L, Badiola JJ, Contreras A, Berriatua E, Juste RA, Mamoun RZ, Rolland M, Amorena B y De Andres D. 2006. Molecular characterization and phylogenetic study of Maedi Visna and Caprine Arthritis Encephalitis viral sequences in sheep and goats from Spain. Virus Res, 121(2):189-98.

Remond M, Larenaudi B, Boutrouille A y Bouchard N. 1985. Maedi Visna infection in France. Results of serological examinations and trial of eradication. En: Sharp, J. M. y Hoff-Jorgensen R editor. Slow Viruses in Sheep, goats and cattle. pp. 297-304. Commission of the European Communities. Luxembourg.

Ressang AA, Stam FC y De Boer GF. 1966. A Meningo-Leucoencephalomyelitis resembling Visna in Dutch Zwoeger sheep. Path Vet, 3:401-11.

Reviriego F.J. 1998. Seroprevalencia de maedi-visna y artritis encefalitis caprina. Estudio realizado en la provincia de Ávila. Albeitar, 21:15.

Reyburn HT, Roy DJ, Blacklaws BA, Sargan DR, Watt NJ y McConnell I. 1992. Characteristics of the T cell-mediated immune response to maedi-visna virus. Virology, 191(2):1009-12.

Rimstad E, East N, DeRock E, Higgins J y Pedersen NC. 1994. Detection of antibodies to caprine arthritis-encephalitis virus using recombinant gag proteins. Arch Virol, 134(3-4):345-56.

Rimstad E, East NE, Torten M, Higgins J, DeRock E y Pedersen NC. 1993. Delayed seroconversion following naturally acquired caprine arthritis-encephalitis virus infection in goats. Am $J$ Vet Res, 54(11):1858-62.

Robinson WF y Ellis TM. 1986. Caprine arthritis-encephalitis virus infection: from recognition to eradication. Aust Vet J, 63(8):237-41.

Robles CA, Layana JA, Cabrera RF, Raffo F y Cutlip RC. 2003. Estudio serológico retrospectivo de Maedi (Neumonia Progresiva) en ovinos y de Artritis-Encefalitis en caprinos de Patagonia, Argentina. Revista de Medicina Veterinaria (Argentina), 84(3):96-9.

Rosadio RH, Evermann JF y DeMartini JC. 1984. A preliminary serological survey of viral antibodies in peruvian sheep. Vet Microbiol, 10(1):91-6.

Rosadio RH, Lairmore MD, Russell HI y DeMartini JC. 1988. Retrovirus-associated Ovine Pulmonary Carcinoma (Sheep Pulmonary Adenomatosis) and Lymphoid Interstitial Pneumonia. I.Lesion development and age susceptibility. Vet Pathol, 25:475-83. 
Rosati S, Kwang J, Tolari F y Keen J. 1994. A comparison of whole virus and recombinant transmembrane ELISA and immunodiffusion for detection of ovine lentivirus antibodies in Italian sheep flocks. Vet Res Commun, 18(1):73-80.

Rowe JD y East NE. 1997. Risk factors for transmission and methods for control of caprine arthritisencephalitis virus infection. Vet Clin North Am Food Anim Pract, 13(1):35-53.

Rowe JD, East NE, Thurmond MC y Franti CE. 1991. Risk factors associated with caprine arthritisencephalitis virus infection in goats on California dairies. Am J Vet Res, 52(3):510-4.

Rowe JD, East NE, Thurmond MC, Franti CE y Pedersen NC. 1992. Cohort study of natural transmission and two methods for control of caprine arthritis-encephalitis virus infection in goats on a California dairy. Am J Vet Res, 53(12):2386-95.

Roy DJ, Watt NJ, Ingman T, Houwers DJ, Sargan DR y McConnell I. 1992. A simplified method for the detection of maedi-visna virus RNA by insitu hybridization. $J$ Virol Methods, 36(1):1-11.

Ruff G y Lazary S. 1988. Evidence for linkage between the caprine leucocyte antigen (CLA) system and susceptibility to CAE virus-induced arthritis in goats. Immunogenetics, 28(5):303-9.

Ruff G, Regli JG y Lazary S. 1993. Occurrence of caprine leucocyte class I and II antigens in Saanen goats affected by caprine arthritis (CAE). Eur J Immunogenet, 20(4):285-8.

Ryan S, Tiley L, McConnell I y Blacklaws BA. 2000. Infection of dendritic cells by the Maedi-Visna lentivirus. J Virol, 74(21):10096-103.

Salazar E, Monleon E, Bolea R, Acin C, Perez M, Alvarez N, Leginagoikoa I, Juste RA, Minguijon E, Reina R, Glaria I, Berriatua E, De Andres D, Badiola JJ, Amorena B y Lujan L. 2010. Detection of $\operatorname{PrP}(\mathrm{Sc})$ in lung and mammary gland is favored by the presence of Visna/maedi virus lesions in naturally coinfected sheep. Vet Res, 41(5):58.

Saman E, Van Eynde G, Lujan L, Extramiana AB, Harkiss G, Tolari F, Gonzalez L, Amorena B y Badiola JJ. 1999. A new sensitive serological assay for detection of lentivirus infections in small ruminants. Clin Diag Lab Immunol, 6(5):734-40.

Sambrook J, Fritsch EF y Maniatis T. 1989, Molecular cloning: a laboratory manual. Second edition Cold Spring Harbor Laboratory Press.

Sargan DR, Sutton KA, Bennet ID, McConnell I y Harkiss GD. 1995. Sequence and repeat structure variants in the long terminal repeat of maedi-visna virus EV1. Virology, 208(1):343-8.

Scheer-Czechowski P, Vogt HR, Tontis A, Peterhans E y Zanoni R. 2000. Pilot project for eradicating maedi-visna in Walliser blacknose sheep. Schweiz Arch Tierheilkd, 142(4):155-64. 
Schipper IA, Light MR y Ludeman L. 1985. Control of Ovine Progressive Pneumonia (OPP). North Dakota Farm Research, 43:30-1.

Shah C, Boni J, Huder JB, Vogt HR, Muhlherr J, Zanoni R, Miserez R, Lutz H y Schupbach J. 2004a. Phylogenetic analysis and reclassification of caprine and ovine lentiviruses based on 104 new isolates: evidence for regular sheep-to-goat transmission and worldwide propagation through livestock trade. Virology, 319(1):12-26.

Shah C, Huder JB, Boni J, Schonmann M, Muhlherr J, Lutz H y Schupbach J. 2004b. Direct evidence for natural transmission of small-ruminant lentiviruses of subtype A4 from goats to sheep and vice versa. J Virol, 78(14):7518-22.

Sigurdsson B. 1954a. Maedi, a slow progressive pneumonia of sheep: an epizoological and a pathological study. Br Vet J, 110:255-70.

Sigurdsson B. 1954b. Rida, a chronic encephalitis of sheep with general remarks on infections which develop slowly and some of their special characteristics. Br Vet J, 110:341-54.

Sigurdsson B. 1957. Visna, a demyelinating transmisible disease of sheep. J Neuropath Exp Neurol, 16(3):389-403.

Sigurdsson B, Grimsson H y Palsson PA. 1951. Maedi, a chronic, progressive infection of sheeps lungs. J Infect Dis, 90(3):233-41.

Sigurdsson B, Palsson PA y Tryggvadottir A. 1953. Transmission experiments with Maedi. J Infect Dis, 93(2):166-75.

Sigurdsson B, Thormar H y Palsson PA. 1960. Cultivation of visna virus in tissue culture. Arch Ges Virusforsch, 10:368-81.

Sihvonen L. 1980. Studies on transmission of Maedi virus to lambs. Acta Vet Scand, 21:689-98.

Sihvonen L. 1981. Early immune responses in experimental Maedi. Res Vet Sci, 30:217-22.

Sihvonen L, Estola T y Tuomi J. 1980. Experimental Maedi infection in sheep. Acta Vet Scand, 21:113-23.

Sihvonen L, Hirvela-Koski V, Nuotio L y Kokkonen UM. 1999. Serological survey and epidemiological investigation of maedi-visna in sheep in Finland. Vet Microbiol, 65(4):265-70.

Sihvonen L, Nuotio L, Rikula U, Hirvela-Koski V y Kokkonen U. 2000. Preventing the spread of maedi-visna in sheep through a voluntary control programme in Finland. Prev Vet Med, 47(3):213-20. 
Sihvonen L y Veijalainen P. 1981. Kinetics of Maedi virus production in sheep chroroid plexus cells. Vet Microbiol, 6:1-8.

Simard C y Morley RS. 1991. Seroprevalence of maedi-visna in Canadian sheep. Can J Vet Res, 55(3):269-73.

Simard CL y Briscoe MR. 1990. An enzyme-linked immunosorbent assay for detection of antibodies to maedi-visna virus in sheep. II. Comparison to conventional agar gel immunodiffusion test. Can $J$ Vet Res, 54(4):451-6.

Simmard C y Morley RS. 1991. Seroprevalence of Maedi-Visna in Canadian sheep. Can J Vet Res, 55(3):269-73.

Slettbakk T, Jørstad A, Farver T y Holmes J. 1995. Impact of milking characteristics and morphology of udder and teats on clinical mastitis in first- and second-lactation Norwegian cattle. Prev Vet Med, 24(4):235-44.

Smith VW, Dickson J, Coackley W y Carman H. 1985. Response of Merino sheep to inoculation with a caprine retrovirus. Vet $\operatorname{Rec}, 20: 61-3$.

Snowder GD, Gates NL, Glimp.H.A. y Gorham JR. 1990. Prevalence and effect of subclinical Ovine Progressive Pneumonia virus infection on ewe wool and lamb production. $J$ Am Vet Med Assoc, 197(4):475-9.

Snowder GD, Gates NL, Glimp.H.A. y Knowles DP. 1991. The effect of production trait selection over 10 years on the seroprevalence of Ovine Progressive Pneumonia virus in a closed flock. SID Sheep Res J, 7(2):24-8.

Snyder SP, DeMartini JC, Ameghino E y Caletti E. 1983. Coexistence of Pulmonary Adenomatosis and Progressive Pneumonia in sheep in the central sierra of Peru. Am J Vet Res, 44(7):1334-8.

Sonigo P, Alizon M, Staskus KA, Klatzmann D, Cole S, Danos O, Retzel E, Tioilals P, Haase A y Wain-Hobson W. 1985. Nucleotide sequence of the visna lentivirus: Relationship to the AIDS virus. Cell, 42(1):369-82.

Sotelo J, Gutierrez A, Fernandez M, Carmenes P y Muñoz M. 1995. Seroprevalencia de la infección por lentivirus en ganado ovino y caprino de la provincia de León. IV Congreso Nacional de Virologia. Madrid. 21-23 Septiembre 1995.

Stark KD. 1999. The role of infectious aerosols in disease transmission in pigs. Vet J, 158(3):164-81. 
Staskus KA, Couch L, Bitterman P, Retzel EF, Zupancic M, List J y Haase AT. 1991. In situ amplification of Visna virus DNA in tissue sections reveals a reservoir of latently infected cells. Microb Pathog, 11(1):67-76.

Stevenson RG y Bouffard A. 1984. Chronic Viral Respiratory Diseases of Sheep. Can Vet J, 25:3451.

Stowring L, Haase AT, Petursson G, Georgsson G, Palsson PA, Lutley R, Roos R y Szuchet S. 1985. Detection of Visna Virus antigens and RNA in glial cells in foci demyelination. Virology, 141:311-8.

Straub OC. 1985. Transmission studies of Maedi/visna in sheep. En: Commission of the European Communities editor. Slow Viruses in Sheep, goats and cattle. pp. 87-91. Luxemburgo.

Suveges T, Suveges T y Szeky A. 1973. Incidence of Maedi (chronic progressive interstitial pneumonia) among sheep in Hungary. Acta Vet Acad Sci Hung, 23(3):205-17.

Thormar H. 1963. The growth cycle of Visna virus in momolayer cultures of sheep cells. Virology, 19:273-8.

Thormar H. 1965. A comparison of Visna and Maedi viruses. 1.- Physical, Chemical and Biological properties. Res Vet Sci, 6:117-29.

Thormar H. 2005. Maedi-visna virus and its relationship to human immunodeficiency virus. AIDS Rev, $7(4): 233-45$.

Thormar H, Barshatzky MR, Arnesen K y Kozlowski PB. 1983. The emergence of antigenic variants is a rare event in long-term visna virus infection in vivo. J Gen Virol, 64(Pt 7):1427-32.

Thrusfield M. 1995, Veterinary epidemiology. Second edition The University Press.Cambridge.

Tiley LS, Malim MH y Cullen BR. 1991. Conserved functional organization of the human immunodeficiency virus Type 1 and visna virus rev proteins. J Virol, 65(7):3877-81.

Toft N, Akerstedt J, Tharaldsen J y Hopp P. 2006. Evaluation of three serological tests for diagnosis of Maedi-Visna virus infection using latent class analysis. Vet Microbiol, 120(1-2):77-86.

Tolari F, Cosi C, Carrozza ML, Mazzei M y Bandecchi P. 2010. Comparision of ELISA, immunoblotting and PCR to detect MVV infected sheep. 1, p. 61. Queen's College, Cambridge UK.

Toohey KL y Haasey AT. 1994. The rev gene of visna virus is required for productive infection. Virology, 200:276-80. 
Torres-Acosta J.F.J, Gutierrez-Ruiz EJ, Butler CV, Schmidt A., Evans J y Babington J. 2008. Serological survey of caprine arthritis-encephalitis virus in 83 goat herds of Yucatan, Mexico. Small Rum Res, 49:207-11.

Torsteinsdottir S, Carlsdottir HM, Svansson V, Matthiasdottir S, Martin AH y Petursson G. 2007. Vaccination of sheep with Maedi-visna virus gag gene and protein, beneficial or harmful? Vaccine, 25(37-38):6713-20.

Torsteinsdottir S, Matthiasdottir S, Vidarsdottir N, Svansson V y Petursson G. 2003. Intratracheal inoculation as an efficient route of experimental infection with maedi-visna virus. Res Vet Sci, 75(3):245-7.

Travassos C, Benoit C, Valas S, da Silva A y Perrin G. 1998. Detection of caprine arthritis encephalitis virus in sperm of experimentally infected bucks. Vet Res, 29(6):579-84.

Valsson O, Alenius S, Nielsen TK, Nyberg O y Salmela P. 2001. Surveillance of ruminant diseases in the Nordic countries. Acta Vet Scand Suppl, 94:27-8.

Van der Molen EJ y Houwers DJ. 1987. Indurative lymphocytic mastitis in sheep after experimental infection with Maedi-Visna Virus. Vet Q, 9(3):193-202.

Van der Molen EJ, Vecht U y Houwers DJ. 1985. A chronic indurative mastitis in sheep, associated with Maedi-Visna Virus infection. Vet Q, 7(2):112-9.

Vander SJ, Bradway DS, Besser TE y Evermann JF. 1994. Evaluation of a kinetic enzyme-linked immunosorbent assay for detection of caprine arthritis-encephalitis virus-specific antibodies. $J$ Vet Diagn Invest, 6(1):30-3.

Varea R, Monleon E, Pacheco C, Lujan L, Bolea R, Vargas MA, Van Eynde G, Saman E, Dickson L, Harkiss G, Amorena B y Badiola JJ. 2001. Early detection of maedi-visna (ovine progressive pneumonia) virus seroconversion in field sheep samples. J Vet Diagn Invest, 13(4):301-7.

Vellutini C, Philippon V, Gambarelli D, Horschowski N, Nave KA, Navarro JM, Auphan M, Courcoul MA y Filippi P. 1994. The maedi-visna virus Tat protein induces multiorgan lymphoid hyperplasia in transgenic mice. J Virol, 68(8):4955-62.

Vogt HR, Bertoni G, Hertig C, Stalder HP, Zanoni R y Peterhans E. 1999, The Interlaken goat and sheep show mystery: Highly clustered seroconversions to SRLV in a Swiss breed of goats in the final stage of the CAE eradication program.

Wagter LH, Jansen A, Bleumink-Pluym NM, Lenstra JA y Houwers DJ. 1998. PCR detection of lentiviral GAG segment DNA in the white blood cells of sheep and goats. Vet Res Commun, 22(5):355-62. 
Walker CM, Erickson AL, Hsueh FC y Levy JA. 1991. Inhibition of human immunodeficiency virus replication in acutely infected CD4+ cells by CD8+ cells involves a noncytotoxic mechanism. $J$ Virol, 65 (11): 5921-5927.

Watt N, Scott PR y Collie D. 1994. Maedi-Visna virus infection in practice. In Practice, 16(5):239-47.

Watt N, Scott PR y Gessert M. 1995. Maedi Visna Ovine Progressive Pneumonia Virus Infection: A comartative study of the disease in the United Kingdom and the United States. Agri-PracticeRespiratory Disease, 16(10):29-34.

Watt NJ, King TJ, Collie DDS, McIntyre N y Mc-Connell I. 1992. Clinicopathological investigation of primary, uncomplicated Maedi-Visna infection. Vet Rec, 131:455-61.

Williams-Fulton NR y Simard CL. 1989. Evaluation of two management procedures for the control of maedi-visna. Can J Vet Res, 53(4):419-23.

Wilson IG. 1997. Inhibition and Facilitation of Nucleic Acid Amplification. Appl Environ Microbiol, 63(10):3741-851.

Woldemeskel M y Tibbo M. 2010. Pulmonary adenomatosis and maedi-visna in Ethiopian central highland sheep: a microscopic study. Trop Anim Health Prod, 42:995-9.

Zanoni R, Nauta IM, Kuhnert P, Pauli U, Pohl B y Peterhans E. 1992. Genomic heterogeneity of small ruminant lentiviruses detected by PCR. Vet Microbiol, 33:341-51.

Zanoni R, Pauli U y Peterhans E. 1990a. Caprine arthritis-encephalitis (CAE) and Maedi-Visna viruses detected by the Polymerase Chain Reaction (PCR). Vet Microbiol, 23:329.

Zanoni R, Pauli U y Peterhans E. 1990b. Detection of caprine arthritis-encephalitis- and maedi-visna viruses using the polymerase chain reaction. Experientia, 46(3):316-9.

Zanoni R, Vogt HR, Pohl B, Bottcher J, Bommeli W y Peterhans E. 1994. An ELISA based on whole virus for the detection of antibodies to small-ruminant lentiviruses. Zentralbl Veterinarmed $B$, 41(10):662-9.

Zhang Z, Watt NJ, Hopkins J, Harkiss G y Woodall CJ. 2000. Quantitative analysis of maedi-visna virus DNA load in peripheral blood monocytes and alveolar macrophages. $J$ Virol Methods, 86(1):1320.

Zink MC y Johnson LK. 1994. Pathobiology of lentivirus infections of sheep and goats. Virus Res, 32:139-54. 
Zink MC, Narayan O, Kennedy PG y Clements JE. 1987. Pathogenesis of visna/maedi and caprine arthritis-encephalitis: new leads on the mechanism of restricted virus replication and persistent inflammation. Vet Immunol Immunopathol, 15(1-2):167-80.

Zink MC, Yager JA y Myers JD. 1990. Pathogenesis of caprine arthritis encephalitis virus. Cellular localization of viral transcripts in tissues of infected goats. Am J Pathol, 136(4):843-54. 